\title{
THE EFFECT OF HEAD FLEXION/EXTENSION ON ACOUSTIC MEASURES
}

OF SINGING VOICE QUALITY

Elizabeth Johnson Knight, B.M., M.M.

Dissertation Prepared for the Degree of

DOCTOR OF MUSICAL ARTS

UNIVERSITY OF NORTH TEXAS

August 2013

\section{APPROVED:}

Stephen Austin, Major Professor

Kris Chesky, Committee Member

Stephen Morscheck, Committee Member

Jeffrey Snider, Chair of the Division of Vocal Studies

Benjamin Brand, Director of Graduate Studies in the College of Music

James C. Scott, Dean of College of Music

Mark Wardell, Dean of the Toulouse Graduate School 
Knight, Elizabeth Johnson. The Effect of Head Flexion/Extension on Acoustic Measures of Singing Voice Quality. Doctor of Musical Arts (Performance), August 2013, 76 pp., 6 tables, 14 figures, bibliography, 77 titles.

A study was undertaken to identify the effect of head flexion/extension on singing voice quality. The amplitude of the fundamental frequency (F0), and the singing power ratio (SPR), an indirect measure of singer's formant activity, were measured. F0 and SPR scores at four experimental head positions were compared with the subjects' scores at their habitual positions. Three vowels and three pitch levels were tested. F0 amplitudes and low frequency partials in general were greater with more extended head positions, while SPR increased with neck flexion. No effect of pitch or vowel was found. Gains in SPR appear to be the result of damping low frequency partials rather than amplifying those in the singer's formant region. Raising the amplitude of F0 is an important resonance tool for female voices in the high range, and may be of benefit to other voice types in resonance, loudness, and laryngeal function. 
Copyright 2013

by

Elizabeth Johnson Knight 


\section{TABLE OF CONTENTS}

Page

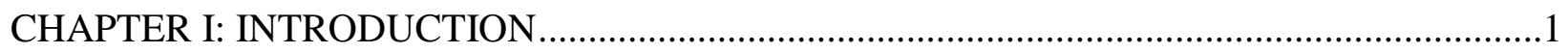

Pedagogical Perspectives on Head Posture ..............................................................2

Head Posture and the Vocal Tract ..........................................................................

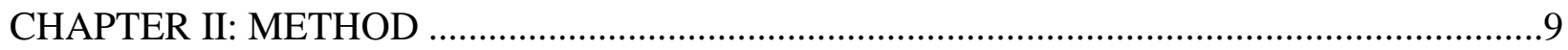

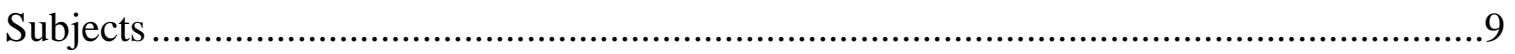

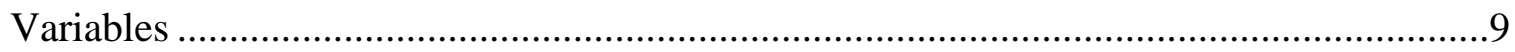

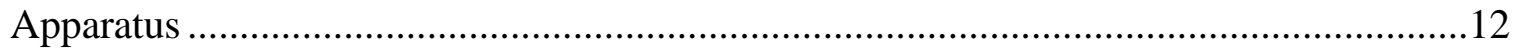

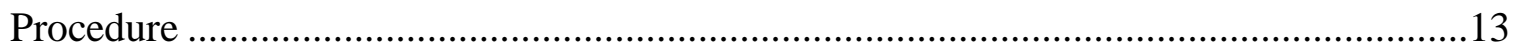

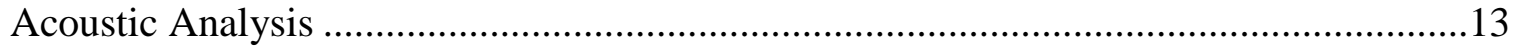

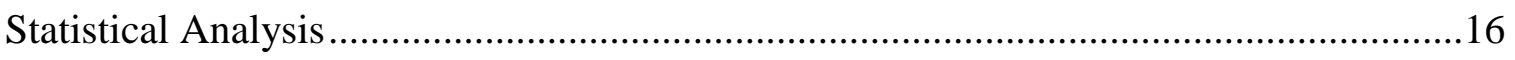

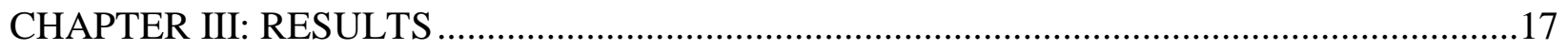

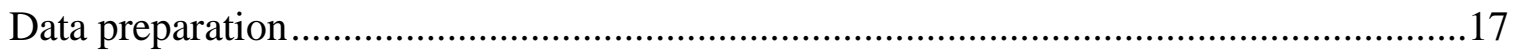

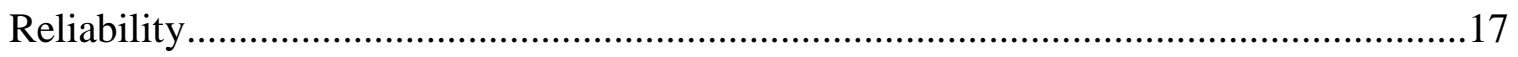

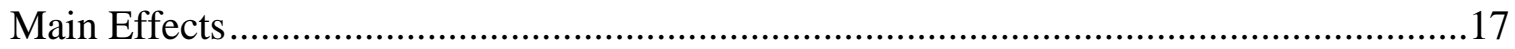

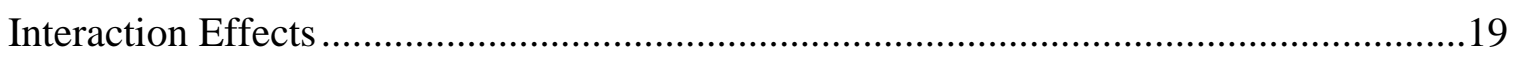

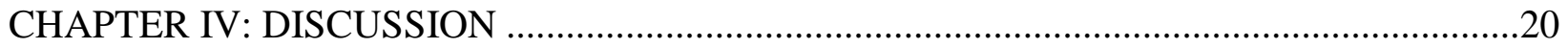

Relationships Among SPR, F0, High Peak, and Low Peak........................................20

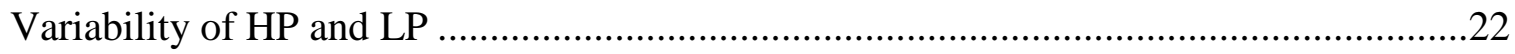

Fach, Habitual Head Position, and High Peak Amplitude ...........................................25

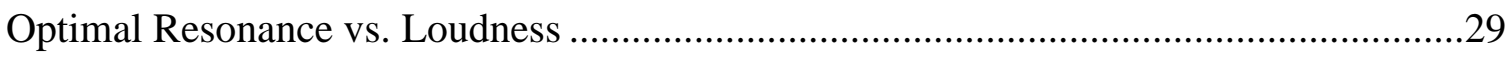

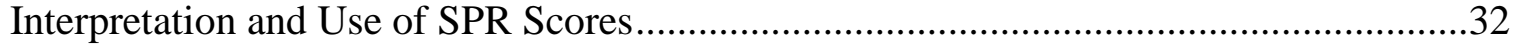


Limitations and Recommendations for Further Study

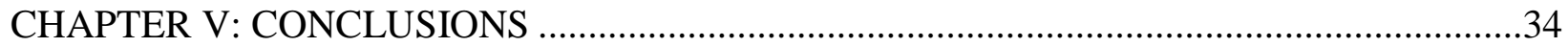

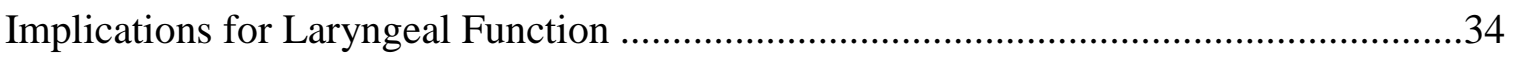

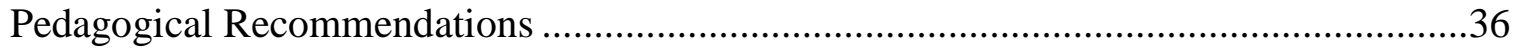

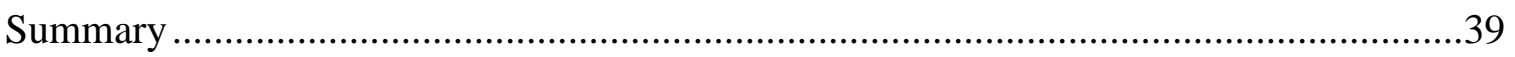

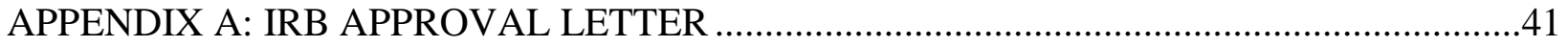

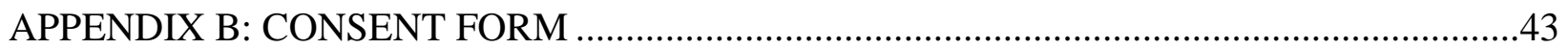

APPENDIX C: PARTICIPANT QUESTIONNAIRE ..................................................46

APPENDIX D: PARTICIPANT HABITUAL POSTURES AND TEST PITCHES ..................48

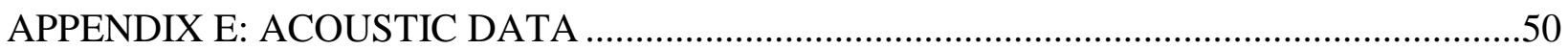

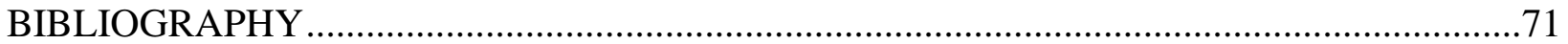




\section{CHAPTER I}

\section{INTRODUCTION}

There is general agreement among voice pedagogues as to certain general features of good posture for singing, but physical descriptions are not always precise, nor is there consensus regarding the effect of various head positions on tone quality. A singer's posture is one of the most readily observable qualities, and is widely believed to affect not only the voice production, but also the way in which the singer is perceived by the audience. As such, it is often one of the first issues addressed in vocal study, and many voice pedagogues stress the importance of correct posture, often including the carriage of the head and neck, for singing. However, much of the voice literature relies on anecdotal evidence or intuition for ideas regarding optimal head position, and value judgments are subject to each author's preference.

Voice science has provided much insight into the complex interactions of the vocal tract and the voice source, the larynx. The configuration of the articulators (tongue, jaw, lips) determines the shape of the vocal tract, the primary determiner of vowel quality, while the vertical height of the larynx is largely responsible for the overall length of the tract, the primary determinant of timbre. The role of the external frame (extrinsic muscles of the larynx and the skeletal structures to which they attach) on laryngeal positioning and function is also fairly well understood, ${ }^{1}$ but to date no study has precisely correlated head postures with quantitative acoustic data on voice quality. The purpose of the current study was to examine the effect of head positioning in the vertical plane (chin up/down) on voice quality as reflected in acoustic measurements. Specifically, the aims of this study were 1) to identify changes in spectral energy as a result of head flexion/extension that indicate increased or decreased resonance in the voice

\footnotetext{
${ }^{1}$ E. Vilkman, A. Sonninen, P. Hurme, and P. Körkkö, "External Laryngeal Frame Function in Voice Production Revisited: A Review," Journal of Voice 10, no. 1 (1996): 78-92.
} 
and 2) to examine the relationships among head flexion/extension and the different vowel and pitch conditions to move toward an understanding of ideal head position for singing.

\section{Pedagogical Perspectives on Head Posture}

A description of good singing posture found in many pedagogical sources is as follows:

A line dropped from the top of the head will fall through the ear, the point of the shoulder..., the highest point of the pelvis, just behind the kneecap and just in front of the ankle. ${ }^{2}$

Figure 1 demonstrates this alignment, which Richard Miller describes as a "'noble posture' in which head, neck, and torso are in line with pelvic and hip regions."3 McKinney adds that "the head should not be allowed to hang forward of the shoulders" and the singer should "feel as if [the] chin has been tucked in slightly."4 However, most teachers agree that the chin should be "neither thrust forward nor pulled into the V of the chest." ${ }^{5}$ In his review of 702 pedagogical sources published between 1928 and 1942, Fields finds 275 statements associating postural faults with poor phonation. He summarizes the attitude represented in the majority of the works as follows.

Because many common faults of phonation are attributed to faulty posture, authors of singing texts continually stress the importance of head position, chest position, tongue position, etc., as technical elements in maintaining a correct all-over posture of the body for artistic singing. Freedom and flexibility of the neck, shoulders, spine, ribs, and chest are therefore contributing factors in phonation. Artist singers caution beginners against assuming backward tilting head positions, flat chest or drooping shoulders. Such postural deformities impose abnormal strains upon the neck muscles which, in turn, might set up

\footnotetext{
${ }^{2}$ Meribeth Bunch Dayme, The Performer's Voice (New York: W.W. Norton, 2005), 27-28.

${ }^{3}$ Richard Miller, Training Tenor Voices (New York: Schirmer Books, 1993), 25.

${ }^{4}$ James C. McKinney, The Diagnosis and Correction of Vocal Faults, revised ed. (Nashville: Genevox Music Group, 1994), .39.

${ }^{5}$ Richard Alderson, Complete Handbook of Voice Training (New York: Parker Publishing, 1979), 47.
} 
chronic laryngeal tensions and result in injuries to the vocal apparatus under the exertion of sustained singing. ${ }^{6}$

Similar statements encouraging balance, freedom of movement, and alleviation of muscle tension are found in many recent pedagogical sources as well. ${ }^{7891011}$

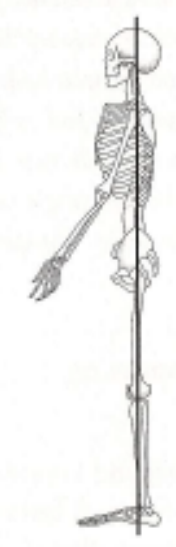

Fig. 1. Axial alignment. Reprinted from M. B. Dayme, The Performer's Voice (New York: W. W. Norton \& Co., 2005): 27.

The general axial alignment described above is not contested; several studies indicate a correlation between anteroposition of the head and voice problems, ${ }^{12}$ particularly impairing airflow, resonance, ${ }^{13}$ and pitch control. ${ }^{14}$ Jones found improvement in resonance, breath

\footnotetext{
${ }^{6}$ Victor A. Fields, Training the Singing Voice: An Analysis of the Working Concepts Contained in Recent Contributions to Vocal Pedagogy (Morningside Heights, NY: King's Crown Press, 1947), 126-127.

${ }^{7}$ William Shakespeare, The Art of Singing (Philadelphia: Oliver Ditson, 1899), 24.

${ }^{8}$ Barbara M. Doscher, The Functional Unity of the Singing Voice, 2d ed. (Lanham, MD: Scarecrow Press, 1994), 24.

9 Alderson, 47.

${ }^{10}$ Dayme, 27-28.

${ }^{11}$ William Vennard, Singing: The Mechanism and the Technic, 2d ed. (Ann Arbor: Edwards Brothers, 1950), 17.

${ }^{12}$ Filip F. Staes, Lieve Jansen, Ann Vilette, et al., "Physical Therapy as a Means to Optimize Posture and Voice Parameters in Student Classical Singers: A Case Report,” Journal of Voice 25, no. 3 (2011): 91-101.

${ }^{13}$ Barbara M. Wilson Arboleda and Arlette L. Frederick, "Considerations for Maintenance of Postural Alignment for Voice Production,” Journal of Voice 22, no. 1 (2008): 90-99.

${ }^{14}$ P.G.C. Kooijman, F.I.C.R.S. de Jong, M.J. Oudes, et al., "Muscular Tension and Body Posture in Relation to Voice Handicap and Voice Quality in Teachers with Persistent Voice Complaints." Folia Phoniatrica et Logopaedica 57 (2005): 134-147.
} 
efficiency, and ease of phonation by correcting a forward thrusting head posture. ${ }^{15}$ However, one may maintain a correct linear relationship between the ear and the shoulder and still move the head into a variety of positions. (Going forward, rotation around an inter-aural axis, or chin up/down, will be referred to as extension and flexion of the head, respectively. These terms do not indicate any repositioning of the head anterior or posterior to the shoulder.) The optimal extension and flexion of the head is a point of debate in the voice literature. Several pedagogues suggest that the singer should feel his eyes are level or that the chin is parallel to the floor, ${ }^{16} 17$ ${ }^{18}$ and there is some agreement that flexion of the head downward produces undesirable vocal tone. Doscher writes "When the head is bowed, functional equilibrium of the suspensory network is sacrificed. The tone becomes too dark and lacks overtones; it will not carry.",19 Austin cautions that young singers may intentionally adopt such a posture to "produce tones that simulate someone more mature" but that this can result in a shortened range, vocal fatigue, lack of flexibility, and a wobbly vibrato. ${ }^{20}$ Miller associates this posture with singers attempting to fix the larynx too low in the throat, as "chin and mandible exert pressure on the larynx, inhibiting its ascent."21

There is less agreement in the voice community over the usefulness of extension of the head. Miller is particularly vehement that the head should not be elevated, as it results in a raised

${ }^{15}$ Frank Pierce Jones, "Voice Production as a Function of Head Balance in Singers," The Journal of Psychology 82 (1972): 209-215.

${ }^{16}$ Carole M. Schneider, Carolyn A. Dennehy, and Keith G. Saxon, "Exercise Physiology Principles Applied to Vocal Performance: The Improvement of Postural Alignment" Journal of Voice 11, no. 3 (1997): 333.

${ }^{17}$ Miller, Training Tenor Voices, 20.

${ }^{18}$ Carlo Bassini, Bassini's Art of Singing: An Analytical Physiological and Practical System for the Cultivation of the Voice, ed. R. Storrs Willis. (Boston: O. Ditson \& Co., ca. 1857); quoted in Brent J. Monahan, The Art of Singing: A Compendium of Thoughts on Singing Published Between 1777 and 1927 (Metuchen, NJ: Scarecrow Press, 1978), 60-61.

${ }^{19}$ Doscher, 76-79.

${ }^{20}$ Stephen F. Austin, “Bobble-heads," Journal of Singing 68, no. 4 (March/April 2012): 457.

${ }^{21}$ Richard Miller, National Schools of Singing, rev. ed. (Lanham, MD: Scarecrow Press, 1997), 86. 
larynx and a tight-sounding tone lacking vibrato. ${ }^{22} 23$ He suggests establishing a normal head position looking "eye-level" and physically inhibiting any head motion during vocalization by placing the hands atop the head. ${ }^{24}$ McKinney warns against "raising the chin to 'reach' for high notes" and suggests instead lowering the chin and feeling the back of the neck stretch. ${ }^{25}$ To the contrary, Coffin and Doscher both assert that for high notes, singers should adopt a "head to the gallery" 26 posture "akin to that of a sword swallower." 27 They offer as evidence of the efficacy of this technique images and accounts of internationally successful singers including Caruso, Gigli, Nilsson, and de Reszke. The advice in the voice pedagogy literature is often the result of years of observation, singing, and teaching, but is less often supported by quantitative research. The terminology is sometimes confusing, and contradictions abound. More concrete evidence is required to begin to understand the complex interactions of head position, pitch, and vowel.

\section{Head Posture and the Vocal Tract}

\section{Pharyngeal Width and Laryngeal Tilt}

Evidence gathered from the fields of voice science, dentistry, and physical therapy has increased our understanding of the effect head position may have upon the vocal tract, but offers no conclusive answer to the riddle of optimal head position for singing. Heman-Ackah states that an overly extended head posture bends the vocal tract so that the area near the tongue base is narrowed, which negatively impacts resonance. ${ }^{28}$ However, X-ray studies measuring the area of the pharyngeal airway at various degrees of flexion/extension show an increase in the width of

\footnotetext{
${ }^{22}$ Ibid., 83-84.

${ }^{23}$ Miller, Training Tenor Voices, 128.

${ }^{24}$ Ibid., 125.

${ }^{25}$ McKinney, 39.

${ }^{26}$ Berton Coffin, Overtones of Bel Canto (Lanham, MD: Scarecrow Press, 1980), 179.

${ }^{27}$ Doscher, 80-81.

${ }^{28}$ Yolanda D Heman-Ackah, "Physiology of Voice Production: Considerations for the Vocal Performer," Journal of Singing 62, no. 2 (November/December 2005): 174.
} 
the airway with head extension. ${ }^{29}{ }^{30}$ MRI data corroborate widening of the pharynx with head extension, and point out the important relationship of the cervical spine to pharyngeal width and the tilting of the laryngeal cartilages. ${ }^{31}$ Honda finds that "the posterior plate of the cricoid cartilage maintains a parallel relationship with the arch of the cervical lordosis," which changes its curvature depending upon pitch range. It is clear that in some professional singers an inversion of the curve of the cervical spine occurs "in order to create space for pharyngeal widening and the forward tilt of the thyroid cartilage, a requirement for singing in the upper pitch range.",32 This inversion would seem to be consistent with an extension of the head for singing high notes, but may not result in an obvious visible posture shift; cervical motion has been observed in studies requiring the subject to lie supine with a fixed head position. ${ }^{33} 34$ Similar postural changes are seen going from non-singing to singing tasks as singing low to high. ${ }^{35}$ However, Miller's MRI study shows professional singers employing more neck flexion in high notes than in low notes. ${ }^{36}$ In reality, singers may successfully adopt a variety of head postures, depending upon their unique physiologies. For example, though studies have indeed shown professional singers extending the head for high notes, there is evidence that flexing the neck in order to achieve posteriorization of the occiput to allow the thyroid cartilage to tilt may be a

${ }^{29}$ Toshitaka Muto, S. Takeda, M. Kanazawa, et al., "The Effect of Head Posture on the Pharyngeal Airway Space (PAS)," International Journal of Oral and Maxillofacial Surgery 31 (2002): 581.

${ }^{30}$ Gillian Johnson and Margot Skinner, "The Demands of Professional Opera Singing on Cranio-cervical Posture,” European Spine Journal 18 (2009): 565.

${ }^{31}$ Kiyoshi Honda, Hiroyuki Hirai, Shinobu Masaki, and Yasohiro Shimada, "Role of Vertical Larynx Movement and Cervical Lordosis in F0 Control," in Language and Speech 42, no. 4 (1999): 409.

${ }^{32}$ Nicole Scotto Di Carlo, "Cervical Spine Abnormalities in Professional Singers," Folia Phoniatrica et Logopaedica 50, no. 4 (1998): 216.

${ }^{33}$ Nicola A. Miller, Jennifer S. Gregory, Scottle I. K. Semple, et al., "The Effects of Humming and Pitch on Craniofacial and Craniocervical Morphology Measured Using MRI,” Journal of Voice 26, no. 1 (2012): 90-101.

${ }^{34}$ Kiyoshi Honda, Hiroyuki Hirai, Jo Estill, and Yoh'ichi Tohkura, "Contributions of Vocal Tract Shape to Voice Quality: MRI Data and Articulatory Modeling," in Vocal Fold Physiology: Voice Quality Control, ed. Osamu Fujimura and Minoru Hirano (San Diego: Singular Publishing, 1995), 34.

${ }^{35}$ See Johnson and Skinner.

${ }^{36}$ N. Miller, 99. 
successful compensatory strategy for a soprano with reduced laryngeal mobility. ${ }^{37}$ While these studies give an indication of what singers habitually do while singing in different pitch ranges, there is an assumption that this behavior is desirable or superior to some other postural behavior. The current study compares different head positions to determine if one is more effective in producing an optimally resonant voice, with no assumption that the habitual posture is correct. Larynx Height

In addition to assisting with frequency control as described above, head posture may also play a part in vertical laryngeal position and vocal timbre. Garcia was one of the first to establish a link between larynx position and timbre, observing that while progressing from low to high pitch in any register, the larynx, unchecked, will gradually rise. He refers to this tone production as the "clear timbre," and notes that at the upper extreme of the range, "the head tips back a little in order to facilitate the elevation of the larynx." In the "somber timbre," the larynx is not allowed to rise as the pitch ascends. If carried to extremes of pitch and volume, Garcia observes that the singer must "facilitate this position by leaning the head forward a little.",38 These two timbres are often called "open" and "covered" in contemporary literature, and Garcia's general observations about larynx position and timbre have been supported by radiographic studies. ${ }^{39} 4041$ His additional observations about accompanying head postures are telling; while extending or flexing the head alone is not responsible for the raising or lowering of

\footnotetext{
${ }^{37}$ Nicole Scotto Di Carlo, "X-Ray Study of a Professional Soprano's Postural Strategy for Increasing Laryngeal Mobility," Folia Phoniatrica et Logopaedica 54 (2002): 169.

${ }^{38}$ Manuel Garcia, A Complete Treatise on the Art of Singing, Part One, the editions of 1841 and 1872 collated, edited, and translated by Donald V. Paschke (New York: Da Capo Press, 1984), liv-lv.

${ }^{39}$ Meribeth A. Bunch, "A Cephalometric Study of Structures of the Head and Neck During Sustained Phonation of Covered and Open Qualities," Folia Phoniatrica 28 (1976): 321-328.

${ }^{40}$ Aatto Sonninen, Pertti Hurme, and Anne-Maria Laukkanen, "The External Frame Function in the Control of Pitch, Register, and Singing Mode: Radiographic Observations of a Female Singer," Journal of Voice 13, no. 3 (1999): 319-340.

${ }^{41}$ Raymond H. Colton and Jo A. Estill, "Elements of Voice Quality: Perceptual, Acoustic, and Physiologic Aspects," In Speech and Language: Advances in Basic Research and Practice, Vol. 5, ed. Norman J. Lass, 311-403. New York: Academic Press, 1981.
} 
the larynx, movements of the external frame may assist in laryngeal positioning. Iwarsson finds similar corollaries between head position and larynx height in a study on posture for inhalation. ${ }^{42}$ Though these studies give us a good idea of what timbral changes we might expect with changes in head flexion/extension, there is no attempt to test the ability of singers to produce their best quality with a variety of head postures, nor to quantify the resulting sounds.

42 Jenny Iwarsson, "Effects of Inhalatory Abdominal Wall Movement on Vertical Laryngeal Position During Phonation," Journal of Voice 15, no. 3 (2001): 390. 


\section{CHAPTER II}

\section{METHOD}

\section{Subjects}

A pool of trained singers $(n=20)$ was recruited as test subjects, and screened via questionnaire for any voice disorder or head or neck injury or condition that would exclude them from participation. All subjects reported currently having good vocal health, and had a normal range of head flexion and extension. ${ }^{43}$ The group consisted of singers holding at minimum a Bachelor's degree in voice performance, who are currently pursuing graduate studies in voice, or are working professionally as singers and/or voice teachers in the Dallas/Fort Worth area. An equal number of male and female subjects participated, and subjects represent all four major voice classifications. Table 1 shows the subject demographic information. Subjects selected for participation were informed of the nature of the research, and provided consent as required by the University of North Texas Institutional Review Board.

\section{Variables}

An experimental protocol comprising three independent variables—-pitch, vowel, and degree of head flexion/extension — was used to examine the effect of head flexion and extension on tone quality. Each subject sang at 3 pitch levels, 3 vowels, and at 5 different angles of head extension/flexion, yielding a total of 45 conditions. To determine appropriate low, medium, and high pitches for each subject, the entire range was determined, and pitches at $20 \%, 50 \%$, and $80 \%$ of the total range were selected. The vowels [i], [a], and [E] were used, as they represent front, back, and neutral tongue positions respectively. Each subject self-selected his or her

\footnotetext{
43 The normal range of head flexion is $45-60^{\circ}$, and extension is $45-75^{\circ}$. Jay Hoffman, Norms for Fitness, Performance, and Health (Champaign, IL: Human Kinetics, Inc., 2006), 98.
} 
comfortable, habitual head position. Additional head positions at $-15^{\circ}, 0^{\circ},+15^{\circ}$, and $+30^{\circ}$ were determined (see Fig. 2), aligning the Frankfurt Horizontal (FH) plane parallel to the ground as 0. The Frankfurt plane is commonly used to orient the head to horizontal position for radiographic study; the plane is from Porion to Orbitale, easily identifiable landmarks radiographically. ${ }^{44}$ Since its adoption in 1884 as a measure of true physiologic horizontal, other measures of horizontal head posture have been established and validated, but FH is still in use in both radiography and clinical settings in which identification is made using the soft-tissue landmarks of Tragus and Orbitale, ${ }^{45}$ shown in Figure 3. Though it has been argued that FH does not represent a true natural head posture, it has not been shown to significantly alter cervical curvature compared to a self-balanced posture. ${ }^{46}$ Inasmuch as it is easily identifiable without an X-ray image and reproducible, the Frankfurt Horizontal served the current purpose well.
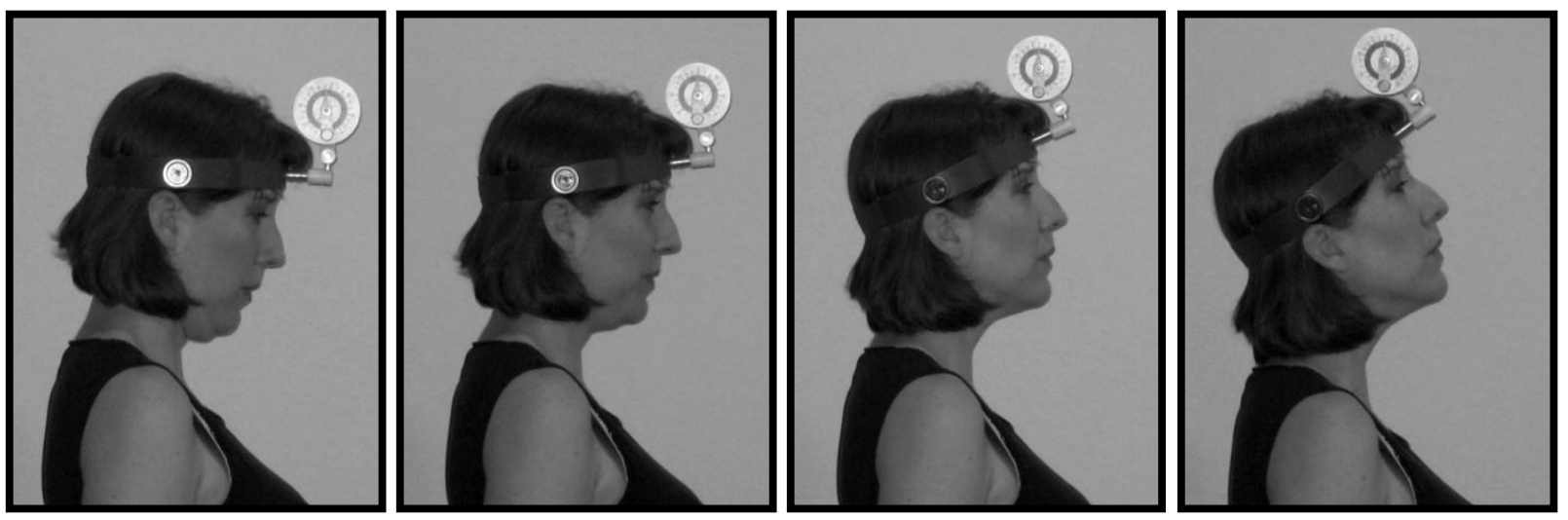

Fig. 2. The four experimental head angles, $-15^{\circ}, 0^{\circ}, 15^{\circ}$, and $30^{\circ}$.

${ }^{44}$ Coenraad F. A. Moorrees, "Natural Head Position, a Basic Consideration in the Interpretation of Cephalometric Radiographs,” American Journal of Physical Anthropology, 16, no. 2 (1958): 214.

${ }^{45}$ Virgilio F. Ferrario, Chiarella Sforza, Alessandro Miani, and Gianluca Tartaglia, "Craniofacial Morphometry by Photographic Evaluations," American Journal of Orthodontics and Dentofacial Orthopedics 103, no. 4 (1993): 328.

${ }^{46}$ S. Armijo-Olivo, X. Jara, N. Castillo, et al., "A Comparison of the Head and Cervical Posture Between the Self-balanced Position and the Frankfurt Method," Journal of Oral Rehabilitation 33, no. 3 (2006): 200. 

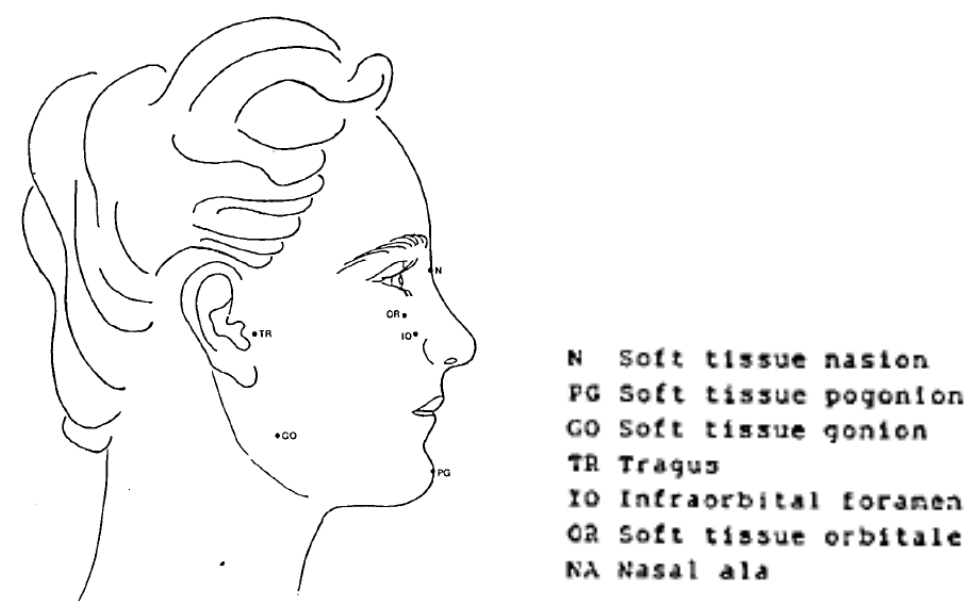

Fig. 3. Soft-tissue landmarks for identification of craniocervical angles. Reprinted from Ferrario, Virgilio F., Chiarella Sforza, Alessandro Miani, and Gianluca Tartaglia, "Craniofacial Morphometry by Photographic Evaluations," American Journal of Orthodontics and Dentofacial Orthopedics 103, no. 4 (1993): 329.

Table 1

Participant Demographics

\begin{tabular}{|c|c|c|c|c|c|}
\hline $\begin{array}{l}\text { Subject } \\
\text { ID }\end{array}$ & Voice Type & Age & $\begin{array}{l}\text { Highest Level } \\
\text { of Education }\end{array}$ & $\begin{array}{l}\text { Years of } \\
\text { Pro Singing } \\
\end{array}$ & Current Occupation \\
\hline S1 & Soprano & 50 & MM & 30 & Singer/Independent Voice Teacher \\
\hline S2 & Soprano & 33 & MM & 8 & Singer/University Voice Teacher \\
\hline S3 & Soprano & 26 & MM & 2 & Singer/Graduate Student \\
\hline S4 & Soprano & 25 & MM & 6 & Singer/Independent Voice Teacher \\
\hline S5 & Soprano & 25 & MM & 1 & Singer/Graduate Student \\
\hline S6 & Soprano & 57 & MM & 40 & Singer/Independent Voice Teacher \\
\hline M1 & Mezzo & 26 & $\mathrm{BM}$ & 1 & Singer/Graduate Student \\
\hline M2 & Mezzo & 38 & $\mathrm{BM}$ & 2 & Singer/Graduate Student/Independent Voice Teacher \\
\hline M3 & Mezzo & 30 & MM & 1.5 & Singer/Graduate Student \\
\hline M4 & Mezzo & 29 & MM & 8 & Singer/Independent Voice Teacher \\
\hline $\mathbf{T 1}$ & Tenor & 25 & $\mathrm{BM}$ & 8 & Singer/Graduate Student \\
\hline $\mathbf{T 2}$ & Tenor & 50 & MM & 22 & Singer/University Voice Teacher/Graduate Student \\
\hline T3 & Tenor & 42 & $\mathrm{ABD}$ & 20 & Singer \\
\hline T4 & Tenor & 26 & MM & 4 & Singer/Independent Voice Teacher \\
\hline T5 & Tenor & 27 & MM & $<1$ & Singer/Graduate Student \\
\hline B1 & Bass-baritone & 33 & $\mathrm{ABD}$ & 10 & Singer/University Voice Teacher \\
\hline B2 & Baritone & 31 & $\mathrm{BM}$ & 5 & Singer/Graduate Student \\
\hline B3 & Bass-baritone & 26 & $\mathrm{BM}$ & 6 & Singer/Graduate Student \\
\hline B4 & Baritone & 28 & MM & 7 & Singer/Graduate Student \\
\hline B5 & Bass-baritone & 54 & DMA & 20 & Singer/University Voice Teacher \\
\hline $\begin{array}{l}\text { Mean } \\
\text { SD } \\
\end{array}$ & & $\begin{array}{l}34.1 \\
10.7 \\
\end{array}$ & & $\begin{array}{l}10.1 \\
10.8 \\
\end{array}$ & \\
\hline
\end{tabular}


Because there are well-documented acoustic implications for changes in jaw opening, this variable was controlled. Lindblom and Sundberg's articulatory model shows that an increase in jaw opening decreases pharyngeal width, ${ }^{47}$ and is correlated with a rise in the first formant frequency. ${ }^{48}$ Trained singers also "tune" the first formant frequency by opening or closing the jaw in order to gain loudness; the desired degree of jaw opening is dependent upon pitch, vowel, and voice type. ${ }^{49}$ Additionally, the opening of the jaw has been shown to increase extension of the head by up to 15 degrees. ${ }^{50}$ Scotto di Carlo found head extension increased in singers at increased pitch levels, part of which was attributed to jaw opening. There was also an inversion of the natural lordosis of the cervical spine "in order to create space for pharyngeal widening and the forward tilt of the thyroid cartilage." ${ }^{.51}$ To eliminate acoustical changes that may be attributable to jaw movement, jaw height was fixed for all subjects at all pitches and vowels using a small bite block.

\section{Apparatus}

Subjects sang into a head-mounted microphone, C 420 Headset by AKG. The audio signal was fed into a Behringer Ultragain Pro High Precision Tube Mic/Line pre-amplifier, model Mic 2200. The microphone signal was attenuated with a Tucker-Davis Technologies PA5 Programmable Attenuator to avoid signal clipping. A two-channel electroglottograph (EGG) was used to monitor phonatory function using an EG2-PC two channel EGG and microphone preamplifier from Glottal Enterprises. Audio and EGG data were collected with a software

\footnotetext{
${ }^{47}$ Björn E. F. Lindblom and Johan E. F. Sundberg, “Acoustical Consequences of Lip, Tongue, Jaw, and Larynx Movement,” Journal of the Acoustical Society of America 50, no. 4 (1971): 1167.

${ }^{48}$ Ibid., 1174.

${ }^{49}$ Johan Sundberg, The Science of the Singing Voice (DeKalb: Northern Illinois University Press, 1987), 129.

${ }^{50}$ Toshitaka Muto and Masaaki Kanazawa, "Positional Change of the Hyoid Bone at Maximal Mouth Opening," Oral Surgery Oral Medicine Oral Pathology 77, no. 5 (May 1994): 453.

${ }^{51}$ Scotto di Carlo, "Cervical Spine Abnormalities," 215-216.
} 
program Voce Vista, version 3.0 (2006) for Windows. Analysis of the acoustic waveforms was done using a Fast Fourier Transform (FFT) which was accomplished with a software package called SIGVIEW32 Version 2.5.1, using a Hanning window and 15 pt smoothing. Head flexion/extension was measured with a head-mounted inclinometer manufactured by Donegan Optical Co., Inc. Frankfurt Horizontal plane for the human skull (FH) was established visually with a level and ruler as reported in the literature.

\section{Procedure}

Each subject reported his or her comfortable range, from which the test pitches at 20, 50, and 80 percent of the range, measured in half-steps, ${ }^{52}$ were selected. The subject then put on the head-mounted microphone, and was fitted with the EGG electrodes, inclinometer, and bite block. The standing posture was visually inspected to ensure correct axial alignment, and to determine the head position to be used as 0 (FH parallel to floor). The 45 experimental conditions were run in a randomized order. Subjects sang the carrier phrase "I say (insert vowel) again" at the specified pitch level and head position. A one-second segment of the acoustic signal from the stable vowel was extracted for analysis.

\section{Acoustic analysis}

The power spectrum of each sound sample was evaluated to determine the relative amplitude in decibels $(\mathrm{dB})$ of each partial. The Sigview program calculates $\mathrm{dB}$ from recorded sound using the formula $20 * \log 10(\mathrm{M})$, wherein $\mathrm{M}$ is the spectrum magnitude of a given

${ }^{52}$ Ofer Amir, Noam Amir, and Orit Michaeli, "Evaluating the Influence of Warmup on Singing Voice Quality Using Acoustic Measures," Journal of Voice 19, no. 2 (2005): 254. 
frequency. ${ }^{53}$ Absent interaction from the vocal tract, a source spectrum shows a regular slope indicating a $12 \mathrm{~dB}$ per octave decrease. However, in reality, the vocal tract acts as a filter, amplifying or damping certain frequencies, resulting in spectra of varying shapes. The spectrum is also influenced by the glottal source; for example, higher rates of airflow through the glottis are associated with a strong fundamental frequency, and an increase in the speed of vocal fold closure results in increased amplitude of high partials. ${ }^{54}$ The relative strength of the partials for any given tone, determined by the interaction of the glottal source and the vocal tract, determines the timbre of that tone. ${ }^{55}$

The special configuration of the vocal tract and the resulting sound spectra that allow a singer to project over an orchestra without amplification is one of the primary characteristics of the trained voice. In the male voice especially, this optimal resonance is achieved by formation of the Singer's Formant, a clustering of the third, fourth, and fifth formants of the vocal tract that boosts amplitudes in the $2-4 \mathrm{kHz}$ range. ${ }^{56}$ To explore this activity, the Singing Power Ratio (SPR), ${ }^{57}$ a comparison of the amplitude of the highest peak in the $2-4 \mathrm{kHz}$ range and the highest amplitude in the 0-2 kHz range was measured (see Fig. 4). Higher SPR has been associated with perceived "ringing" quality in both singing and speaking voices ${ }^{58}$ and implies the presence of the Singer's Formant. SPR has been shown to be higher in trained versus untrained singers ${ }^{59}$ and

${ }^{53}$ Goran Orbadovic, email message to author, May 15, 2013.

${ }_{55}^{54}$ Sundberg, Science of the Singing Voice, 79.

${ }^{55}$ Ibid., 71 .

${ }^{56}$ Ibid., 119.

${ }^{57}$ Koichi Omori, Ashutosh Kacker, Linda M. Carroll, William D. Riley, and Stanley M. Blaugrund, "Singing Power Ratio: Quantitative Evaluation of Singing Voice Quality," Journal of Voice 10, no. 3 (1996): 228235 .

${ }^{58}$ Ibid.

${ }^{59}$ Christopher Watts, Kathryn Barnes-Burroughs, Julie Estis, and Debra Blanton, "The Singing Power Ratio as an Objective Measure of Singing Voice Quality in Untrained Talented and Nontalented Singers," Journal of Voice 20, no. 1 (2006): 82-88. 
to increase from pre-warm up to post-warm up conditions in singers, ${ }^{60}$ both of which indicate better voice quality. For the female high voice, fundamental frequencies (F0) are too high, and thus the partials spaced too wide, to take advantage of the Singer's Formant as a resonance strategy. Instead, female singers employ "Formant Tuning," or manipulation of the vocal tract to move the first formant to a frequency near that of the sung fundamental. ${ }^{61}$ This is done primarily by adjusting the jaw opening. ${ }^{62}$ Therefore, changes in the strength of F0 were also recorded as a measure of singing voice quality. The calculated SPR and the F0 amplitude of each sample were documented, and then normalized with respect to the subject's habitual posture (see Table 2).

The scores for each outcome thus represent change from the singer's "normal"; a positive number indicates an increase in SPR or F0 amplitude, and a negative a decrease.

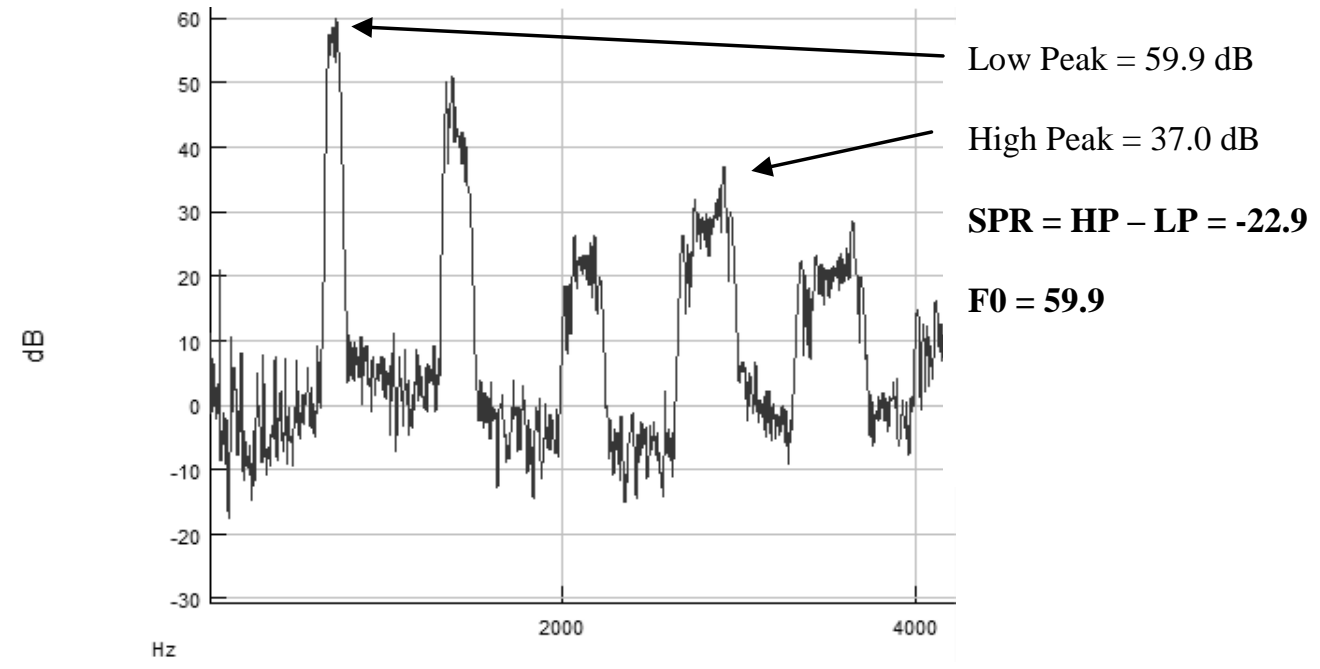

Fig. 4. Singing Power Ratio and F0 calculation. To calculate SPR, the highest peak amplitude in the $0-2 \mathrm{kHz}$ range (LP) is subtracted from the highest peak amplitude in the $2-4 \mathrm{kHz}$ range (HP). In this example, as is often the case, LP is the Fundamental Frequency.

\footnotetext{
${ }^{60}$ Amir, Amir, and Michaeli.

${ }^{61}$ Johan Sundberg, "Formant Technique in a Professional Female Singer," Acoustica 32 (1975): 89-96.

62 Ibid.
} 
Table 2

Conversion of raw scores into normalized scores

\begin{tabular}{llllll}
\hline & Habitual & $\mathbf{- 1 5}$ & $\mathbf{0}$ & $\mathbf{1 5}$ & $\mathbf{3 0}$ \\
\hline F0 Raw & 58.29735 & 56.38457 & 56.37405 & 57.95138 & 59.40514 \\
F0 Change & & -1.91278 & -1.9233 & -0.34597 & 1.10779 \\
SPR Raw & -25.262 & -22.4697 & -20.2809 & -25.0592 & -23.4355 \\
SPR Change & & 2.7923 & 4.9811 & 0.2028 & 1.8265 \\
\hline
\end{tabular}

The SPR and F0 scores for the habitual head position were subtracted from the subject's score at each experimental head position, to yield a change score. This table shows the conversion for Subject S6's scores for the high pitch/[a] vowel condition.

\section{Statistical Analysis}

Statistical analysis was completed with IBM SPSS Statistics version 21. Normalized scores for the dependent variables F0 and SPR were correlated using Pearson's $r$ to determine if the two main outcomes were related. A repeated measures multivariate analysis of variance (rMANOVA) was then performed with the SPSS General Linear Model (GLM) function, with head position as the within-subjects variable, to determine main effects and interaction effects on F0 and SPR from the independent variables. These results are represented graphically as error bar or scatter plots, showing normalized mean scores over an x-axis representing the 4 experimental head positions. Secondary rANOVA analyses were completed on High Peak and Low Peak measures to explore the behavior of these components of SPR with changing head position. GLM-generated tests of within-subjects contrasts were used to determine the significance of changes in the dependent variables between levels of head position. $P$-values < .05 were considered statistically significant; however, in most cases exact $p$-values are reported (a value of .000 is represented here as $<.001$ ). 


\section{CHAPTER III}

\section{RESULTS}

\section{Data preparation}

The complete data set contained 1,440 scores for the two outcome variables F0 and SPR. There were sound file errors in one subject's high note conditions, so those 24 data points were excluded. Before analysis was completed on the remaining scores, 25 outliers were removed from the data set. SPSS identified extreme values as follows: for the F0 scores $(N=708, M=-$ $.09, S D=2.29)$, scores $\geq 5.8$ and $\leq-6.0$; for SPR scores $(N=708, M=-.01, S D=3.87)$, scores $\geq 11.4$ and $\leq-9.5$.

\section{Reliability}

Reliability of the protocol was assessed via a test-retest procedure, in which three randomly assigned test conditions were repeated within the course of each subject's trial. An intraclass correlation coefficient (ICC) was calculated for the repeated conditions. For F0 amplitudes $\operatorname{ICC}(57)=.96, p<.001$, and for SPR values $\operatorname{ICC}(49)=.83, p<.001$. Though opinions vary regarding acceptable ICC values, those above .75 are "often taken as representing excellent agreement."

\section{Main Effects}

The two outcome variables, SPR and F0, are negatively correlated $(r=-.241, p<.001)$. Because of the significant correlation of these two measures, they were analyzed together in a multivariate analysis rather in a separate ANOVA for each. Results of the rMANOVA show that

\footnotetext{
${ }^{63}$ Betty R. Kirkwood and Jonathan A. C. Sterne, Essential Medical Statistics, 2d ed. (Malden, MA: Blackwell Science, Inc., 2003), 434.
} 
head position has a significant effect on the acoustic measures, Wilks' Lambda $F(6,117)=$ 29.12, $p=<.001$. There are not significant effects from the between-subjects factors of pitch $F(4,242)=.64, p=.63$, vowel $F(4,242)=.47, p=.76$, or voice type $F(6,242)=1.17, p=.32$.

Head extension is negatively correlated with SPR score $(r=-.189, p<.001)$, and positively correlated with F0 score $(r=.388, p<.001)$. That is, the more the head is extended, the higher the F0 amplitude score, and the lower the SPR (see Table 3). The standard deviations are quite large, however, indicating that though there are significant trends in the means, there is also a great deal of variability between individuals.

Table 3

Mean FO and SPR scores and Standard Deviations at each head position

\begin{tabular}{lllcl}
\hline & & \multicolumn{3}{c}{ Head Position } \\
& $\mathbf{- 1 5}$ & $\mathbf{0}$ & $\mathbf{+ 1 5}$ & $\mathbf{+ 3 0}$ \\
\hline F0 N & 173 & 174 & 174 & 175 \\
F0 Mean & -1.13 & -.72 & .15 & 1.09 \\
FO SD & 1.86 & 1.89 & 2.04 & 2.14 \\
SPR N & 172 & 177 & 174 & 173 \\
SPR Mean & .96 & .30 & -.23 & -.86 \\
SPR SD & 3.56 & 3.36 & 3.27 & 3.74 \\
\hline
\end{tabular}

Tests of within-subjects contrasts show significant differences between the levels of head position for all F0 scores, and for two of three contrasts in SPR scores. Table 4 shows these results. The increasingly higher $F$ values suggest that, with further extension, head position may account for more of the variability between the levels. 
Table 4

Within-subjects difference contrasts, main effects

\begin{tabular}{lllll}
\hline Measure & Comparison & F & df & Sig. \\
\hline F0 & 0 vs. -15 & 4.51 & 1 & .036 \\
& 15 vs. 0 & 38.45 & 1 & .000 \\
SPR & 30 vs. 15 & 155.18 & 1 & .000 \\
& 0 vs. -15 & 2.81 & 1 & .096 \\
& 15 vs. 0 & 9.03 & 1 & .003 \\
\hline
\end{tabular}

Interaction Effects

The interactions of head position with pitch, vowel, and voice type do not have a significant effect upon the outcome variables. There are likewise no significant effects from the interactions of pitch, vowel, and voice type with each other. 


\section{CHAPTER IV}

\section{DISCUSSION}

\section{Relationships Among SPR, F0, High Peak, and Low Peak}

It seems at first puzzling that head position affects the two measures of voice quality oppositely. A closer look at the way in which these two measures are determined explains the negative correlation between SPR and F0 amplitude. SPR is an expression of the relationship between amplitudes in the $0-2 \mathrm{kHz}$ range and amplitudes in the $2-4 \mathrm{kHz}$ range, called Low Peak (LP) and High Peak (HP) respectively. In most spectra, LP has a higher amplitude than HP. The smaller the difference there is between the two amplitudes, the higher the SPR. In the event that HP has higher amplitude than LP, the SPR is higher still. Figure 6 demonstrates these relationships and resulting SPR values.

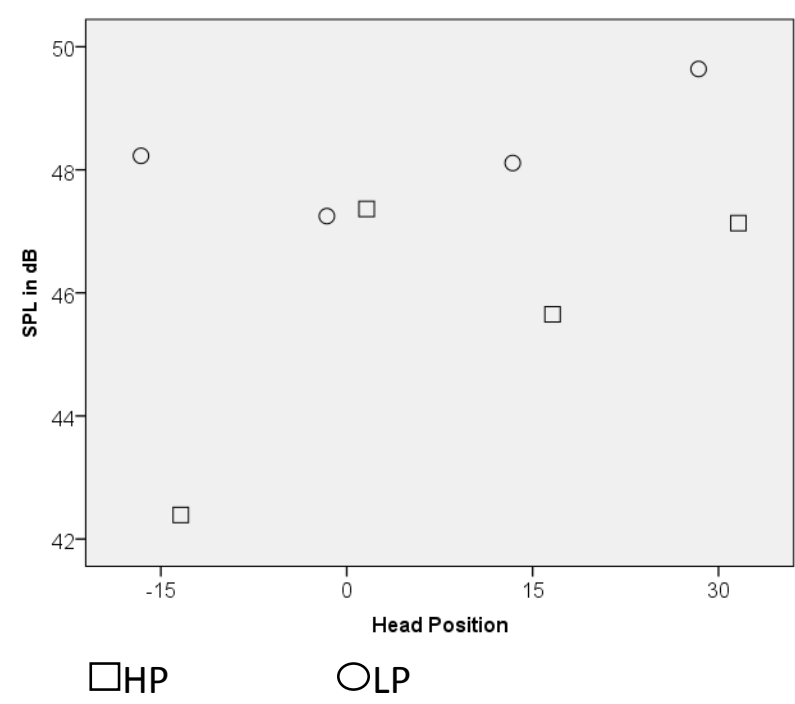

(a)

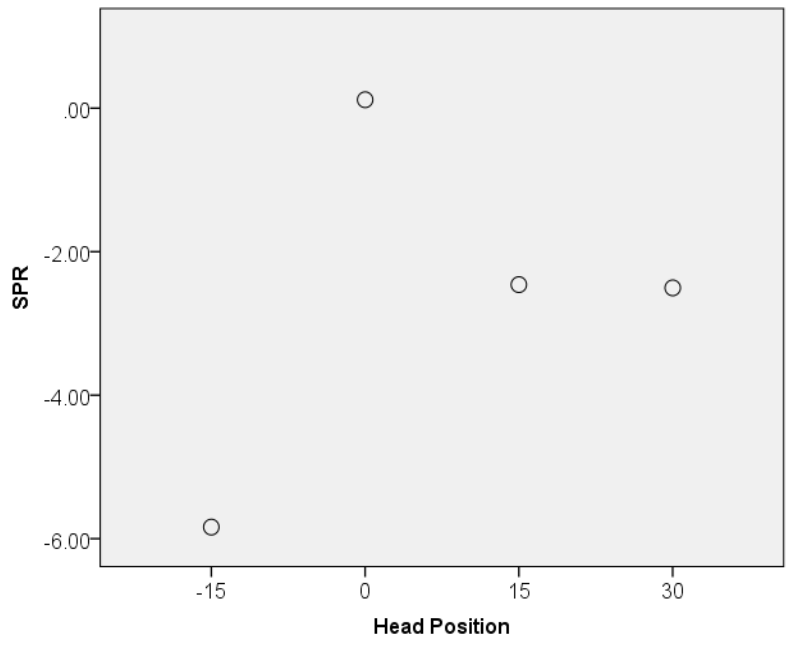

(b)

Fig. 6. (a) Raw scores for a single condition High Peak and Low Peak and (b) the resulting SPR. 


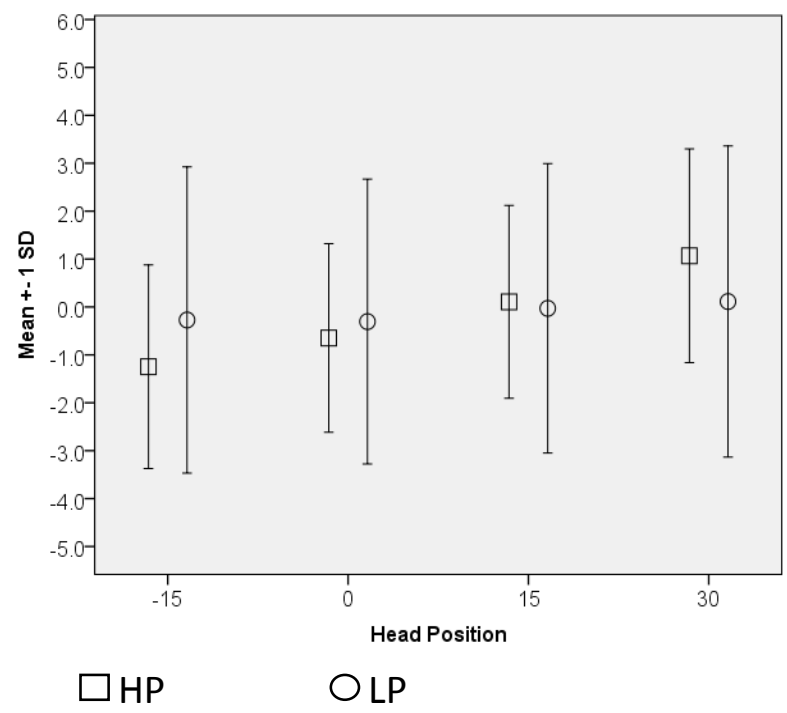

(a)

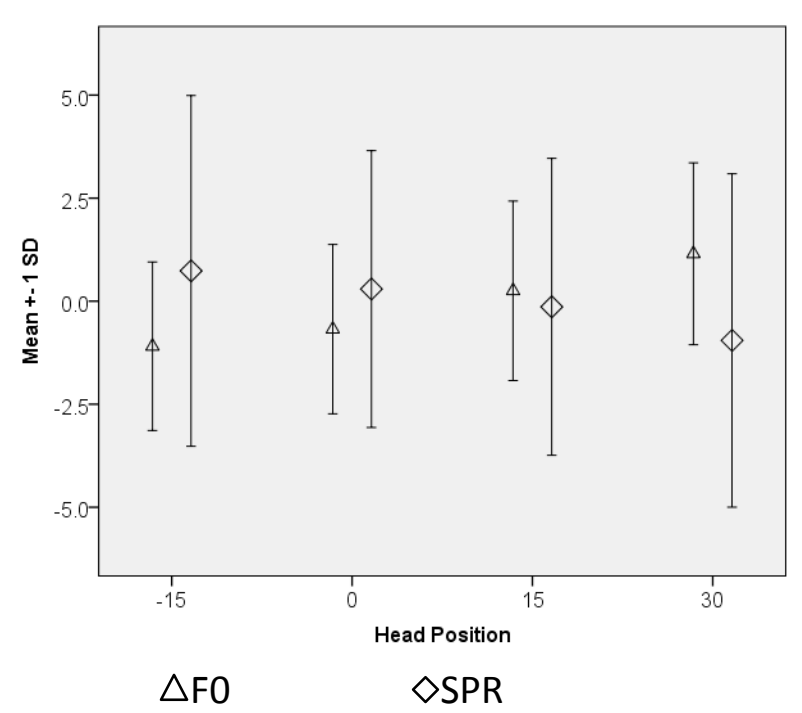

(b)

Fig. 7. Relationships of Mean High Peak, Low Peak, SPR and F0 with standard deviations across different head positions.

Figure 7 illustrates the interactions of LP, HP, SPR, and F0 with varying head position; these are normalized mean scores for all participants. As the head is extended, mean Low Peak amplitudes rise sharply, whereas mean High Peak amplitudes stay much more static. As this relationship changes, the SPR is lowered. Tests of within-subjects contrasts show no significant differences across the experimental head positions for HP, and significant differences between all levels for LP (See Table 5).

Table 5

Within-subjects difference contrasts, HP and LP

\begin{tabular}{lllll}
\hline Measure & Comparison & F & df & Sig. \\
\hline High Peak & 0 vs. -15 & .03 & 1 & .861 \\
& 15 vs. 0 & 1.99 & 1 & .161 \\
& 30 vs. 15 & 3.72 & 1 & .056 \\
Low Peak & 0 vs. -15 & 16.00 & 1 & .000 \\
& 15 vs. 0 & 37.46 & 1 & .000 \\
& 30 vs. 15 & 152.01 & 1 & .000 \\
\hline
\end{tabular}


One can see in Figure 7a that increased head extension is related to marked increases in mean Low Peak amplitudes and only slight increases in the mean amplitudes of the High Peak. Thus, frequencies in the $0-2 \mathrm{kHz}$ range appear to be more sensitive to changes in head position than do higher frequencies. Indeed, separate rANOVAs on these two variables show that Head Position does not have a significant effect on High Peak amplitudes, $F(1)=2.11, p=.149$, but does have a significant effect on Low Peak amplitudes, $F(1)=721.31, p=<.001$.

A comparison of Figure 7a with 7b shows that Low Peak amplitudes and F0 amplitudes are very close, indicating that in many cases (approximately 44\%), the fundamental frequency itself has the highest amplitude in the $0-2 \mathrm{kHz}$ range. Of the cases in which $\mathrm{F} 0$ was also LP, most were in the female voices (78\%), distributed fairly evenly across the pitch conditions. The F0/LP concurrences often followed predictable patterns based on formant locations. For example, there is a large number $(46.5 \%)$ in the female voices on the [i] vowel but many fewer $(18.3 \%)$ on [a]; the first formant frequency of [i] is rather low compared to [a], so more of our test pitches' fundamental frequencies fell under its formant. In the male voices, $78.6 \%$ of the incidences of F0 being the LP were on an [i] vowel, the majority at pitches just under $300 \mathrm{~Hz}$, where the first formant of [i] lies in the male voice.

\section{Variability of HP and LP}

Many of the subjects exemplified the trends revealed by the overall mean amplitudes of the acoustic measures F0 and SPR, and their components HP and LP. That is, with increased head extension, amplitudes in the range of $0-2 \mathrm{kHz}$ tend to increase while those in the $2-4 \mathrm{kHz}$ range remain relatively static; this results in increases of F0 amplitude but lower SPRs. Subject 
M3 is an example of the typical profile seen; Figure 8 shows mean change scores from her habitual for all four measures.

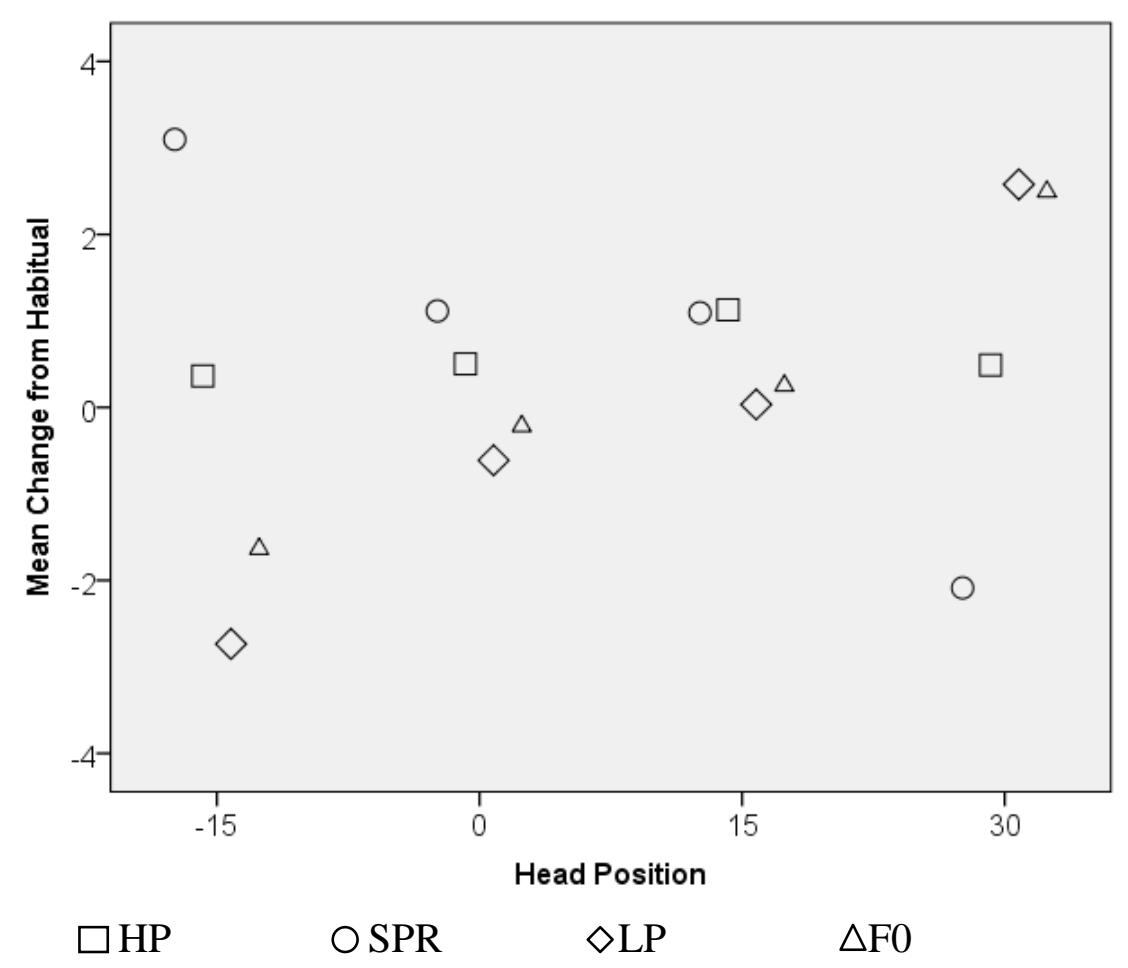

Fig. 8. A typical profile, Subject M3's mean LP, HP, F0, and SPR scores.

As with F0 and SPR, the standard deviations for HP and LP are large, indicating a considerable amount of variability between subjects (see Table 6). One must assume that some of the variability is due to the singers' reactions to different vowel and pitch conditions, though no clear trends are evident in the data. Clearly, however, not every subject follows the general trends indicated by the means. For example, several subjects had substantial gains in both LP and HP amplitude with head extension, whereas the overall trend across subjects and conditions was only a slight increase in HP. Most notably M3 and B4 demonstrate steep increases of HP with more extended head positions. B4 shows improvement in LP amplitude in all 3 vowel conditions, while M3's [a] vowel has the most linear relationship with head position. Her [i] and 
$[\mathcal{E}]$ vowels were both at their highest $\mathrm{HP}$ amplitude at $+15^{\circ}$ and decreased a little again at $+30^{\circ}$ (see Fig. 9).

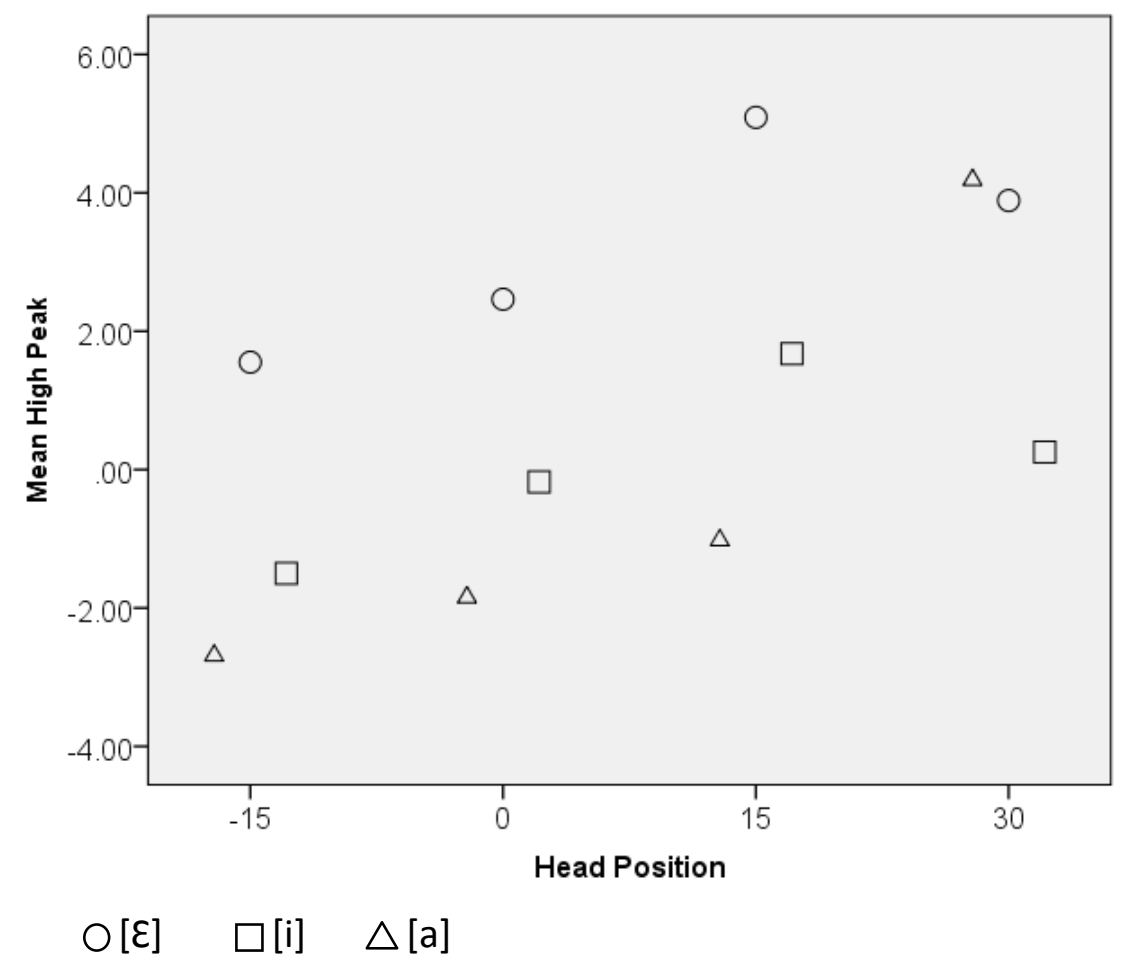

Fig. 9. Subject M3 Mean HP across head positions, by vowel.

Another example of individual variance, S5 follows expected pattern of an increase in LP amplitude with head extension, but almost no mean scores were better than her habitual. Closer examination shows that she had considerable gains in LP on the high note conditions at more extended head positions ( .80 and 2.71 at $+15^{\circ}$ and $+30^{\circ}$ respectively), but they were offset by losses in LP for the middle range conditions ( -1.65 and -1.34 at $+15^{\circ}$ and $\left.+30^{\circ}\right)$. For this soprano it appears that head extension may be advantageous for higher pitches, but the habitual position is preferred for middle and low. Figure 10 illustrates the differences in LP response to head position by pitch level. 


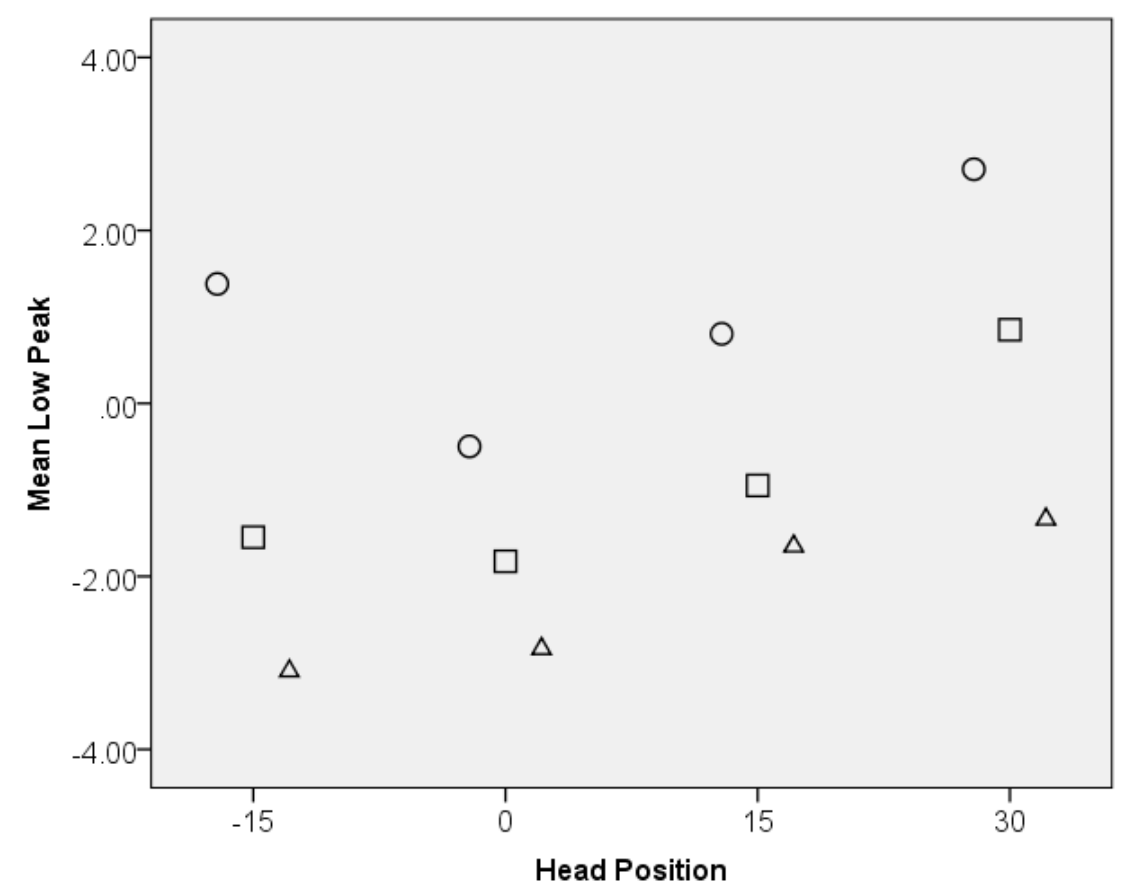

OHigh $\square$ Low $\triangle$ Mid

Fig. 10. Subject S5 LP Mean across head positions, by pitch.

Table 6

Mean HP and LP Scores and Standard Deviations

\begin{tabular}{lllll}
\hline & & \multicolumn{3}{c}{ Head Position } \\
& -15 & 0 & 15 & 30 \\
\hline HP N & 171 & 176 & 171 & 172 \\
HP Mean & -0.2494 & -0.3048 & -0.0389 & 0.1127 \\
\hline HP SD & 3.25221 & 2.97372 & 3.01556 & 3.22163 \\
LP N & 174 & 177 & 175 & 174 \\
LP Mean & -1.2482 & -0.6496 & 0.0335 & 1.0814 \\
LP SD & 2.10974 & 1.96251 & 2.03216 & 2.21174 \\
\hline
\end{tabular}

Fach, Habitual Head Position, and High Peak Amplitude

An interesting observation from the secondary rANOVA analyses is that Fach as a between-subjects factor has a significant effect on High Peak amplitudes, $F(3)=2.89, p=.038$, but not on Low Peak amplitudes, $F(3)=1.45, p=.23$. So, while head position may not make a 
difference in the mean change of High Peak amplitudes, the subject's voice type may. Figure 11 shows the mean High Peak amplitudes by voice type, and demonstrates the complexity of this variable. The High Peak amplitudes for baritones, for example, tend to decrease as head extension increases, whereas tenors, mezzos, and sopranos generally see an overall amplitude increase. The pattern for each voice type appears to be unique, and not follow any predictable model based on sex, high or low voice, etc. It must be remembered that this is a very small sample; therefore any characteristics that appear to be group phenomena may in reality only reflect individual differences between subjects.

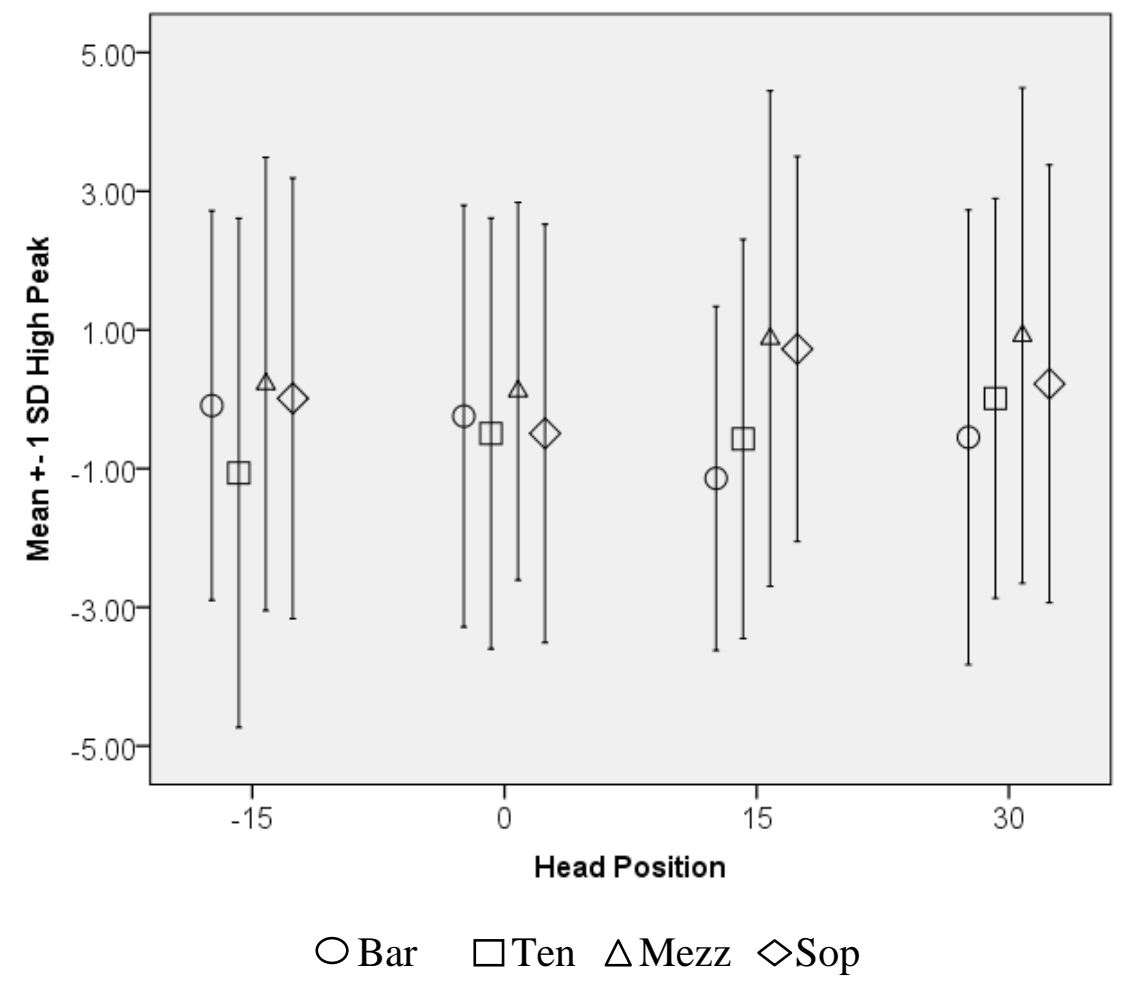

Figure 11. Mean HP with SD across the different head positions, by voice type.

Also noteworthy in Figure 11 is the almost complete lack of positive HP values for tenors and baritones, meaning that at all experimental head positions, the High Peak amplitude is lower than at the subjects' habitual positions. Though the habitual head position is not a statistically 
significant part of the overall model, there are differences by voice type and sex that are worth noting. The mean habitual head position of the females is $8.19^{\circ}$, while for males it is $9.94^{\circ}$, a statistically significant difference, $t(157)=4.37, p=<.001$. Additionally, and perhaps more importantly, in the baritones and tenors there is a much greater range and variability of habitual head positions as compared to sopranos and mezzos (see Fig. 12).

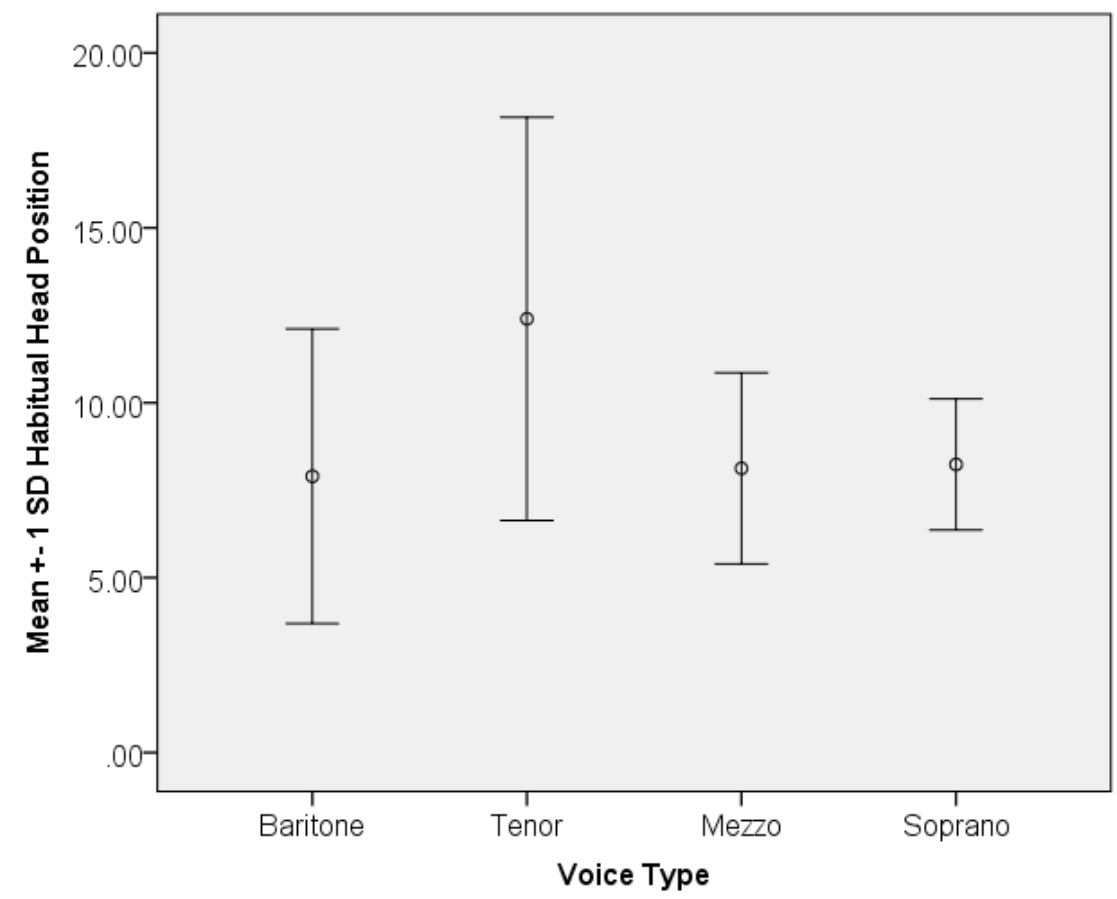

Fig. 12. Habitual head position by voice type.

To determine what effect this variability of habitual head position might have on the behavior of HP, it is useful to look more closely at the subjects with the most extreme head positions (see Fig. 13). Subject T4 had the most extended habitual head posture observed, $22^{\circ}$. Both the HP and LP scores showed little or no gain from the baseline habitual position at any of the experimental positions. His scores at $30^{\circ}$ are closest to those of his habitual posture, and he saw the most gains in SPR at the head position furthest from his habitual, $-15^{\circ}$. There was a 
marked decrease in HP and consequently the SPR at $15^{\circ}$. Subject B5, rather than showing great variability like T4, was perhaps the most consistent subject in terms of score ranking. His habitual position was $0^{\circ}$, the least extended of the subjects. For every pitch and vowel combination, his SPR scores were highest in the $-15^{\circ}$ head position, and both HP and SPR show a clear downward trend with increasing head extension. For this singer, all conditions extending the head more than the habitual posture had increasingly lower SPR scores. It is interesting to note that Subject B5 is among the most experienced singers in the pool, and has certainly had, though not the longest, the most high-profile performing career. His physicality is deliberate and calm. Subject T4, by contrast, is among the younger singers with considerably less training and performing experience. T4 was also less able to maintain axial alignment throughout the test procedure; he was frequently reminded not to allow the head to move in front of the shoulders. He often found it difficult to hold the experimental head positions for the duration of the test phrase; his tendency was always to extend the head further and the chin forward. These two cases demonstrate the consequence of learned physical behavior on the resulting tone. In one case, a firmly entrenched technique yields predictable results; in the other, an inconsistent technique may be easily influenced by outside factors. 

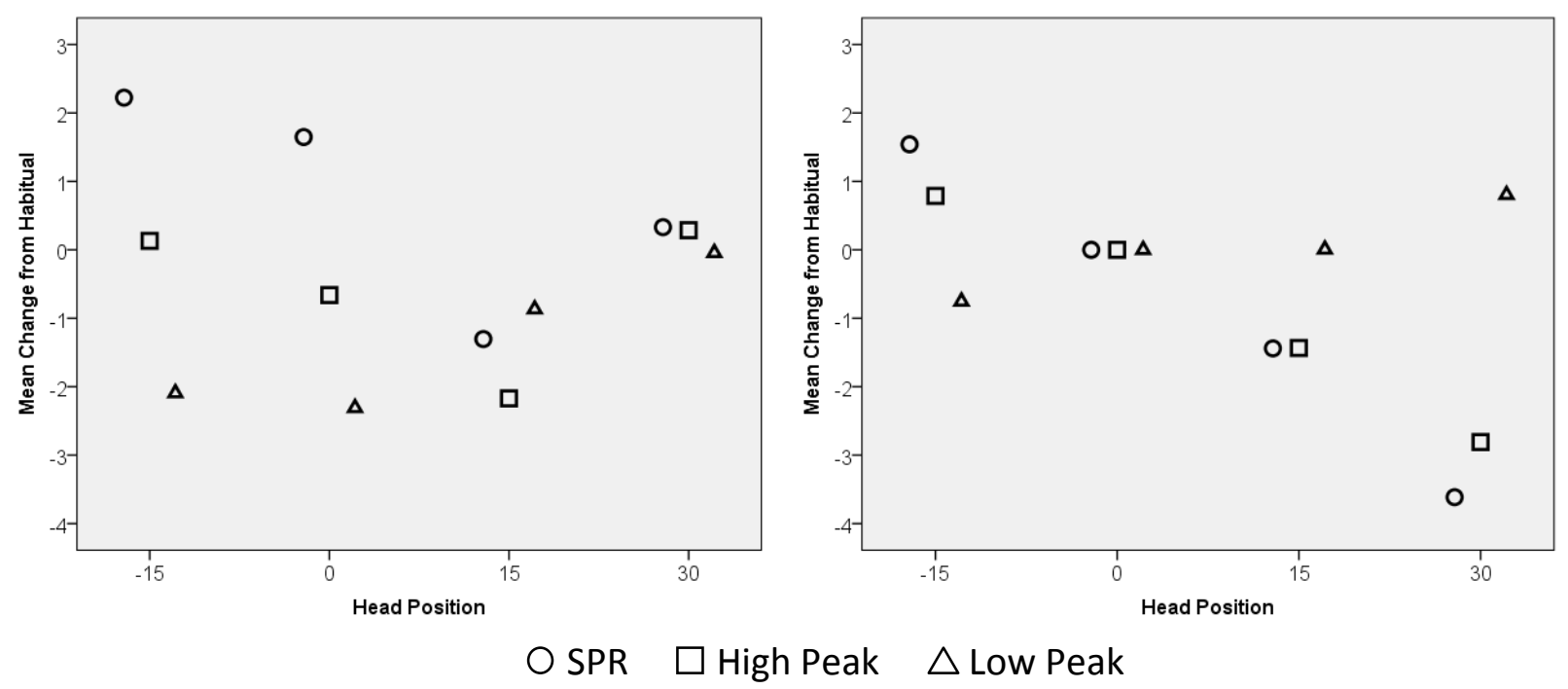

(a)

(b)

Fig 13. (a) Subject T4 mean HP, LP, and SPR. (b). Subject B5 mean HP, LP, and SPR.

\section{Optimal Resonance vs. Intensity}

Because of the clear trend for LP amplitudes to increase with head extension, this seems an obvious advantage for females, especially in high notes where boosting F0 is the most important resonance tool available. Potential resonance benefits of changing head position for the male voice are less immediately clear. If the primary means of optimizing resonance is in increasing energy in the Singer's Formant range (roughly 2-4 kHz), SPR data suggest that flexion of the neck would be valuable. However, one must recall that changes in SPR observed here with changing head position are due much more to the changes in low frequency peak amplitudes than high. Therefore, one must weigh the possible losses in LP with flexion of the neck against any gains in SPR. All voices can gain sound level by boosting LP amplitudes. Sundberg tell us that loudness of phonation is "almost entirely determined by the amplitude of the strongest spectrum partial, and normally this partial is the one that is closest to the first 
formant frequency." ${ }^{, 64}$ The first formants of all vowels are in the LP range of $0-2 \mathrm{kHz}$, so this is a possible loudness enhancer for almost any combination of voice type, pitch, and vowel. Figure 13 demonstrates a scenario in which head extension raises LP and lowers HP and the overall SPR. Though the SPR is lower at $15^{\circ}$ than at $0^{\circ}$, the intensity gained from an increase of 4.29 $\mathrm{dB}$ in LP may more than compensate for the loss of $1.61 \mathrm{~dB}$ in HP. Because this study did not include a perceptual rating, the changes in voice quality as a result of these spectral changes are not known for certain. Richard Miller analyzed recordings of some famous tenors and found a variety of spectral configurations. Figure 14 compares average spectra of Bjoerling and Pavarotti singing the same phrase; Bjoerling's SPR is considerably higher than Pavarotti's. However, Miller points out that Pavarotti has a much broader distribution of energy in all parts of the spectrum, extending even beyond 3,500 Hz, where Bjoerling's acoustic energy begins to fall off. He characterizes Pavarotti's phonation as "thrilling" "65 but says that Bjoerling's is "admirable in the cleanness of its distribution of acoustic strength; i.e., there is almost no indication of undesirable nonharmonic energy between the harmonic multiples of the fundamental frequency." ${ }^{, 66}$ Miller goes on to say that Bjoerling's production combines "lyricism and energy to produce beautiful vocal sound. ${ }^{, 67}$ Part of Pavarotti's thrilling sound may come from the intensity achieved by the amplitude of the third harmonic, at about $50 \mathrm{~dB}$. Bjoerling's highest harmonic measures less than $40 \mathrm{~dB}$. Of course, there are instances when these singers' spectra do not follow these patterns; experienced singers probably make resonances changes unconsciously based on the performance context and character of the music in addition to their individual techniques. Comparative analysis of professionally mastered recordings must also be

\footnotetext{
${ }^{64}$ Sundberg, Science of the Singing Voice, 79.

${ }^{65}$ R. Miller, Training Tenor Voices, 147.

${ }^{66}$ Ibid., 146.

${ }^{67}$ Ibid., 146.
} 
treated as suspect; there is no way to account ex post facto for differing room acoustics, microphone placement, or adjustments in the sound made by the engineers. Further controlled study is needed to determine the perceptual effect of this type of spectrum change, but it is clear that in some cases, higher amplitudes of LP frequencies are advantageous over higher HP amplitudes.
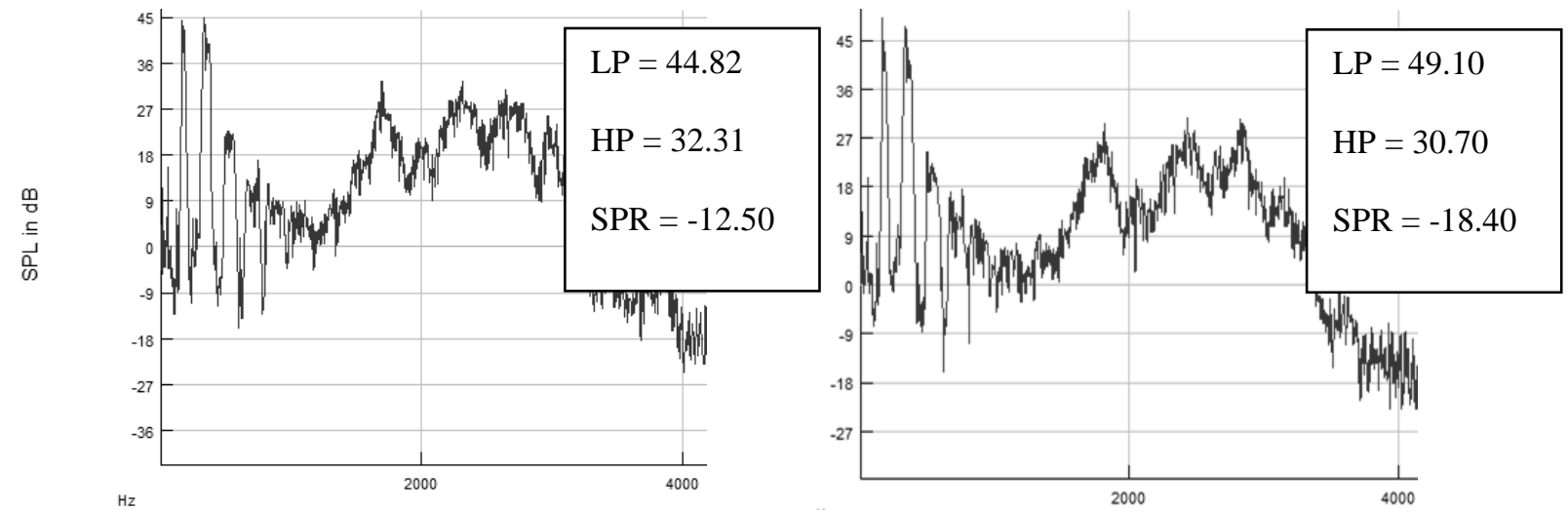

(a)

(b)

Fig. 13. Subject B5, [i] vowel at pitch $\mathrm{F}_{3}$, approximately $175 \mathrm{~Hz}$. Head positions (a) $0^{\circ}$ and (b) $15^{\circ}$ respectively.

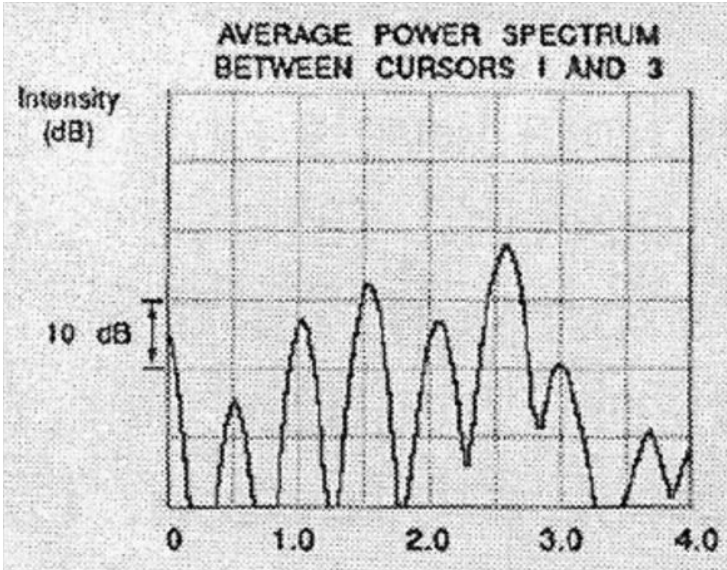

(a)

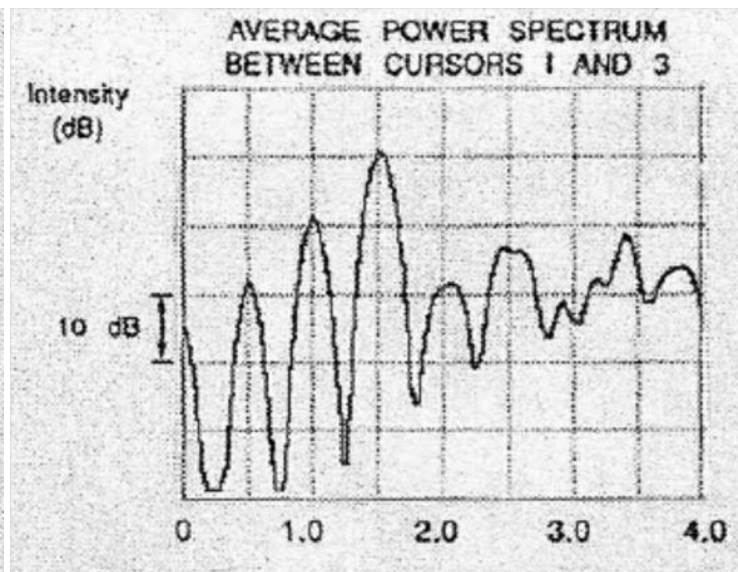

(b)

Fig. 14. Average power spectra of (a) Jussi Bjoerling and (b) Luciano Pavarotti singing the final "pensier" in "La donna è mobile" from Rigoletto. Reprinted from R. Miller, Training Tenor Voices (New York: Schirmer, 1993): 148-149. 


\section{Interpretation and Use of SPR Scores}

From the previous discussion of SPR components, it is evident that the behavior of the HP is much less influenced by changes in head position overall, and that singer idiosyncrasies may play a role in its amplitude changes. Because the changes in SPR at different head positions in this study seem largely to be the result of changes in LP amplitude rather than HP, the relationship of these SPR scores to actual voice quality is unclear. In the original study introducing SPR as a measure of singing voice quality, Omori et al. used a perceptual scale to verify their results. Listeners rated sound samples on a 1-7 scale from dull to ringing, and 1-7 from thin to rich. Overall SPR was significantly correlated with ringing quality, but not with richness. The researchers manipulated the amplitude of the higher frequency peak (which they termed the Singing Power Peak), and found that the lower this peak, the lower the perception of both ring and richness. ${ }^{68}$ They did not, however, alter the SPR by manipulating the lower frequency peak, so it is not known whether the perceived ring and richness are actually a function of the ratio between these two peaks, or merely a function of the strength of HP. In other words, one cannot be sure in the present study if SPR gains resulting from a damping of LP amplitudes with head flexion actually represent a desirable tone quality.

\section{Limitations and Recommendations for Further Research}

This initial study was limited to a small sample size, so generalization to the wider population of singers should be done with caution. In particular, a larger study looking specifically at the effects of head position on the behavior of HP frequencies between voice types might identify group differences that here could only be attributed to individuals. Another limitation in the scope of this study was the focus on acoustic data alone; there was no perceptual

\footnotetext{
${ }^{68}$ Omori et al., 229-232.
} 
measure of the changes in voice quality. Therefore the perceived quality of tones sung at the different head positions is not known. A future study with a perceptual rating instrument could increase understanding of the effect of head position on tone quality. Additionally, this study did not measure laryngeal position or function, so implications of head position on these parameters is speculative at this point. Measures of laryngeal height and airflow through the glottis at different head positions would give insight into these effects. 


\section{CHAPTER V}

\section{CONCLUSIONS}

\section{Implications for Laryngeal Function}

The most significant finding from this study is that low frequency harmonics are more sensitive to changes in head position than relatively higher frequency harmonics. There is a connection between increased head extension and higher fundamental frequency amplitudes for all voice types and at all pitch and vowel conditions. The effect seems to be similar to that of jaw opening, which has an effect on the first formant frequency. Female singers use jaw opening to tune the first formant to a frequency near the sung fundamental in high notes, thereby boosting the amplitude of F0. This study controlled jaw opening, so if formant tuning is responsible for gains in F0, it could be because of changes in vocal tract length due to raising or lowering the larynx. ${ }^{69}$ Remembering that extension of the head may facilitate raising of the larynx, it is possible that the gains in F0 amplitude seen are the result of a shortened vocal tract and raised first formant. It is impossible to say with any certainty whether this is the case, as larynx height was not measured. Further, singers are typically trained to avoid large excursions of the larynx in order to maintain consistent timbre throughout the range. The subjects were instructed to produce their best soloistic quality throughout, so it is safe to assume they made at least some attempt to prevent the larynx from raising with head extension. The extent to which these attempts were successful is not known; EGG measurements may be useful in determining larynx height, but the specific calibrations necessary to do so were not made prior to collecting data. (EGG information collected includes closed and open quotients, which may be analyzed for a subsequent study.) From observation of electrode activity during the testing, it was noted that some subjects' larynxes did reposition when the head position changed. These observations are

\footnotetext{
${ }^{69}$ Sundberg, Science of the Singing Voice, 128.
} 
purely anecdotal, however, so the extent to which larynx movement affected the spectra cannot be quantified.

Larynx height is a factor in the creation of the Singer's Formant. As the larynx lowers, the pharynx is elongated and the bottom part of the pharynx widens. ${ }^{70}$ This relationship of a long, narrow larynx tube to the surrounding widened pharynx contributes to increased energy in the upper partials. Recalling that extending the head widens the pharynx, and that on average there is a small increase in HP amplitude with head extension (see Fig. 7), it is possible that these postures may assist with the creation of the Singer's Formant. This would be contingent upon the singers' ability to maintain a low laryngeal position as the head extends. More research in this area is needed to determine more precisely the effect of head flexion and extension on larynx height.

It has been noted in the literature that singers may increase head extension (with or without a noticeable change in posture) to widen the pharynx and allow the larynx to tilt. Laryngeal tilt occurs as the vocal folds elongate to produce higher pitches. Head extension may be used, then, to facilitate ease of production for high notes. The results of this study did not show significant differences in F0 or SPR scores for higher pitches; head position seems to affect all pitch levels about the same. However, the increases in F0 amplitude with head extension suggest that head position may be important for other aspects of laryngeal function. Specifically, the balance of subglottic pressure and breath flow, or glottal resistance, may be affected. The amount of airflow through the glottis determines the strength of the fundamental; the higher the flow amplitude, the higher the F0 amplitude. ${ }^{71}$ If the vocal folds are too tightly adducted, flow is decreased, F0 amplitude is decreased, and the resulting sound is considered "pressed phonation."

\footnotetext{
${ }^{70}$ Ibid., 120.

${ }^{71}$ Ibid., 79.
} 
The other end of this glottal resistance continuum, "breathy phonation," is marked by weak adduction, very high airflow, and a strong F0 but very little energy in the upper partials. In addition to the amount of airflow, tone quality is determined by the rate at which the vocal folds close. A faster closing rate will result in higher amplitudes in the upper frequency range. It is plausible that changes in head position that result in F0 amplitude change do so because of altered laryngeal function affecting airflow through the glottis and/or closing rate. A follow up study correlating changes in head position with glottal resistance directly could confirm this speculation.

\section{Pedagogical Recommendations}

The positioning of the head involves a complex of some twenty pairs of muscles; ${ }^{72}$ the muscles on the posterior neck work to extend the head, while those on the anterior flex it. ${ }^{73}$ If one set of muscles is tense or overworked, another set will compensate in order to stabilize the cervical spine. ${ }^{74} 75$ Singers are particularly prone to neck stiffness and pain ${ }^{76}$ and given the interactions that neck flexion and extension may have with the function and position of the larynx, it is plausible that technical issues may arise from unaddressed posture problems. Indeed, physical misalignment is highly correlated with voice complaints and functional disorders. ${ }^{77}$ It is therefore of utmost importance for singers and those who teach, coach, and direct them to understand the potential vocal implications of head position. Not only may pain

\footnotetext{
${ }^{72}$ Honda, et al., "Contributions of Vocal Tract Shape," 409.

${ }^{73}$ John S. Rubin, Ed Blake, and Lesley Mathieson, "Musculoskeletal Patterns in Patients with Voice Disorders," Journal of Voice 21, no. 4 (2007): 477-484.

${ }^{74}$ Ibid.

${ }^{75}$ Viggo Pettersen and Rolf H. Westgaard, "The Activity Patterns of Neck Muscles in Professional Classical Singing,” Journal of Voice 19, no. 2 (2005): 238-251.

${ }^{76}$ Ibid.

${ }^{77}$ P.G.C. Kooijman, F.I.C.R.S. de Jong, M.J. Oudes, et al., "Muscular Tension and Body Posture in Relation to Voice Handicap and Voice Quality in Teachers with Persistent Voice Complaints," Folia Phoniatrica et Logopaedica 57 (2005): 134-147.
} 
and dysfunction be diminished, but singers may be taught to position their heads to maximize the acoustic benefits. The changes in spectra as a result of various head positions indicate that there are real advantages to such an approach. F0 scores averaged -1.13 at the lowest head position and 1.09 at the highest. This range of just over $2 \mathrm{~dB}$ may seem inconsequential, but on the logarithmic $\mathrm{dB}$ scale, a change of $3 \mathrm{~dB}$ represents a doubling of intensity. Therefore, even seemingly small changes may be significant.

Though much follow up research is needed to more fully understand the complex relationship of head position with voice quality, this initial study has produced some findings which may be useful to pedagogues. It has been shown that F0 increases with head extension; increased amplitude of low frequency partials can result in overall higher sound level. The ability to produce sufficiently loud tones is essential for the aspiring singer. A singer with an otherwise efficient technique may be able to leverage postural adjustments to gain intensity; as Sundberg notes with regard to jaw position, such adjustments come at much lower cost in muscle energy than increasing the workload of the breathing and glottal resistance mechanisms. ${ }^{78}$ Additionally, because changes in F0 amplitude are associated with rates of airflow through the glottis, head position may be a valuable tool in addressing problems of laryngeal function such as breathy or pressed phonation. A singer with a habitually low head posture whose tone is pressed might benefit from a more extended head position, and a singer with a breathy tone might try a less extended head position. Problematic vibrato is also caused by an imbalance of breath pressure and muscle activity in the larynx, so faulty vibrato might also be addressed by changing head posture. Additionally, singers who struggle to access the top of their range might check that a low head position is not inhibiting the laryngeal tilt necessary for ascent. As head position may influence the vertical larynx position, and gains in F0 amplitude with head extension may

\footnotetext{
${ }^{78}$ Ibid., 127.
} 
therefore be attributed to a shortened vocal tract, the timbre of such a tone must be carefully monitored. A student must be taught to consistently maintain a relatively low laryngeal position in addition to using head position to gain optimal glottal resistance, resonance, or loudness.

With male voices and lower female voices in particular, the primary resonance strategy is increased spectral energy in the area of the Singer's Formant. Though this study shows gains in SPR, an acoustic measure of voice quality, with flexion of the neck, closer examination reveals that such a strategy may not be beneficial. As the head is lowered, the amplitude of low frequency partials is reduced. Head position does not have a predictable effect on the amplitude of high frequency partials. Thus a possible boost in ring with head flexion may also result in a decrease in overall intensity. Decisions regarding the proper balance of ring and sound level must be made carefully, taking into consideration musical and emotional context as well as the singer's technical facility. Given the possible negative effects of neck flexion on laryngeal function noted in the literature, the lower head positions are not recommended.

Choral conductors should be aware of the rehearsal posture of their ensembles. Often choral singers look down at their scores rather than raising the music to eye level. This head position, inasmuch as it damps low frequencies, could be limiting the dynamic range of the ensemble. One can easily imagine singers, in response to a request for more sound, using inappropriately high subglottic pressure and putting undue strain on the larynx in order to gain intensity, when the same result might be had from raising their heads. In collegiate settings, choral conductors often spend more instructional time with students than their voice teachers do. It is imperative, then, that conductors encourage good vocal habits in their rehearsals. Posture is easily identifiable and correctable in a group setting, and it should be taught in order to both protect singers and improve the tone quality of the ensemble. 
Stage directors may find it useful to know that high overtones are more directional than lower ones which radiate out equally in all directions from the source, causing much of the low spectral energy to be lost to the audience. So, the Singer's Formant is an advantage when the singer is facing the audience. ${ }^{79}$ However, if a singer needs to face upstage or toward the wings for a line, it may be useful for him to boost the lower frequencies which will carry toward the audience no matter where his voice is directed. This could be accomplished by having the performer raise his head posture slightly. Directors should also be aware of the possible losses in volume with lower head position, and make staging decisions accordingly. Less experienced singers might also benefit from reminders to look for the conductor peripherally rather than moving the head to look down toward the pit while singing.

Singers need to be made aware of the implications of habitual head position on tone quality, so that they do not reinforce poor habits in their personal practice, rehearsals, or ensemble singing. Voice teachers should encourage their students to develop awareness of their bodies and take responsibility for those things, like head position, that they can fix quickly. Other areas of technical development may take months or years to resolve, but establishing good habits with regard to head posture may prevent some phonation problems from arising, and may give a singer some acoustical advantages as well. Though not a panacea, head position should most certainly be among the tools a voice teacher uses to promote healthy, vibrant singing.

\section{Summary}

This study was undertaken with the goal of identifying the effect of head position on measures of singing voice quality. The spectra of sung vowels at experimental head positions

\footnotetext{
${ }^{79}$ Ibid., 123.
} 
were compared to participants' habitual posture spectra. Two outcomes were measured, the amplitude of the fundamental frequency, and the Singing Power Ratio, a measure derived from the relationship of the energy intensity in the low part of the spectrum to that in the high part. The finding that low frequency (often, but not always the fundamental) amplitudes are greater with more extended head positions means that these positions may be used to boost the overall loudness of the voice. This is an important resonance tool for female voices in the high range, and is likely of benefit to other voice types as well. This finding also has implications for laryngeal function; head extension may increase airflow through the glottis, so it may be useful in addressing phonation and vibrato faults. Voice teachers are cautioned to monitor laryngeal position, however, as increased head extension can help the larynx to rise, resulting in undesirable timbre. The study found that SPR increased with neck flexion, but a simple interpretation of this finding is misleading. Gains in SPR are due mainly to losses in low frequency energy rather than increases in amplitude in the region of the Singer's Formant, so lowering the head may not be beneficial. Participants saw improvement in low frequency amplitudes at postures 15 and 30 degrees extended from horizontal. As their mean habitual head position was just under $10^{\circ}$, almost all of the singers in this study could benefit from adopting a higher posture. Given the advantages in resonance and laryngeal function to be had from utilizing these head positions, this issue is certainly worth the consideration of singers, voice teachers, directors, coaches, and conductors. 
APPENDIX A

IRB APPROVAL LETTER 


\title{
UNT
}

A green light to greatness."."

January 7, 2013

Office of the Vice President of Research and Economic Development

Office of Research Services

Supervising Investigator: Dr. Stephen Austin

Student Investigator: Elizabeth Knight

College of Music

University of North Texas

Re: Human Subjects Application No. 12517

Dear Dr. Austin:

As permitted by federal law and regulations governing the use of human subjects in research projects (45 CFR 46), the UNT Institutional Review Board has reviewed your proposed project titled "The Effect of Head Flexion/Extension on Acoustic Measures of Singing Voice Quality." The risks inherent in this research are minimal, and the potential benefits to the subject outweigh those risks. The submitted protocol is hereby approved for the use of human subjects in this study. Federal Policy 45 CFR 46.109(e) stipulates that IRB approval is for one year only, January 7, 2013 to January 6, 2014.

Enclosed is the consent document with stamped IRB approval. Please copy and use this form only for your study subjects.

It is your responsibility according to U.S. Department of Health and Human Services regulations to submit annual and terminal progress reports to the IRB for this project. The IRB must also review this project prior to any modifications. If continuing review is not granted before January 6,2014 , approval of this research expires on that date.

Please contact Shelia Bourns, Research Compliance Analyst, or Boyd Herndon, Director of Research Compliance, at extension 3940, if you wish to make changes or need additional information.

Sincerely,

$$
\text { Bund ffereem for PCK }
$$

Patricia L. Kaminski, Ph.D.

Associate Professor

Department of Psychology

Chair, Institutional Review Board

$\mathrm{PK} / \mathrm{sb}$

\author{
UNIVERSITY OF NORTH TEXAS \\ 1155 Union Circle \#305250 Denton, Texas 76203-5017 \\ 940.565 .3940940 .565 .4277 fax http://research.unt.edu \\ PROUDLY USTNG ENVXRONMENTALLY ERTENDUY PAPER-
}


APPENDIX B

CONSENT FORM 


\section{University of North Texas Institutional Review Board \\ Informed Consent Form}

Before agreeing to participate in this research study, it is important that you read and understand the following explanation of the purpose, benefits and risks of the study and how it will be conducted.

Title of Study: The effect of head flexion/extension on acoustic measures of singing voice quality

Student Investigator: Elizabeth Knight, University of North Texas (UNT) College of Music. Supervising Investigator: Dr.Stephen Austin.

Purpose of the Study: You are being asked to participate in a research study which involves acoustic analysis of the singing voice as performed with various head postures. Specifically, the aims of this study are 1) to identify changes in spectral energy as a result of head flexion/extension that indicate increased or decreased "ring" in the voice and 2) to examine the relationships among head flexion/extension and the different vowel and pitch conditions to move toward an understanding of ideal head position for singing.

Study Procedures: You will be asked to

- Sing simple vocalises to test your comfortable singing range,

- Put on the measurement apparatus - a head-mounted microphone, head-mounted inclinometer to measure angle, and electroglottography electrodes on a Velcro strap around the neck,

- With a small bite block between your teeth to maintain uniform jaw opening, you will sing the phrase "I say ([i], [E], or [a]) again" on three different notes, at 5 different head positions each. Your singing will be digitally recorded and analyzed later.

The procedure will take about one hour of your time.

Foreseeable Risks: The potential risks involved in this study are slight discomfort from singing with unfamiliar head and jaw postures, and possible minor discomfort from wearing the headmounted apparatus. If discomfort occurs, apparatus may be adjusted, or the participant may take breaks between tasks.

Benefits to the Subjects or Others: This study is not expected to be of any direct benefit to you, but we hope to learn more about how different head positions may affect tone quality, and how singers and voice teachers can use this knowledge to maximize vocal efficiency.

Procedures for Maintaining Confidentiality of Research Records: In all research data records, you will be identified solely by a participant number. Your name and personal

Office of Research Services University of North Texas

Last Updated: July 11, 2011

Page 1 of 2

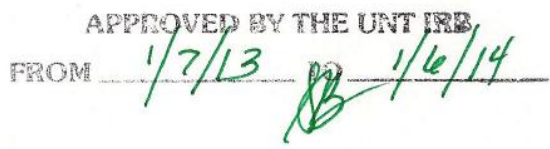


information will be stored in a separate location. The confidentiality of your individual information will be maintained in any publications or presentations regarding this study.

Questions about the Study: If you have any questions about the study, you may contact Elizabeth Knight at elizabethknight@my.unt.edu or Dr. Stephen Austin at stephen.austin@unt.edu.

Review for the Protection of Participants: This research study has been reviewed and approved by the UNT Institutional Review Board (IRB). The UNT IRB can be contacted at (940) 565-3940 with any questions regarding the rights of research subjects.

Research Participants' Rights: Your signature below indicates that you have read or have had read to you all of the above and that you confirm all of the following:

- Elizabeth Knight has explained the study to you and answered all of your questions. You have been told the possible benefits and the potential risks and/or discomforts of the study.

- You understand that you do not have to take part in this study, and your refusal to participate or your decision to withdraw will involve no penalty or loss of rights or benefits. The study personnel may choose to stop your participation at any time.

- You understand why the study is being conducted and how it will be performed.

- You understand your rights as a research participant and you voluntarily consent to participate in this study.

- You have been told you will receive a copy of this form.

Printed Name of Participant

Signature of Participant

Date

For the Student Investigator: I certify that I have reviewed the contents of this form with the subject signing above. I have explained the possible benefits and the potential risks and/or discomforts of the study. It is my opinion that the participant understood the explanation.

Signature of Student Investigator

Office of Research Services University of North Texas Last Updated: July 11, 2011
Date

Page $\mathbf{2}$ of $\mathbf{2}$ 
APPENDIX C

PARTICIPANT QUESTIONNAIRE 
Participant Information Sheet

Name

ID\#

Date

Voice type: SOP MEZZ TEN BAR BASS

Age:

Test pitches: High

Mid

Low

Habitual head position:

Current occupation: Teach voice full time Sing full time

Graduate voice student Combination of singing/teaching

Highest level of education in voice: Bachelor's Master's Doctorate

Years of voice training

Years of voice teaching

Years of professional singing

History of voice pathology?

Y N

If yes, when, and describe.

Normal range of flexion/extension? $\mathrm{Y} \quad \mathrm{N}$ 
APPENDIX D

PARTICIPANT HABITUAL POSTURES AND TEST PITCHES 


\begin{tabular}{|c|c|c|c|c|}
\hline Subject ID & $\begin{array}{l}\text { Habitual Head } \\
\text { Position }\end{array}$ & $\begin{array}{l}\text { High Pitch } \\
80 \% \text { of Range }\end{array}$ & $\begin{array}{l}\text { Medium Pitch } \\
50 \% \text { of Range }\end{array}$ & $\begin{array}{l}\text { Low Pitch } \\
20 \% \text { of Range }\end{array}$ \\
\hline S1 & $10^{\circ}$ & E5 & $\mathrm{A} b 4$ & B3 \\
\hline S2 & $10^{\circ}$ & A5 & $\mathrm{C} 5$ & $\mathrm{E} b 4$ \\
\hline S3 & $5^{\circ}$ & G5 & B4 & D4 \\
\hline S4 & $7.5^{\circ}$ & $\mathrm{F} \# 5$ & $\mathrm{C} 5$ & F4 \\
\hline S5 & $7.5^{\circ}$ & F5 & A4 & $\mathrm{C} \# 4$ \\
\hline S6 & $10^{\circ}$ & E5 & A4 & D4 \\
\hline M1 & $7.5^{\circ}$ & $\mathrm{Eb} 5$ & $\mathrm{Ab} 4$ & $\mathrm{C} \# 4$ \\
\hline M2 & $12.5^{\circ}$ & E5 & $\mathrm{A} b 4$ & B3 \\
\hline M3 & $7.5^{\circ}$ & $\mathrm{C} \# 5$ & G4 & $\mathrm{C} 4$ \\
\hline M4 & $5^{\circ}$ & F5 & $\mathrm{A} 4$ & $\mathrm{C} \# 4$ \\
\hline T1 & $15^{\circ}$ & G4 & B3 & E3 \\
\hline $\mathbf{T 2}$ & $5^{\circ}$ & $\mathrm{F} 4$ & $\mathrm{~B} b 3$ & D3 \\
\hline T3 & $10^{\circ}$ & $\mathrm{Ab} 4$ & $\mathrm{C} \# 4$ & $\mathrm{~F} \# 3$ \\
\hline T4 & $22^{\circ}$ & E4 & $\mathrm{B} b 3$ & $\mathrm{~Eb} 3$ \\
\hline T5 & $10^{\circ}$ & G4 & $\mathrm{C} 4$ & F3 \\
\hline B1 & $10^{\circ}$ & B3 & $\mathrm{F} 3$ & $\mathrm{~B} b 2$ \\
\hline B2 & $10^{\circ}$ & $\mathrm{C} 4$ & G3 & $\mathrm{C} \# 3$ \\
\hline B3 & $7.5^{\circ}$ & $\mathrm{C} 4$ & $\mathrm{~F} \# 3$ & $\mathrm{C} 3$ \\
\hline B4 & $12^{\circ}$ & $\mathrm{C} \# 4$ & $\mathrm{~F} \# 3$ & B2 \\
\hline B5 & $0^{\circ}$ & $\mathrm{C} 4$ & F3 & A2 \\
\hline
\end{tabular}

Mean habitual posture $=9.2^{\circ}$ 
APPENDIX E

ACOUSTIC DATA 
Table E.1

Subject S1 Data

\begin{tabular}{|c|c|c|c|c|c|c|c|c|c|c|}
\hline \multirow[t]{2}{*}{ Pitch } & \multirow[t]{2}{*}{ Harmonic } & \multicolumn{5}{|c|}{ Raw Amplitude Score in dB } & \multicolumn{4}{|c|}{$\begin{array}{l}\text { Normalized Score } \\
\text { (Difference from Habitual) }\end{array}$} \\
\hline & & $\begin{array}{l}\text { Habitual } \\
10^{\circ}\end{array}$ & $-15^{\circ}$ & $\mathbf{0}^{\circ}$ & $15^{-}$ & $30^{\circ}$ & $\mathrm{N}-\mathbf{1 5}^{\circ}$ & $\mathbf{N ~ O}^{\circ}$ & $\mathbf{N}+15^{\circ}$ & $\mathbf{N}+30^{\circ}$ \\
\hline \multirow[t]{4}{*}{ High [a] } & F0 & 59.66 & 59.25 & 58.82 & 58.01 & 59.82 & -0.41 & -0.84 & -1.65 & 0.16 \\
\hline & Peak 0-2 kHz & 59.66 & 59.25 & 58.82 & 58.01 & 59.82 & -0.41 & -0.84 & -1.65 & 0.16 \\
\hline & Peak 2-4 kHz & 32.27 & 22.37 & 23.92 & 22.67 & 24.68 & -9.90 & -8.36 & -9.61 & -7.59 \\
\hline & SPR & -27.39 & -36.88 & -34.90 & -35.35 & -35.14 & -9.49 & -7.51 & -7.96 & -7.75 \\
\hline \multirow[t]{4}{*}{ High [E] } & F0 & 59.23 & 60.68 & 61.17 & 59.32 & 60.63 & 1.45 & 1.94 & 0.09 & 1.40 \\
\hline & Peak $0-2 \mathrm{kHz}$ & 59.23 & 60.68 & 61.17 & 59.32 & 60.63 & 1.45 & 1.94 & 0.09 & 1.40 \\
\hline & Peak 2-4 kHz & 30.46 & 30.02 & 30.06 & 41.91 & 25.67 & -0.44 & -0.40 & 11.44 & -4.79 \\
\hline & SPR & -28.77 & -30.66 & -31.11 & -17.41 & -34.96 & -1.89 & -2.34 & 11.36 & -6.19 \\
\hline \multirow[t]{4}{*}{ High [i] } & F0 & 59.40 & 58.67 & 57.39 & 61.72 & 63.04 & -0.74 & -2.02 & 2.31 & 3.63 \\
\hline & Peak 0-2 kHz & 59.40 & 58.67 & 57.39 & 61.72 & 63.04 & -0.74 & -2.02 & 2.31 & 3.63 \\
\hline & Peak 2-4 kHz & 35.66 & 41.01 & 41.17 & 40.20 & 39.39 & 5.35 & 5.51 & 4.54 & 3.74 \\
\hline & SPR & -23.75 & -17.66 & -16.22 & -21.52 & -23.65 & 6.09 & 7.53 & 2.23 & 0.10 \\
\hline \multirow[t]{4}{*}{ Mid [a] } & F0 & 44.25 & 42.03 & 46.76 & 46.61 & 48.88 & -2.22 & 2.52 & 2.36 & 4.64 \\
\hline & Peak 0-2 kHz & 45.55 & 42.80 & 46.76 & 46.61 & 48.88 & -2.75 & 1.21 & 1.05 & 3.33 \\
\hline & Peak 2-4 kHz & 14.69 & 15.02 & 17.57 & 15.88 & 22.61 & 0.34 & 2.89 & 1.19 & 7.93 \\
\hline & SPR & -30.87 & -27.78 & -29.19 & -30.73 & -26.27 & 3.09 & 1.67 & 0.14 & 4.60 \\
\hline \multirow[t]{4}{*}{ Mid [E] } & F0 & 44.25 & 42.03 & 46.76 & 46.61 & 48.88 & -2.22 & 2.52 & 2.36 & 4.64 \\
\hline & Peak 0-2 kHz & 45.55 & 42.80 & 46.76 & 46.61 & 48.88 & -2.75 & 1.21 & 1.05 & 3.33 \\
\hline & Peak 2-4 kHz & 14.69 & 15.02 & 17.57 & 15.88 & 22.61 & 0.34 & 2.89 & 1.19 & 7.93 \\
\hline & SPR & -30.87 & -27.78 & -29.19 & -30.73 & -26.27 & 3.09 & 1.67 & 0.14 & 4.60 \\
\hline \multirow[t]{4}{*}{ Mid [i] } & F0 & 51.50 & 52.67 & 52.02 & 55.43 & 54.49 & 1.18 & 0.53 & 3.93 & 3.00 \\
\hline & Peak 0-2 kHz & 51.50 & 52.67 & 52.02 & 55.43 & 54.49 & 1.18 & 0.53 & 3.93 & 3.00 \\
\hline & Peak 2-4 kHz & 22.92 & 24.10 & 24.26 & 29.71 & 32.05 & 1.18 & 1.33 & 6.79 & 9.13 \\
\hline & SPR & -28.57 & -28.57 & -27.77 & -25.72 & -22.44 & 0.00 & 0.80 & 2.85 & 6.13 \\
\hline \multirow[t]{4}{*}{ Low [a] } & F0 & 44.75 & 43.51 & 44.06 & 46.65 & 46.34 & -1.24 & -0.69 & 1.90 & 1.59 \\
\hline & Peak 0-2 kHz & 44.75 & 43.51 & 44.06 & 46.65 & 48.48 & -1.24 & -0.69 & 1.90 & 3.73 \\
\hline & Peak $2-4 \mathrm{kHz}$ & 13.44 & 11.89 & 13.04 & 17.07 & 20.52 & -1.56 & -0.40 & 3.62 & 7.08 \\
\hline & SPR & -31.31 & -31.62 & -31.02 & -29.58 & -27.96 & -0.32 & 0.29 & 1.72 & 3.35 \\
\hline \multirow[t]{4}{*}{ Low $[E]$} & F0 & 46.32 & 42.65 & 45.46 & 44.29 & 44.62 & -3.67 & -0.86 & -2.03 & -1.70 \\
\hline & Peak 0-2 kHz & 46.32 & 42.65 & 45.46 & 44.29 & 44.62 & -3.67 & -0.86 & -2.03 & -1.70 \\
\hline & Peak 2-4 kHz & 22.90 & 13.78 & 13.87 & 19.38 & 19.77 & -9.13 & -9.04 & -3.52 & -3.13 \\
\hline & SPR & -23.42 & -28.87 & -31.60 & -24.92 & -24.84 & -5.45 & -8.18 & -1.50 & -1.42 \\
\hline \multirow[t]{4}{*}{ Low [i] } & F0 & 47.01 & 44.85 & 43.81 & 48.57 & 48.94 & -2.16 & -3.20 & 1.56 & 1.93 \\
\hline & Peak 0-2 kHz & 47.01 & 44.85 & 43.81 & 48.57 & 48.94 & -2.16 & -3.20 & 1.56 & 1.93 \\
\hline & Peak 2-4 kHz & 12.88 & 14.56 & 14.92 & 17.00 & 21.54 & 1.67 & 2.03 & 4.12 & 8.66 \\
\hline & SPR & -34.12 & -30.29 & -28.89 & -31.57 & -27.39 & 3.84 & 5.23 & 2.56 & 6.73 \\
\hline
\end{tabular}


Table E.2

Subject S2 Data

\begin{tabular}{|c|c|c|c|c|c|c|c|c|c|c|}
\hline \multirow[t]{2}{*}{ Pitch } & \multirow[t]{2}{*}{ Harmonic } & \multicolumn{5}{|c|}{ Raw Amplitude Score in dB } & \multicolumn{4}{|c|}{$\begin{array}{l}\text { Normalized Score } \\
\text { (Difference from Habitual) }\end{array}$} \\
\hline & & $\begin{array}{l}\text { Habitual } \\
10^{\circ}\end{array}$ & $-15^{\circ}$ & $\mathbf{0}^{\circ}$ & $15^{-}$ & $30^{\circ}$ & $\mathbf{N}-\mathbf{1 5}^{\circ}$ & $\mathbf{N ~ O}^{\circ}$ & $\mathbf{N}+15^{\circ}$ & $\mathbf{N}+30^{\circ}$ \\
\hline \multirow[t]{4}{*}{ Mid [a] } & F0 & 53.37 & 53.33 & 51.95 & 53.35 & 49.39 & -0.04 & -1.42 & -0.02 & -3.98 \\
\hline & Peak 0-2 kHz & 53.37 & 57.82 & 54.63 & 57.55 & 56.53 & 4.45 & 1.26 & 4.18 & 3.16 \\
\hline & Peak 2-4 kHz & 30.91 & 32.05 & 26.48 & 32.75 & 29.09 & 1.14 & -4.44 & 1.84 & -1.82 \\
\hline & SPR & -22.46 & -25.77 & -28.15 & -24.80 & -27.43 & -3.32 & -5.69 & -2.34 & -4.97 \\
\hline \multirow[t]{4}{*}{ Mid [E] } & F0 & 55.67 & 55.24 & 57.20 & 58.82 & 58.55 & -0.43 & 1.53 & 3.15 & 2.88 \\
\hline & Peak $0-2 \mathrm{kHz}$ & 55.67 & 55.24 & 57.20 & 58.82 & 58.55 & -0.43 & 1.53 & 3.15 & 2.88 \\
\hline & Peak 2-4 kHz & 30.08 & 36.28 & 36.93 & 31.80 & 24.75 & 6.20 & 6.84 & 1.72 & -5.33 \\
\hline & SPR & -25.59 & -18.97 & -20.27 & -27.02 & -33.80 & 6.62 & 5.32 & -1.44 & -8.21 \\
\hline \multirow[t]{4}{*}{ Mid [i] } & F0 & 60.08 & 57.36 & 57.73 & 60.84 & 60.76 & -2.72 & -2.35 & 0.76 & 0.68 \\
\hline & Peak 0-2 kHz & 60.08 & 57.36 & 57.73 & 60.84 & 60.76 & -2.72 & -2.35 & 0.76 & 0.68 \\
\hline & Peak 2-4 kHz & 41.32 & 40.95 & 36.34 & 38.36 & 41.11 & -0.37 & -4.98 & -2.96 & -0.21 \\
\hline & SPR & -18.76 & -16.41 & -21.39 & -22.48 & -19.65 & 2.35 & -2.63 & -3.72 & -0.90 \\
\hline \multirow[t]{4}{*}{ Low [a] } & F0 & 42.69 & 44.60 & 42.89 & 45.23 & 43.34 & 1.90 & 0.19 & 2.54 & 0.64 \\
\hline & Peak $0-2 \mathrm{kHz}$ & 44.09 & 44.60 & 45.68 & 47.51 & 46.56 & 0.51 & 1.60 & 3.42 & 2.47 \\
\hline & Peak 2-4 kHz & 16.56 & 23.34 & 14.76 & 23.96 & 19.22 & 6.78 & -1.80 & 7.40 & 2.66 \\
\hline & SPR & -27.53 & -21.26 & -30.92 & -23.55 & -27.34 & 6.27 & -3.40 & 3.98 & 0.19 \\
\hline \multirow[t]{4}{*}{ Low $[E]$} & F0 & 43.34 & 44.12 & 43.25 & 44.12 & 43.34 & 0.79 & -0.09 & 0.78 & 0.00 \\
\hline & Peak $0-2 \mathrm{kHz}$ & 47.02 & 45.00 & 46.20 & 44.12 & 46.56 & -2.02 & -0.83 & -2.90 & -0.47 \\
\hline & Peak 2-4 kHz & 22.25 & 19.34 & 18.06 & 16.94 & 19.22 & -2.91 & -4.18 & -5.31 & -3.03 \\
\hline & SPR & -24.78 & -25.66 & -28.13 & -27.18 & -27.34 & -0.88 & -3.36 & -2.41 & -2.56 \\
\hline \multirow[t]{4}{*}{ Low [i] } & F0 & 46.58 & 46.03 & 44.23 & 47.49 & 48.52 & -0.55 & -2.35 & 0.91 & 1.94 \\
\hline & Peak 0-2 kHz & 46.58 & 46.03 & 44.23 & 47.49 & 48.52 & -0.55 & -2.35 & 0.91 & 1.94 \\
\hline & Peak 2-4 kHz & 29.89 & 27.97 & 25.64 & 28.69 & 27.99 & -1.92 & -4.25 & -1.20 & -1.90 \\
\hline & SPR & -16.69 & -18.06 & -18.59 & -18.80 & -20.53 & -1.37 & -1.90 & -2.12 & -3.84 \\
\hline
\end{tabular}

*High note conditions contained sound filer errors and were not included for analysis. 
Table E.3

Subject S3 Data

\begin{tabular}{|c|c|c|c|c|c|c|c|c|c|c|}
\hline \multirow[t]{2}{*}{ Pitch } & \multirow[t]{2}{*}{ Harmonic } & \multicolumn{5}{|c|}{ Raw Amplitude Score in dB } & \multicolumn{4}{|c|}{$\begin{array}{l}\text { Normalized Score } \\
\text { (Difference from Habitual) }\end{array}$} \\
\hline & & $\begin{array}{l}\text { Habitual } \\
5^{\circ}\end{array}$ & $-15^{\circ}$ & $\mathbf{0}^{\circ}$ & $15^{-}$ & $30^{\circ}$ & $\mathbf{N}-\mathbf{1 5}^{\circ}$ & $\mathbf{N ~ O}^{\circ}$ & $\mathrm{N}+15^{\circ}$ & $\mathbf{N}+30^{\circ}$ \\
\hline \multirow[t]{4}{*}{ High [a] } & F0 & 62.41 & 61.20 & 59.26 & 63.55 & 62.66 & -1.21 & -3.15 & 1.14 & 0.25 \\
\hline & Peak 0-2 kHz & 62.41 & 61.20 & 59.26 & 63.55 & 62.66 & -1.21 & -3.15 & 1.14 & 0.25 \\
\hline & Peak 2-4 kHz & 34.85 & 34.64 & 31.63 & 36.38 & 36.31 & -0.22 & -3.22 & 1.52 & 1.45 \\
\hline & SPR & -27.56 & -26.56 & -27.63 & -27.18 & -26.36 & 1.00 & -0.07 & 0.38 & 1.20 \\
\hline \multirow[t]{4}{*}{ High [E] } & F0 & 63.36 & 60.75 & 62.25 & 62.69 & 62.90 & -2.61 & -1.11 & -0.67 & -0.46 \\
\hline & Peak 0-2 kHz & 63.36 & 60.75 & 62.25 & 62.69 & 62.90 & -2.61 & -1.11 & -0.67 & -0.46 \\
\hline & Peak 2-4 kHz & 33.59 & 34.88 & 35.75 & 35.28 & 34.61 & 1.29 & 2.16 & 1.68 & 1.02 \\
\hline & SPR & -29.77 & -25.87 & -26.50 & -27.41 & -28.29 & 3.89 & 3.27 & 2.35 & 1.47 \\
\hline \multirow[t]{4}{*}{ High [i] } & F0 & 62.92 & 60.68 & 60.16 & 62.37 & 64.92 & -2.24 & -2.76 & -0.55 & 2.00 \\
\hline & Peak 0-2 kHz & 62.92 & 60.68 & 60.16 & 62.37 & 64.92 & -2.24 & -2.76 & -0.55 & 2.00 \\
\hline & Peak 2-4 kHz & 36.40 & 36.23 & 39.04 & 39.85 & 36.20 & -0.16 & 2.65 & 3.46 & -0.20 \\
\hline & SPR & -26.52 & -24.45 & -21.12 & -22.52 & -28.73 & 2.07 & 5.41 & 4.00 & -2.20 \\
\hline \multirow[t]{4}{*}{ Mid [a] } & F0 & 46.35 & 45.15 & 44.41 & 46.85 & 43.44 & -1.21 & -1.94 & 0.50 & -2.91 \\
\hline & Peak 0-2 kHz & 48.13 & 47.13 & 49.42 & 49.67 & 46.52 & -1.00 & 1.30 & 1.55 & -1.61 \\
\hline & Peak 2-4 kHz & 24.47 & 23.08 & 25.53 & 26.75 & 22.82 & -1.39 & 1.06 & 2.29 & -1.65 \\
\hline & SPR & -23.66 & -24.05 & -23.90 & -22.92 & -23.71 & -0.39 & -0.24 & 0.74 & -0.05 \\
\hline \multirow[t]{4}{*}{ Mid [E] } & F0 & 46.35 & 44.00 & 46.51 & 45.78 & 45.19 & -2.35 & 0.15 & -0.58 & -1.16 \\
\hline & Peak 0-2 kHz & 46.35 & 44.00 & 46.51 & 45.78 & 45.19 & -2.35 & 0.15 & -0.58 & -1.16 \\
\hline & Peak 2-4 kHz & 27.05 & 25.33 & 26.78 & 29.25 & 29.31 & -1.72 & -0.27 & 2.19 & 2.26 \\
\hline & SPR & -19.30 & -18.67 & -19.72 & -16.53 & -15.88 & 0.63 & -0.42 & 2.77 & 3.42 \\
\hline \multirow[t]{4}{*}{ Mid [i] } & F0 & 53.52 & 53.07 & 55.20 & 54.30 & 56.23 & -0.46 & 1.67 & 0.78 & 2.70 \\
\hline & Peak 0-2 kHz & 53.52 & 53.07 & 55.20 & 54.30 & 56.23 & -0.46 & 1.67 & 0.78 & 2.70 \\
\hline & Peak 2-4 kHz & 34.98 & 35.66 & 37.08 & 34.40 & 33.52 & 0.67 & 2.10 & -0.58 & -1.46 \\
\hline & SPR & -18.54 & -17.41 & -18.12 & -19.90 & -22.70 & 1.13 & 0.42 & -1.37 & -4.16 \\
\hline \multirow[t]{4}{*}{ Low [a] } & F0 & 40.61 & 38.28 & 39.33 & 41.73 & 42.85 & -2.32 & -1.28 & 1.12 & 2.25 \\
\hline & Peak 0-2 kHz & 40.61 & 38.28 & 42.48 & 42.48 & 42.85 & -2.32 & 1.88 & 1.87 & 2.25 \\
\hline & Peak 2-4 kHz & 14.51 & 18.91 & 17.66 & 17.14 & 15.19 & 4.39 & 3.15 & 2.63 & 0.67 \\
\hline & SPR & -26.09 & -19.37 & -24.82 & -25.33 & -27.67 & 6.72 & 1.27 & 0.76 & -1.57 \\
\hline \multirow[t]{4}{*}{ Low $[E]$} & F0 & 41.70 & 40.41 & 41.07 & 42.94 & 46.85 & -1.29 & -0.63 & 1.24 & 5.15 \\
\hline & Peak 0-2 kHz & 41.70 & 40.41 & 41.07 & 42.94 & 46.85 & -1.29 & -0.63 & 1.24 & 5.15 \\
\hline & Peak 2-4 kHz & 21.89 & 22.67 & 20.03 & 20.64 & 19.89 & 0.77 & -1.86 & -1.25 & -2.00 \\
\hline & SPR & -19.81 & -17.74 & -21.04 & -22.30 & -26.96 & 2.07 & -1.23 & -2.49 & -7.16 \\
\hline \multirow[t]{4}{*}{ Low [i] } & F0 & 44.30 & 45.01 & 44.05 & 43.42 & 48.69 & 0.71 & -0.26 & -0.88 & 4.39 \\
\hline & Peak 0-2 kHz & 44.30 & 45.01 & 44.05 & 43.42 & 48.69 & 0.71 & -0.26 & -0.88 & 4.39 \\
\hline & Peak 2-4 kHz & 25.88 & 23.85 & 27.59 & 25.97 & 27.28 & -2.03 & 1.71 & 0.09 & 1.40 \\
\hline & SPR & -18.42 & -21.16 & -16.45 & -17.45 & -21.42 & -2.74 & 1.97 & 0.98 & -2.99 \\
\hline
\end{tabular}


Table E.4

Subject S4 Data

\begin{tabular}{|c|c|c|c|c|c|c|c|c|c|c|}
\hline \multirow[t]{2}{*}{ Pitch } & \multirow[t]{2}{*}{ Harmonic } & \multicolumn{5}{|c|}{ Raw Amplitude Score in dB } & \multicolumn{4}{|c|}{$\begin{array}{l}\text { Normalized Score } \\
\text { (Difference from Habitual) }\end{array}$} \\
\hline & & $\begin{array}{l}\text { Habitual } \\
7.5^{\circ}\end{array}$ & $-15^{\circ}$ & $\mathbf{0}^{\circ}$ & $15^{-}$ & $30^{\circ}$ & $\mathbf{N}-\mathbf{1 5}^{\circ}$ & $\mathbf{N ~ O}^{\circ}$ & $\mathbf{N}+15^{\circ}$ & $\mathbf{N}+30^{\circ}$ \\
\hline \multirow[t]{4}{*}{ High [a] } & F0 & 59.63 & 58.46 & 59.54 & 60.00 & 61.12 & -1.17 & -0.09 & 0.37 & 1.49 \\
\hline & Peak $0-2 \mathrm{kHz}$ & 59.63 & 58.46 & 59.54 & 60.00 & 61.12 & -1.17 & -0.09 & 0.37 & 1.49 \\
\hline & Peak 2-4 kHz & 37.52 & 38.78 & 36.58 & 34.53 & 36.30 & 1.26 & -0.94 & -2.99 & -1.22 \\
\hline & SPR & -22.11 & -19.69 & -22.95 & -25.47 & -24.81 & 2.42 & -0.84 & -3.36 & -2.70 \\
\hline \multirow[t]{4}{*}{ High [E] } & F0 & 61.98 & 58.40 & 61.34 & 61.73 & 63.08 & -3.58 & -0.64 & -0.25 & 1.10 \\
\hline & Peak $0-2 \mathrm{kHz}$ & 61.98 & 58.40 & 61.34 & 61.73 & 63.08 & -3.58 & -0.64 & -0.25 & 1.10 \\
\hline & Peak 2-4 kHz & 40.85 & 40.61 & 37.91 & 41.19 & 40.01 & -0.24 & -2.94 & 0.34 & -0.84 \\
\hline & SPR & -21.13 & -17.79 & -23.43 & -20.54 & -23.07 & 3.34 & -2.30 & 0.59 & -1.94 \\
\hline \multirow[t]{4}{*}{ High [i] } & F0 & 62.32 & 59.11 & 59.41 & 62.31 & 64.24 & -3.21 & -2.91 & 0.00 & 1.92 \\
\hline & Peak 0-2 kHz & 62.32 & 59.11 & 59.41 & 62.31 & 64.24 & -3.21 & -2.91 & 0.00 & 1.92 \\
\hline & Peak 2-4 kHz & 41.80 & 37.33 & 40.05 & 38.92 & 38.86 & -4.47 & -1.75 & -2.88 & -2.95 \\
\hline & SPR & -20.51 & -21.77 & -19.35 & -23.39 & -25.39 & -1.26 & 1.16 & -2.88 & -4.87 \\
\hline \multirow[t]{4}{*}{ Mid [a] } & F0 & 48.01 & 48.47 & 46.77 & 49.17 & 48.30 & 0.46 & -1.24 & 1.16 & 0.29 \\
\hline & Peak $0-2 \mathrm{kHz}$ & 48.17 & 49.62 & 49.77 & 51.93 & 52.28 & 1.45 & 1.60 & 3.76 & 4.11 \\
\hline & Peak 2-4 kHz & 28.17 & 30.40 & 26.63 & 30.84 & 31.79 & 2.23 & -1.54 & 2.66 & 3.62 \\
\hline & SPR & -20.00 & -19.22 & -23.14 & -21.09 & -20.48 & 0.78 & -3.14 & -1.10 & -0.49 \\
\hline \multirow[t]{4}{*}{ Mid [E] } & F0 & 53.13 & 48.33 & 53.51 & 50.03 & 52.25 & -4.81 & 0.38 & -3.10 & -0.89 \\
\hline & Peak 0-2 kHz & 53.13 & 48.33 & 53.51 & 50.03 & 52.25 & -4.81 & 0.38 & -3.10 & -0.89 \\
\hline & Peak 2-4 kHz & 30.19 & 30.20 & 29.64 & 30.00 & 31.47 & 0.01 & -0.55 & -0.19 & 1.28 \\
\hline & SPR & -22.94 & -18.13 & -23.87 & -20.03 & -20.78 & 4.81 & -0.93 & 2.91 & 2.16 \\
\hline \multirow[t]{4}{*}{ Mid [i] } & F0 & 56.43 & 57.10 & 54.46 & 56.57 & 58.96 & 0.66 & -1.97 & 0.14 & 2.52 \\
\hline & Peak 0-2 kHz & 56.43 & 57.10 & 54.46 & 56.57 & 58.96 & 0.66 & -1.97 & 0.14 & 2.52 \\
\hline & Peak 2-4 kHz & 40.40 & 38.60 & 40.84 & 43.01 & 42.16 & -1.80 & 0.44 & 2.60 & 1.76 \\
\hline & SPR & -16.03 & -18.50 & -13.62 & -13.56 & -16.79 & -2.47 & 2.41 & 2.47 & -0.76 \\
\hline \multirow[t]{4}{*}{ Low [a] } & F0 & 41.96 & 38.97 & 41.51 & 40.29 & 40.57 & -2.99 & -0.45 & -1.67 & -1.39 \\
\hline & Peak 0-2 kHz & 48.48 & 43.59 & 47.04 & 47.02 & 45.59 & -4.89 & -1.44 & -1.46 & -2.89 \\
\hline & Peak 2-4 kHz & 23.28 & 23.77 & 23.65 & 24.37 & 25.96 & 0.49 & 0.37 & 1.10 & 2.68 \\
\hline & SPR & -25.20 & -19.82 & -23.39 & -22.64 & -19.63 & 5.38 & 1.81 & 2.56 & 5.57 \\
\hline \multirow[t]{4}{*}{ Low $[E]$} & F0 & 40.42 & 40.27 & 41.05 & 39.28 & 40.75 & -0.15 & 0.63 & -1.14 & 0.33 \\
\hline & Peak 0-2 kHz & 47.01 & 46.48 & 45.76 & 47.20 & 48.97 & -0.52 & -1.25 & 0.19 & 1.96 \\
\hline & Peak 2-4 kHz & 27.13 & 24.56 & 23.09 & 24.15 & 23.63 & -2.57 & -4.04 & -2.98 & -3.50 \\
\hline & SPR & -19.88 & -21.92 & -22.67 & -23.05 & -25.34 & -2.05 & -2.80 & -3.17 & -5.46 \\
\hline \multirow[t]{4}{*}{ Low [i] } & F0 & 46.00 & 47.21 & 46.26 & 46.91 & 46.39 & 1.22 & 0.26 & 0.91 & 0.40 \\
\hline & Peak 0-2 kHz & 46.00 & 47.21 & 46.26 & 46.91 & 46.39 & 1.22 & 0.26 & 0.91 & 0.40 \\
\hline & Peak 2-4 kHz & 31.05 & 26.36 & 29.45 & 32.26 & 32.62 & -4.69 & -1.60 & 1.21 & 1.57 \\
\hline & SPR & -14.95 & -20.85 & -16.81 & -14.65 & -13.77 & -5.90 & -1.86 & 0.30 & 1.18 \\
\hline
\end{tabular}


Table E.5

Subject S5 Data

\begin{tabular}{|c|c|c|c|c|c|c|c|c|c|c|}
\hline \multirow[t]{2}{*}{ Pitch } & \multirow[t]{2}{*}{ Harmonic } & \multicolumn{5}{|c|}{ Raw Amplitude Score in dB } & \multicolumn{4}{|c|}{$\begin{array}{l}\text { Normalized Score } \\
\text { (Difference from Habitual) }\end{array}$} \\
\hline & & $\begin{array}{l}\text { Habitual } \\
7.5^{\circ}\end{array}$ & $-15^{\circ}$ & $\mathbf{0}^{\circ}$ & $15^{-}$ & $30^{\circ}$ & $\mathbf{N}-\mathbf{1 5}^{\circ}$ & $\mathbf{N ~ O}^{\circ}$ & $\mathrm{N}+15^{\circ}$ & $\mathbf{N}+30^{\circ}$ \\
\hline \multirow[t]{4}{*}{ High [a] } & F0 & 54.66 & 55.00 & 54.27 & 56.47 & 58.78 & 0.34 & -0.39 & 1.81 & 4.13 \\
\hline & Peak $0-2 \mathrm{kHz}$ & 54.66 & 55.00 & 54.27 & 56.47 & 58.78 & 0.34 & -0.39 & 1.81 & 4.13 \\
\hline & Peak $2-4$ kHz & 32.34 & 37.84 & 31.68 & 34.43 & 32.60 & 5.49 & -0.66 & 2.09 & 0.26 \\
\hline & SPR & -22.31 & -17.16 & -22.58 & -22.04 & -26.18 & 5.15 & -0.27 & 0.28 & -3.87 \\
\hline \multirow[t]{4}{*}{ High [E] } & F0 & 55.75 & 56.98 & 55.78 & 54.98 & 57.82 & 1.24 & 0.03 & -0.77 & 2.08 \\
\hline & Peak 0-2 kHz & 55.75 & 56.98 & 55.78 & 54.98 & 57.82 & 1.24 & 0.03 & -0.77 & 2.08 \\
\hline & Peak 2-4 kHz & 36.52 & 39.33 & 32.67 & 36.15 & 32.65 & 2.82 & -3.85 & -0.37 & -3.87 \\
\hline & SPR & -19.23 & -17.65 & -23.10 & -18.83 & -25.17 & 1.58 & -3.88 & 0.40 & -5.94 \\
\hline \multirow[t]{4}{*}{ High [i] } & F0 & 56.10 & 58.67 & 54.97 & 57.47 & 58.02 & 2.56 & -1.13 & 1.37 & 1.92 \\
\hline & Peak 0-2 kHz & 56.10 & 58.67 & 54.97 & 57.47 & 58.02 & 2.56 & -1.13 & 1.37 & 1.92 \\
\hline & Peak 2-4 kHz & 39.60 & 42.05 & 38.41 & 39.77 & 40.50 & 2.45 & -1.19 & 0.16 & 0.90 \\
\hline & SPR & -16.50 & -16.62 & -16.56 & -17.71 & -17.52 & -0.12 & -0.06 & -1.21 & -1.02 \\
\hline \multirow[t]{4}{*}{ Mid [a] } & F0 & 43.11 & 43.04 & 40.49 & 42.74 & 38.75 & -0.07 & -2.62 & -0.37 & -4.36 \\
\hline & Peak 0-2 kHz & 47.82 & 44.21 & 43.65 & 45.45 & 48.21 & -3.61 & -4.17 & -2.37 & 0.39 \\
\hline & Peak 2-4 kHz & 29.19 & 22.42 & 26.52 & 28.09 & 27.54 & -6.77 & -2.67 & -1.10 & -1.65 \\
\hline & SPR & -18.63 & -21.79 & -17.13 & -17.36 & -20.67 & -3.16 & 1.50 & 1.27 & -2.03 \\
\hline \multirow[t]{4}{*}{ Mid [E] } & F0 & 45.20 & 43.17 & 44.17 & 44.68 & 43.63 & -2.03 & -1.03 & -0.52 & -1.57 \\
\hline & Peak 0-2 kHz & 45.20 & 43.17 & 45.01 & 44.68 & 44.70 & -2.03 & -0.19 & -0.52 & -0.50 \\
\hline & Peak 2-4 kHz & 22.82 & 26.48 & 26.99 & 25.62 & 23.87 & 3.66 & 4.18 & 2.80 & 1.05 \\
\hline & SPR & -22.38 & -16.69 & -18.02 & -19.06 & -20.83 & 5.69 & 4.37 & 3.32 & 1.55 \\
\hline \multirow[t]{4}{*}{ Mid [i] } & F0 & 52.04 & 48.40 & 47.89 & 49.98 & 48.13 & -3.64 & -4.15 & -2.06 & -3.91 \\
\hline & Peak 0-2 kHz & 52.04 & 48.40 & 47.89 & 49.98 & 48.13 & -3.64 & -4.15 & -2.06 & -3.91 \\
\hline & Peak 2-4 kHz & 29.45 & 28.15 & 27.93 & 29.48 & 31.28 & -1.29 & -1.52 & 0.03 & 1.83 \\
\hline & SPR & -22.60 & -20.25 & -19.96 & -20.50 & -16.85 & 2.35 & 2.64 & 2.09 & 5.74 \\
\hline \multirow[t]{4}{*}{ Low [a] } & F0 & 38.50 & 33.78 & 35.44 & 34.85 & 36.39 & -4.72 & -3.06 & -3.65 & -2.11 \\
\hline & Peak 0-2 kHz & 41.12 & 36.71 & 39.31 & 41.69 & 43.29 & -4.42 & -1.81 & 0.56 & 2.17 \\
\hline & Peak 2-4 kHz & 25.37 & 20.50 & 22.46 & 25.02 & 23.25 & -4.88 & -2.91 & -0.36 & -2.12 \\
\hline & SPR & -15.75 & -16.21 & -16.85 & -16.67 & -20.04 & -0.46 & -1.10 & -0.92 & -4.28 \\
\hline \multirow[t]{4}{*}{ Low $[E]$} & F0 & 38.65 & 36.50 & 35.89 & 36.85 & 40.26 & -2.15 & -2.76 & -1.80 & 1.61 \\
\hline & Peak 0-2 kHz & 38.65 & 38.86 & 36.30 & 36.85 & 40.26 & 0.21 & -2.35 & -1.80 & 1.61 \\
\hline & Peak 2-4 kHz & 21.41 & 18.45 & 19.02 & 24.12 & 21.94 & -2.95 & -2.39 & 2.71 & 0.54 \\
\hline & SPR & -17.24 & -20.41 & -17.28 & -12.74 & -18.32 & -3.17 & -0.04 & 4.51 & -1.08 \\
\hline \multirow[t]{4}{*}{ Low [i] } & F0 & 41.06 & 40.62 & 39.74 & 39.45 & 39.83 & -0.44 & -1.31 & -1.61 & -1.23 \\
\hline & Peak 0-2 kHz & 41.06 & 40.62 & 39.74 & 39.45 & 39.83 & -0.44 & -1.31 & -1.61 & -1.23 \\
\hline & Peak 2-4 kHz & 23.95 & 26.82 & 19.86 & 18.87 & 24.87 & 2.86 & -4.09 & -5.08 & 0.92 \\
\hline & SPR & -17.11 & -13.80 & -19.88 & -20.57 & -14.96 & 3.30 & -2.78 & -3.47 & 2.14 \\
\hline
\end{tabular}


Table E.6

Subject S6 Data

\begin{tabular}{|c|c|c|c|c|c|c|c|c|c|c|}
\hline \multirow[t]{2}{*}{ Pitch } & \multirow[t]{2}{*}{ Harmonic } & \multicolumn{5}{|c|}{ Raw Amplitude Score in dB } & \multicolumn{4}{|c|}{$\begin{array}{l}\text { Normalized Score } \\
\text { (Difference from Habitual) }\end{array}$} \\
\hline & & $\begin{array}{l}\text { Habitual } \\
10^{\circ}\end{array}$ & $-15^{\circ}$ & $\mathbf{0}^{\circ}$ & $15^{-}$ & $30^{\circ}$ & $\mathbf{N}-15^{\circ}$ & $\mathbf{N ~ O}^{\circ}$ & $\mathrm{N}+15^{\circ}$ & $\mathbf{N}+30^{\circ}$ \\
\hline \multirow[t]{4}{*}{ High [a] } & F0 & 58.30 & 56.38 & 56.37 & 57.95 & 59.41 & -1.91 & -1.92 & -0.35 & 1.11 \\
\hline & Peak $0-2 \mathrm{kHz}$ & 58.30 & 56.38 & 56.37 & 57.95 & 59.41 & -1.91 & -1.92 & -0.35 & 1.11 \\
\hline & Peak 2-4 kHz & 33.04 & 33.91 & 36.09 & 32.89 & 35.97 & 0.88 & 3.06 & -0.14 & 2.93 \\
\hline & SPR & -25.26 & -22.47 & -20.28 & -25.06 & -23.44 & 2.79 & 4.98 & 0.20 & 1.83 \\
\hline \multirow[t]{4}{*}{ High [E] } & F0 & 57.22 & 56.67 & 55.53 & 58.81 & 60.12 & -0.56 & -1.69 & 1.59 & 2.90 \\
\hline & Peak $0-2 \mathrm{kHz}$ & 57.22 & 56.67 & 55.53 & 58.81 & 60.12 & -0.56 & -1.69 & 1.59 & 2.90 \\
\hline & Peak 2-4 kHz & 42.84 & 35.58 & 38.63 & 39.86 & 42.37 & -7.26 & -4.21 & -2.98 & -0.47 \\
\hline & SPR & -14.39 & -21.09 & -16.91 & -18.96 & -17.76 & -6.70 & -2.52 & -4.57 & -3.37 \\
\hline \multirow[t]{4}{*}{ High [i] } & F0 & 58.53 & 56.35 & 60.63 & 58.81 & 60.53 & -2.18 & 2.10 & 0.28 & 2.01 \\
\hline & Peak 0-2 kHz & 58.53 & 56.35 & 60.63 & 58.81 & 60.53 & -2.18 & 2.10 & 0.28 & 2.01 \\
\hline & Peak 2-4 kHz & 42.50 & 43.86 & 45.54 & 44.99 & 44.06 & 1.36 & 3.04 & 2.50 & 1.57 \\
\hline & SPR & -16.03 & -12.49 & -15.09 & -13.82 & -16.47 & 3.54 & 0.94 & 2.21 & -0.44 \\
\hline \multirow[t]{4}{*}{ Mid [a] } & F0 & 41.73 & 43.31 & 42.88 & 43.71 & 43.85 & 1.58 & 1.15 & 1.98 & 2.11 \\
\hline & Peak $0-2 \mathrm{kHz}$ & 43.73 & 44.84 & 44.58 & 47.72 & 47.68 & 1.11 & 0.85 & 3.99 & 3.95 \\
\hline & Peak 2-4 kHz & 21.49 & 20.69 & 22.93 & 18.27 & 20.98 & -0.79 & 1.44 & -3.22 & -0.50 \\
\hline & SPR & -22.25 & -24.15 & -21.66 & -29.46 & -26.70 & -1.90 & 0.59 & -7.21 & -4.45 \\
\hline \multirow[t]{4}{*}{ Mid [E] } & F0 & 41.77 & 44.53 & 42.43 & 44.79 & 46.11 & 2.75 & 0.66 & 3.02 & 4.34 \\
\hline & Peak 0-2 kHz & 43.45 & 44.53 & 42.43 & 44.79 & 46.11 & 1.08 & -1.02 & 1.34 & 2.66 \\
\hline & Peak 2-4 kHz & 21.90 & 22.89 & 22.72 & 23.22 & 24.12 & 1.00 & 0.83 & 1.32 & 2.22 \\
\hline & SPR & -21.55 & -21.63 & -19.71 & -21.57 & -21.99 & -0.08 & 1.84 & -0.02 & -0.44 \\
\hline \multirow[t]{4}{*}{ Mid [i] } & F0 & 53.30 & 51.60 & 52.17 & 53.94 & 53.78 & -1.69 & -1.13 & 0.64 & 0.49 \\
\hline & Peak 0-2 kHz & 53.30 & 51.60 & 52.17 & 53.94 & 53.78 & -1.69 & -1.13 & 0.64 & 0.49 \\
\hline & Peak 2-4 kHz & 38.38 & 31.06 & 35.24 & 36.32 & 33.83 & -7.32 & -3.13 & -2.06 & -4.55 \\
\hline & SPR & -14.92 & -20.54 & -16.92 & -17.62 & -19.96 & -5.63 & -2.00 & -2.70 & -5.04 \\
\hline \multirow[t]{4}{*}{ Low [a] } & F0 & 39.56 & 38.21 & 39.35 & 40.04 & 41.33 & -1.35 & -0.21 & 0.49 & 1.78 \\
\hline & Peak 0-2 kHz & 39.56 & 38.21 & 39.35 & 40.04 & 41.33 & -1.35 & -0.21 & 0.49 & 1.78 \\
\hline & Peak 2-4 kHz & 6.95 & 7.35 & 9.83 & 9.22 & 8.10 & 0.39 & 2.87 & 2.27 & 1.14 \\
\hline & SPR & -32.60 & -30.86 & -29.52 & -30.82 & -33.24 & 1.74 & 3.08 & 1.78 & -0.63 \\
\hline \multirow[t]{4}{*}{ Low $[E]$} & F0 & 40.60 & 39.03 & 39.13 & 40.92 & 41.33 & -1.57 & -1.47 & 0.32 & 0.73 \\
\hline & Peak 0-2 kHz & 40.60 & 39.03 & 39.13 & 40.92 & 41.33 & -1.57 & -1.47 & 0.32 & 0.73 \\
\hline & Peak 2-4 kHz & 13.58 & 15.37 & 13.75 & 16.43 & 16.93 & 1.79 & 0.17 & 2.85 & 3.35 \\
\hline & SPR & -27.01 & -23.65 & -25.38 & -24.49 & -24.40 & 3.36 & 1.63 & 2.53 & 2.61 \\
\hline \multirow[t]{4}{*}{ Low [i] } & F0 & 47.26 & 44.16 & 45.72 & 43.30 & 45.97 & -3.10 & -1.54 & -3.97 & -1.29 \\
\hline & Peak 0-2 kHz & 47.26 & 44.16 & 45.72 & 43.30 & 45.97 & -3.10 & -1.54 & -3.97 & -1.29 \\
\hline & Peak 2-4 kHz & 19.15 & 19.63 & 20.87 & 22.79 & 26.76 & 0.48 & 1.72 & 3.64 & 7.61 \\
\hline & SPR & -28.11 & -24.53 & -24.85 & -20.51 & -19.21 & 3.58 & 3.27 & 7.61 & 8.90 \\
\hline
\end{tabular}


Table E.7

Subject M1 Data

\begin{tabular}{|c|c|c|c|c|c|c|c|c|c|c|}
\hline \multirow[t]{2}{*}{ Pitch } & \multirow[t]{2}{*}{ Harmonic } & \multicolumn{5}{|c|}{ Raw Amplitude Score in dB } & \multicolumn{4}{|c|}{$\begin{array}{l}\text { Normalized Score } \\
\text { (Difference from Habitual) }\end{array}$} \\
\hline & & $\begin{array}{l}\text { Habitual } \\
7.5^{\circ}\end{array}$ & $-15^{\circ}$ & $\mathbf{0}^{\circ}$ & $15^{-}$ & $30^{\circ}$ & $\mathbf{N}-\mathbf{1 5}^{\circ}$ & $\mathbf{N ~ 0}^{\circ}$ & $\mathrm{N}+15^{\circ}$ & $\mathbf{N}+30^{\circ}$ \\
\hline \multirow[t]{4}{*}{ High [a] } & F0 & 55.16 & 53.63 & 56.43 & 56.12 & 55.60 & -1.53 & 1.27 & 0.96 & 0.44 \\
\hline & Peak $0-2 \mathrm{kHz}$ & 55.83 & 53.63 & 56.53 & 56.75 & 55.60 & -2.19 & 0.70 & 0.93 & -0.22 \\
\hline & Peak 2-4 kHz & 32.48 & 34.43 & 35.53 & 32.29 & 25.33 & 1.95 & 3.05 & -0.19 & -7.15 \\
\hline & SPR & -23.35 & -19.20 & -21.00 & -24.46 & -30.28 & 4.14 & 2.35 & -1.11 & -6.93 \\
\hline \multirow[t]{4}{*}{ High [E] } & F0 & 59.63 & 56.90 & 55.36 & 60.10 & 60.41 & -2.73 & -4.27 & 0.48 & 0.79 \\
\hline & Peak $0-2 \mathrm{kHz}$ & 59.63 & 56.90 & 55.36 & 60.10 & 60.41 & -2.73 & -4.27 & 0.48 & 0.79 \\
\hline & Peak 2-4 kHz & 27.99 & 33.47 & 30.15 & 33.19 & 35.39 & 5.48 & 2.16 & 5.20 & 7.39 \\
\hline & SPR & -31.64 & -23.43 & -25.20 & -26.91 & -25.03 & 8.21 & 6.43 & 4.72 & 6.61 \\
\hline \multirow[t]{4}{*}{ High [i] } & F0 & 57.99 & 55.77 & 55.45 & 58.24 & 58.89 & -2.22 & -2.54 & 0.25 & 0.90 \\
\hline & Peak 0-2 kHz & 57.99 & 55.77 & 55.45 & 58.24 & 58.89 & -2.22 & -2.54 & 0.25 & 0.90 \\
\hline & Peak 2-4 kHz & 34.52 & 38.62 & 30.56 & 31.22 & 34.25 & 4.10 & -3.96 & -3.30 & -0.27 \\
\hline & SPR & -23.47 & -17.15 & -24.89 & -27.03 & -24.64 & 6.32 & -1.42 & -3.55 & -1.17 \\
\hline \multirow[t]{4}{*}{ Mid [a] } & F0 & 42.22 & 42.34 & 40.57 & 42.80 & 45.16 & 0.12 & -1.65 & 0.57 & 2.94 \\
\hline & Peak $0-2 \mathrm{kHz}$ & 45.46 & 45.88 & 46.91 & 47.68 & 51.11 & 0.42 & 1.44 & 2.22 & 5.64 \\
\hline & Peak 2-4 kHz & 30.34 & 28.90 & 31.81 & 29.36 & 32.97 & -1.44 & 1.47 & -0.98 & 2.63 \\
\hline & SPR & -15.12 & -16.98 & -15.09 & -18.32 & -18.14 & -1.85 & 0.03 & -3.20 & -3.01 \\
\hline \multirow[t]{4}{*}{ Mid [E] } & F0 & 43.76 & 44.46 & 43.52 & 42.55 & 45.68 & 0.70 & -0.23 & -1.21 & 1.92 \\
\hline & Peak 0-2 kHz & 43.76 & 44.46 & 44.74 & 45.81 & 45.68 & 0.70 & 0.99 & 2.06 & 1.92 \\
\hline & Peak 2-4 kHz & 25.00 & 25.56 & 21.99 & 31.19 & 24.67 & 0.55 & -3.02 & 6.19 & -0.34 \\
\hline & SPR & -18.75 & -18.90 & -22.76 & -14.62 & -21.01 & -0.15 & -4.00 & 4.13 & -2.26 \\
\hline \multirow[t]{4}{*}{ Mid [i] } & F0 & 49.53 & 47.62 & 49.51 & 49.67 & 50.99 & -1.91 & -0.02 & 0.14 & 1.47 \\
\hline & Peak 0-2 kHz & 49.53 & 47.62 & 49.51 & 49.67 & 50.99 & -1.91 & -0.02 & 0.14 & 1.47 \\
\hline & Peak 2-4 kHz & 31.04 & 27.76 & 27.04 & 24.39 & 29.27 & -3.27 & -3.99 & -6.64 & -1.76 \\
\hline & SPR & -18.49 & -19.86 & -22.46 & -25.28 & -21.72 & -1.37 & -3.97 & -6.78 & -3.23 \\
\hline \multirow[t]{4}{*}{ Low [a] } & F0 & 35.38 & 35.85 & 35.09 & 34.66 & 35.04 & 0.47 & -0.30 & -0.73 & -0.34 \\
\hline & Peak 0-2 kHz & 46.36 & 43.55 & 45.12 & 45.91 & 46.25 & -2.81 & -1.24 & -0.45 & -0.11 \\
\hline & Peak 2-4 kHz & 26.34 & 25.05 & 26.37 & 27.03 & 26.73 & -1.29 & 0.03 & 0.69 & 0.39 \\
\hline & SPR & -20.02 & -18.50 & -18.75 & -18.88 & -19.52 & 1.52 & 1.27 & 1.14 & 0.50 \\
\hline \multirow[t]{4}{*}{ Low $[E]$} & F0 & 36.93 & 35.68 & 33.48 & 37.72 & 36.13 & -1.25 & -3.44 & 0.79 & -0.80 \\
\hline & Peak 0-2 kHz & 42.62 & 40.45 & 38.97 & 41.58 & 38.84 & -2.17 & -3.65 & -1.04 & -3.79 \\
\hline & Peak 2-4 kHz & 24.80 & 28.93 & 24.78 & 27.67 & 30.15 & 4.13 & -0.02 & 2.87 & 5.35 \\
\hline & SPR & -17.82 & -11.52 & -14.19 & -13.91 & -8.68 & 6.30 & 3.63 & 3.91 & 9.14 \\
\hline \multirow[t]{4}{*}{ Low [i] } & F0 & 42.38 & 37.39 & 36.78 & 40.38 & 40.97 & -4.99 & -5.60 & -2.00 & -1.41 \\
\hline & Peak 0-2 kHz & 43.45 & 45.00 & 47.72 & 40.38 & 41.37 & 1.55 & 4.28 & -3.07 & -2.08 \\
\hline & Peak 2-4 kHz & 31.62 & 20.23 & 27.33 & 24.74 & 31.34 & -11.39 & -4.29 & -6.88 & -0.27 \\
\hline & SPR & -11.83 & -24.77 & -20.39 & -15.64 & -10.03 & -12.94 & -8.56 & -3.81 & 1.80 \\
\hline
\end{tabular}


Table E. 8

Subject M2 Data

\begin{tabular}{|c|c|c|c|c|c|c|c|c|c|c|}
\hline \multirow[t]{2}{*}{ Pitch } & \multirow[t]{2}{*}{ Harmonic } & \multicolumn{5}{|c|}{ Raw Amplitude Score in dB } & \multicolumn{4}{|c|}{$\begin{array}{l}\text { Normalized Score } \\
\text { (Difference from Habitual) }\end{array}$} \\
\hline & & $\begin{array}{l}\text { Habitual } \\
12.5^{\circ}\end{array}$ & $-15^{\circ}$ & $\mathbf{0}^{\circ}$ & $15^{-}$ & $30^{\circ}$ & $\mathrm{N}-15^{\circ}$ & $\mathbf{N ~ O}^{\circ}$ & $\mathrm{N}+15^{\circ}$ & $\mathbf{N}+30^{\circ}$ \\
\hline \multirow[t]{4}{*}{ High [a] } & F0 & 51.96 & 51.48 & 52.86 & 52.80 & 57.28 & -0.48 & 0.90 & 0.84 & 5.32 \\
\hline & Peak $0-2 \mathrm{kHz}$ & 51.96 & 51.48 & 52.86 & 52.80 & 57.28 & -0.48 & 0.90 & 0.84 & 5.32 \\
\hline & Peak 2-4 kHz & 30.71 & 29.38 & 32.30 & 32.13 & 27.48 & -1.32 & 1.59 & 1.42 & -3.22 \\
\hline & SPR & -21.25 & -22.10 & -20.56 & -20.67 & -29.79 & -0.85 & 0.69 & 0.58 & -8.54 \\
\hline \multirow[t]{4}{*}{ High [E] } & F0 & 54.71 & 51.29 & 54.42 & 53.47 & 57.65 & -3.42 & -0.29 & -1.23 & 2.94 \\
\hline & Peak $0-2 \mathrm{kHz}$ & 54.71 & 51.29 & 54.42 & 53.47 & 57.65 & -3.42 & -0.29 & -1.23 & 2.94 \\
\hline & Peak 2-4 kHz & 30.24 & 31.63 & 29.36 & 31.69 & 30.02 & 1.39 & -0.87 & 1.46 & -0.22 \\
\hline & SPR & -24.47 & -19.66 & -25.06 & -21.78 & -27.63 & 4.81 & -0.59 & 2.69 & -3.16 \\
\hline \multirow[t]{4}{*}{ High [i] } & F0 & 53.85 & 51.26 & 56.03 & 55.98 & 57.42 & -2.59 & 2.18 & 2.13 & 3.57 \\
\hline & Peak 0-2 kHz & 53.85 & 51.26 & 56.03 & 55.98 & 57.42 & -2.59 & 2.18 & 2.13 & 3.57 \\
\hline & Peak 2-4 kHz & 37.09 & 26.74 & 41.54 & 38.91 & 36.31 & -10.35 & 4.45 & 1.83 & -0.78 \\
\hline & SPR & -16.76 & -24.52 & -14.49 & -17.06 & -21.11 & -7.76 & 2.27 & -0.31 & -4.35 \\
\hline \multirow[t]{4}{*}{ Mid [a] } & F0 & 39.77 & 38.05 & 38.77 & 40.82 & 41.26 & -1.72 & -1.00 & 1.05 & 1.48 \\
\hline & Peak $0-2 \mathrm{kHz}$ & 49.07 & 42.09 & 47.07 & 48.76 & 51.83 & -6.98 & -2.00 & -0.31 & 2.76 \\
\hline & Peak 2-4 kHz & 23.10 & 24.24 & 23.39 & 24.07 & 25.23 & 1.14 & 0.29 & 0.97 & 2.13 \\
\hline & SPR & -25.97 & -17.85 & -23.68 & 40.82 & -26.60 & 8.12 & 2.29 & 1.27 & -0.63 \\
\hline \multirow[t]{4}{*}{ Mid [E] } & F0 & 40.54 & 39.58 & 39.01 & 40.65 & 41.00 & -0.96 & -1.53 & 0.11 & 0.46 \\
\hline & Peak $0-2 \mathrm{kHz}$ & 48.35 & 45.18 & 46.17 & 47.63 & 48.83 & -3.17 & -2.18 & -0.72 & 0.48 \\
\hline & Peak 2-4 kHz & 25.91 & 26.24 & 29.07 & 22.95 & 29.79 & 0.33 & 3.16 & -2.96 & 3.88 \\
\hline & SPR & -22.44 & -18.94 & -17.10 & -24.68 & -19.05 & 3.50 & 5.34 & -2.24 & 3.40 \\
\hline \multirow[t]{4}{*}{ Mid [i] } & F0 & 47.62 & 44.98 & 45.56 & 47.07 & 49.78 & -2.64 & -2.06 & -0.56 & 2.15 \\
\hline & Peak $0-2 \mathrm{kHz}$ & 47.62 & 44.98 & 45.56 & 47.07 & 49.78 & -2.64 & -2.06 & -0.56 & 2.15 \\
\hline & Peak 2-4 kHz & 35.32 & 33.83 & 30.95 & 35.12 & 32.76 & -1.50 & -4.38 & -0.20 & -2.56 \\
\hline & SPR & -12.30 & -11.15 & -14.61 & -11.94 & -17.02 & 1.14 & -2.31 & 0.35 & -4.72 \\
\hline \multirow[t]{4}{*}{ Low [a] } & F0 & 32.07 & 31.27 & 31.79 & 31.16 & 32.83 & -0.80 & -0.28 & -0.91 & 0.76 \\
\hline & Peak 0-2 kHz & 41.18 & 37.34 & 40.23 & 41.13 & 41.78 & -3.83 & -0.95 & -0.04 & 0.61 \\
\hline & Peak 2-4 kHz & 19.01 & 20.14 & 17.17 & 20.03 & 22.47 & 1.13 & -1.83 & 1.02 & 3.46 \\
\hline & SPR & -22.17 & -17.21 & -23.05 & -21.10 & -19.32 & 4.96 & -0.88 & 1.06 & 2.85 \\
\hline \multirow[t]{4}{*}{ Low $[E]$} & F0 & 31.44 & 30.03 & 32.64 & 32.45 & 33.70 & -1.40 & 1.20 & 1.02 & 2.27 \\
\hline & Peak 0-2 kHz & 42.33 & 38.47 & 42.28 & 42.72 & 44.19 & -3.86 & -0.05 & 0.39 & 1.86 \\
\hline & Peak 2-4 kHz & 18.10 & 21.98 & 21.76 & 22.99 & 22.45 & 3.88 & 3.66 & 4.88 & 4.35 \\
\hline & SPR & -24.23 & -16.49 & -20.52 & -19.73 & -21.74 & 7.74 & 3.71 & 4.50 & 2.49 \\
\hline \multirow[t]{4}{*}{ Low [i] } & F0 & 34.53 & 32.79 & 33.47 & 34.33 & 38.03 & -1.74 & -1.06 & -0.19 & 3.51 \\
\hline & Peak $0-2 \mathrm{kHz}$ & 34.53 & 32.79 & 33.47 & 34.33 & 38.03 & -1.74 & -1.06 & -0.19 & 3.51 \\
\hline & Peak 2-4 kHz & 22.18 & 20.82 & 20.63 & 23.92 & 19.55 & -1.36 & -1.55 & 1.74 & -2.62 \\
\hline & SPR & -12.35 & -11.97 & -12.84 & -10.41 & -18.48 & 0.38 & -0.49 & 1.93 & -6.13 \\
\hline
\end{tabular}


Table E.9

Subject M3 Data

\begin{tabular}{|c|c|c|c|c|c|c|c|c|c|c|}
\hline \multirow[t]{2}{*}{ Pitch } & \multirow[t]{2}{*}{ Harmonic } & \multicolumn{5}{|c|}{ Raw Amplitude Score in dB } & \multicolumn{4}{|c|}{$\begin{array}{l}\text { Normalized Score } \\
\text { (Difference from Habitual) }\end{array}$} \\
\hline & & $\begin{array}{l}\text { Habitual } \\
7.5^{\circ}\end{array}$ & $-15^{\circ}$ & $\mathbf{0}^{\circ}$ & $15^{-}$ & $30^{\circ}$ & $\mathbf{N}-\mathbf{1 5}^{\circ}$ & $\mathbf{N ~ 0}^{\circ}$ & $\mathrm{N}+15^{\circ}$ & $\mathbf{N}+30^{\circ}$ \\
\hline \multirow[t]{4}{*}{ High [a] } & F0 & 45.63 & 46.37 & 43.54 & 52.34 & 48.50 & 0.74 & -2.10 & 6.71 & 2.87 \\
\hline & Peak $0-2 \mathrm{kHz}$ & 52.52 & 48.90 & 51.90 & 52.34 & 54.10 & -3.62 & -0.62 & -0.18 & 1.58 \\
\hline & Peak 2-4 kHz & 26.56 & 21.88 & 25.67 & 25.31 & 29.67 & -4.68 & -0.90 & -1.26 & 3.10 \\
\hline & SPR & -25.96 & -27.02 & -26.24 & -27.04 & -24.44 & -1.06 & -0.28 & -1.08 & 1.52 \\
\hline \multirow[t]{4}{*}{ High [E] } & F0 & 50.83 & 49.88 & 50.56 & 53.32 & 52.07 & -0.95 & -0.27 & 2.49 & 1.24 \\
\hline & Peak $0-2 \mathrm{kHz}$ & 50.83 & 49.88 & 50.56 & 53.32 & 52.07 & -0.95 & -0.27 & 2.49 & 1.24 \\
\hline & Peak 2-4 kHz & 29.09 & 29.69 & 31.74 & 34.85 & 35.87 & 0.60 & 2.65 & 5.76 & 6.78 \\
\hline & SPR & -21.74 & -20.19 & -18.82 & -18.47 & -16.20 & 1.55 & 2.92 & 3.27 & 5.54 \\
\hline \multirow[t]{4}{*}{ High [i] } & F0 & 52.18 & 50.81 & 50.76 & 50.88 & 53.83 & -1.37 & -1.42 & -1.30 & 1.64 \\
\hline & Peak 0-2 kHz & 52.18 & 50.81 & 50.76 & 50.88 & 53.83 & -1.37 & -1.42 & -1.30 & 1.64 \\
\hline & Peak 2-4 kHz & 37.17 & 30.90 & 34.82 & 34.00 & 35.55 & -6.27 & -2.35 & -3.17 & -1.61 \\
\hline & SPR & -15.02 & -19.91 & -15.94 & -16.88 & -18.28 & -4.89 & -0.92 & -1.87 & -3.26 \\
\hline \multirow[t]{4}{*}{ Mid [a] } & F0 & 37.24 & 38.10 & 39.87 & 42.57 & 42.99 & 0.86 & 2.63 & 5.33 & 5.75 \\
\hline & Peak 0-2 kHz & 43.29 & 45.84 & 44.46 & 45.72 & 47.49 & 2.55 & 1.17 & 2.43 & 4.20 \\
\hline & Peak 2-4 kHz & 23.98 & 24.33 & 23.50 & 27.29 & 31.25 & 0.35 & -0.49 & 3.31 & 7.27 \\
\hline & SPR & -19.31 & -21.51 & -20.97 & -18.43 & -16.24 & -2.20 & -1.66 & 0.88 & 3.07 \\
\hline \multirow[t]{4}{*}{ Mid [E] } & F0 & 41.11 & 40.83 & 40.85 & 42.96 & 45.57 & -0.28 & -0.26 & 1.85 & 4.46 \\
\hline & Peak 0-2 kHz & 41.11 & 40.83 & 40.85 & 42.96 & 45.57 & -0.28 & -0.26 & 1.85 & 4.46 \\
\hline & Peak 2-4 kHz & 20.64 & 26.53 & 24.60 & 26.83 & 25.36 & 5.90 & 3.97 & 6.19 & 4.72 \\
\hline & SPR & -20.47 & -14.30 & -16.24 & -16.13 & -20.21 & 6.18 & 4.23 & 4.34 & 0.26 \\
\hline \multirow[t]{4}{*}{ Mid [i] } & F0 & 43.07 & 44.48 & 44.90 & 43.80 & 43.84 & 1.41 & 1.83 & 0.73 & 0.77 \\
\hline & Peak 0-2 kHz & 43.07 & 44.48 & 44.90 & 43.80 & 43.84 & 1.41 & 1.83 & 0.73 & 0.77 \\
\hline & Peak 2-4 kHz & 28.88 & 25.61 & 26.87 & 29.19 & 27.47 & -3.27 & -2.01 & 0.31 & -1.41 \\
\hline & SPR & -14.19 & -18.87 & -18.02 & -14.61 & -16.37 & -4.68 & -3.84 & -0.42 & -2.18 \\
\hline \multirow[t]{4}{*}{ Low [a] } & F0 & 38.01 & 33.77 & 34.99 & 37.74 & 37.11 & -4.24 & -3.02 & -0.26 & -0.90 \\
\hline & Peak 0-2 kHz & 38.01 & 37.99 & 34.99 & 38.90 & 39.17 & -0.02 & -3.02 & 0.90 & 1.16 \\
\hline & Peak 2-4 kHz & 24.03 & 20.31 & 19.88 & 18.92 & 26.22 & -3.73 & -4.16 & -5.12 & 2.19 \\
\hline & SPR & -13.97 & -17.69 & -15.11 & -19.99 & -12.95 & -3.71 & -1.13 & -6.01 & 1.02 \\
\hline \multirow[t]{4}{*}{ Low $[E]$} & F0 & 37.70 & 37.25 & 36.02 & 38.92 & 38.75 & -0.45 & -1.68 & 1.22 & 1.05 \\
\hline & Peak 0-2 kHz & 37.70 & 37.25 & 36.02 & 38.92 & 38.75 & -0.45 & -1.68 & 1.22 & 1.05 \\
\hline & Peak 2-4 kHz & 19.00 & 17.16 & 19.76 & 22.32 & 19.17 & -1.84 & 0.77 & 3.32 & 0.17 \\
\hline & SPR & -18.70 & -20.09 & -16.26 & -16.60 & -19.58 & -1.39 & 2.45 & 2.11 & -0.88 \\
\hline \multirow[t]{4}{*}{ Low [i] } & F0 & 40.84 & 40.04 & 37.46 & 41.46 & 42.63 & -0.80 & -3.37 & 0.62 & 1.79 \\
\hline & Peak 0-2 kHz & 40.84 & 40.04 & 37.46 & 41.46 & 42.63 & -0.80 & -3.37 & 0.62 & 1.79 \\
\hline & Peak 2-4 kHz & 16.47 & 21.51 & 20.29 & 24.36 & 20.25 & 5.04 & 3.82 & 7.88 & 3.78 \\
\hline & SPR & -24.36 & -18.52 & -17.17 & -17.10 & -22.38 & 5.84 & 7.19 & 7.26 & 1.99 \\
\hline
\end{tabular}


Table E.10

Subject M4 Data

\begin{tabular}{|c|c|c|c|c|c|c|c|c|c|c|}
\hline \multirow[t]{2}{*}{ Pitch } & \multirow[t]{2}{*}{ Harmonic } & \multicolumn{5}{|c|}{ Raw Amplitude Score in dB } & \multicolumn{4}{|c|}{$\begin{array}{l}\text { Normalized Score } \\
\text { (Difference from Habitual) }\end{array}$} \\
\hline & & $\begin{array}{l}\text { Habitual } \\
5^{\circ}\end{array}$ & $-15^{\circ}$ & $\mathbf{0}^{\circ}$ & $15^{-}$ & $30^{\circ}$ & $\mathbf{N}-\mathbf{1 5}^{\circ}$ & $\mathbf{N ~ 0}^{\circ}$ & $\mathrm{N}+15^{\circ}$ & $\mathbf{N}+30^{\circ}$ \\
\hline \multirow[t]{4}{*}{ High [a] } & F0 & 57.67 & 56.41 & 59.98 & 59.87 & 60.51 & -1.26 & 2.31 & 2.21 & 2.84 \\
\hline & Peak $0-2 \mathrm{kHz}$ & 57.67 & 56.41 & 59.98 & 59.87 & 60.51 & -1.26 & 2.31 & 2.21 & 2.84 \\
\hline & Peak 2-4 kHz & 35.96 & 36.34 & 37.19 & 37.01 & 33.24 & 0.38 & 1.24 & 1.05 & -2.72 \\
\hline & SPR & -21.71 & -20.07 & -22.78 & -22.86 & -27.27 & 1.64 & -1.08 & -1.16 & -5.56 \\
\hline \multirow[t]{4}{*}{ High [E] } & F0 & 62.61 & 58.61 & 61.96 & 58.05 & 59.18 & -4.00 & -0.65 & -4.56 & -3.44 \\
\hline & Peak $0-2 \mathrm{kHz}$ & 62.61 & 58.61 & 61.96 & 58.05 & 59.18 & -4.00 & -0.65 & -4.56 & -3.44 \\
\hline & Peak 2-4 kHz & 42.62 & 34.16 & 40.47 & 37.77 & 37.31 & -8.46 & -2.15 & -4.85 & -5.31 \\
\hline & SPR & -19.99 & -24.45 & -21.49 & -20.28 & -21.86 & -4.46 & -1.50 & -0.29 & -1.87 \\
\hline \multirow[t]{4}{*}{ High [i] } & F0 & 60.84 & 60.66 & 60.04 & 61.62 & 62.96 & -0.18 & -0.80 & 0.78 & 2.12 \\
\hline & Peak $0-2 \mathrm{kHz}$ & 60.84 & 60.66 & 60.04 & 61.62 & 62.96 & -0.18 & -0.80 & 0.78 & 2.12 \\
\hline & Peak 2-4 kHz & 36.50 & 39.59 & 35.75 & 36.61 & 36.15 & 3.09 & -0.75 & 0.11 & -0.35 \\
\hline & SPR & -24.34 & -21.07 & -24.29 & -25.00 & -26.81 & 3.28 & 0.05 & -0.66 & -2.47 \\
\hline \multirow[t]{4}{*}{ Mid [a] } & F0 & 43.03 & 42.10 & 44.09 & 43.12 & 45.69 & -0.94 & 1.06 & 0.09 & 2.66 \\
\hline & Peak $0-2 \mathrm{kHz}$ & 43.03 & 42.10 & 44.09 & 45.83 & 46.05 & -0.94 & 1.06 & 2.80 & 3.02 \\
\hline & Peak 2-4 kHz & 24.06 & 24.79 & 26.90 & 27.00 & 29.03 & 0.73 & 2.84 & 2.94 & 4.97 \\
\hline & SPR & -18.97 & -17.30 & -17.19 & -18.83 & -17.02 & 1.67 & 1.78 & 0.14 & 1.95 \\
\hline \multirow[t]{4}{*}{ Mid [E] } & F0 & 43.74 & 45.13 & 42.57 & 43.07 & 44.20 & 1.39 & -1.17 & -0.67 & 0.46 \\
\hline & Peak 0-2 kHz & 43.74 & 45.13 & 42.57 & 43.07 & 44.20 & 1.39 & -1.17 & -0.67 & 0.46 \\
\hline & Peak 2-4 kHz & 22.89 & 26.28 & 25.57 & 23.98 & 19.73 & 3.39 & 2.69 & 1.10 & -3.15 \\
\hline & SPR & -20.85 & -18.86 & -17.00 & -19.08 & -24.47 & 2.00 & 3.86 & 1.77 & -3.61 \\
\hline \multirow[t]{4}{*}{ Mid [i] } & F0 & 52.99 & 51.80 & 51.57 & 54.46 & 53.08 & -1.19 & -1.42 & 1.47 & 0.09 \\
\hline & Peak 0-2 kHz & 52.99 & 51.80 & 51.57 & 54.46 & 53.08 & -1.19 & -1.42 & 1.47 & 0.09 \\
\hline & Peak 2-4 kHz & 29.04 & 28.85 & 27.80 & 31.68 & 32.52 & -0.19 & -1.24 & 2.63 & 3.48 \\
\hline & SPR & -23.95 & -22.94 & -23.77 & -22.78 & -20.56 & 1.00 & 0.18 & 1.16 & 3.39 \\
\hline \multirow[t]{4}{*}{ Low [a] } & F0 & 39.54 & 40.36 & 39.12 & 39.99 & 41.92 & 0.82 & -0.41 & 0.45 & 2.38 \\
\hline & Peak 0-2 kHz & 39.54 & 40.36 & 39.12 & 39.99 & 41.92 & 0.82 & -0.41 & 0.45 & 2.38 \\
\hline & Peak 2-4 kHz & 19.85 & 19.93 & 23.01 & 18.76 & 21.60 & 0.08 & 3.17 & -1.08 & 1.76 \\
\hline & SPR & -19.69 & -20.43 & -16.11 & -21.22 & -20.31 & -0.74 & 3.58 & -1.53 & -0.62 \\
\hline \multirow[t]{4}{*}{ Low $[E]$} & F0 & 39.89 & 39.04 & 38.64 & 39.62 & 40.34 & -0.85 & -1.25 & -0.27 & 0.45 \\
\hline & Peak 0-2 kHz & 39.89 & 39.04 & 38.64 & 39.62 & 40.34 & -0.85 & -1.25 & -0.27 & 0.45 \\
\hline & Peak 2-4 kHz & 18.05 & 19.53 & 15.99 & 19.81 & 16.12 & 1.48 & -2.06 & 1.76 & -1.93 \\
\hline & SPR & -21.84 & -19.50 & -22.65 & -19.81 & -24.22 & 2.33 & -0.81 & 2.03 & -2.38 \\
\hline \multirow[t]{4}{*}{ Low [i] } & F0 & 43.66 & 42.17 & 43.90 & 41.54 & 46.41 & -1.49 & 0.23 & -2.13 & 2.75 \\
\hline & Peak 0-2 kHz & 43.66 & 42.17 & 43.90 & 41.54 & 46.41 & -1.49 & 0.23 & -2.13 & 2.75 \\
\hline & Peak 2-4 kHz & 19.17 & 20.18 & 22.33 & 22.68 & 27.88 & 1.01 & 3.15 & 3.50 & 8.70 \\
\hline & SPR & -24.49 & -21.99 & -21.57 & -18.86 & -18.53 & 2.50 & 2.92 & 5.63 & 5.96 \\
\hline
\end{tabular}


Table E.11

Subject T1 Data

\begin{tabular}{|c|c|c|c|c|c|c|c|c|c|c|}
\hline \multirow[t]{2}{*}{ Pitch } & \multirow[t]{2}{*}{ Harmonic } & \multicolumn{5}{|c|}{ Raw Amplitude Score in dB } & \multicolumn{4}{|c|}{$\begin{array}{l}\text { Normalized Score } \\
\text { (Difference from Habitual) }\end{array}$} \\
\hline & & $\begin{array}{l}\text { Habitual } \\
15^{\circ}\end{array}$ & $-15^{\circ}$ & $\mathbf{0}^{\circ}$ & $15^{-}$ & $30^{\circ}$ & $\mathbf{N}-\mathbf{1 5}^{\circ}$ & $\mathbf{N ~ 0}^{\circ}$ & $\mathrm{N}+15^{\circ}$ & $\mathbf{N}+30^{\circ}$ \\
\hline \multirow[t]{4}{*}{ High [a] } & F0 & 52.04 & 49.31 & 45.68 & 52.04 & 48.61 & -2.73 & -6.37 & 0.00 & -3.43 \\
\hline & Peak $0-2 \mathrm{kHz}$ & 53.53 & 53.06 & 52.39 & 53.53 & 53.22 & -0.47 & -1.14 & 0.00 & -0.31 \\
\hline & Peak 2-4 kHz & 47.23 & 47.49 & 41.57 & 47.23 & 45.78 & 0.26 & -5.66 & 0.00 & -1.45 \\
\hline & SPR & -6.30 & -5.57 & -10.82 & -6.30 & -7.44 & 0.73 & -4.52 & 0.00 & -1.14 \\
\hline \multirow[t]{4}{*}{ High [E] } & F0 & 47.86 & 44.57 & 45.34 & 47.86 & 49.53 & -3.29 & -2.52 & 0.00 & 1.66 \\
\hline & Peak $0-2 \mathrm{kHz}$ & 47.86 & 44.57 & 45.58 & 47.86 & 49.53 & -3.29 & -2.28 & 0.00 & 1.66 \\
\hline & Peak 2-4 kHz & 46.01 & 42.15 & 46.25 & 46.01 & 43.96 & -3.85 & 0.24 & 0.00 & -2.05 \\
\hline & SPR & -1.86 & -2.41 & 0.67 & -1.86 & -5.57 & -0.56 & 2.53 & 0.00 & -3.71 \\
\hline \multirow[t]{4}{*}{ High [i] } & F0 & 47.56 & 47.24 & 47.25 & 47.56 & 48.75 & -0.32 & -0.31 & 0.00 & 1.19 \\
\hline & Peak 0-2 kHz & 48.11 & 48.23 & 47.25 & 48.11 & 49.64 & 0.12 & -0.86 & 0.00 & 1.53 \\
\hline & Peak 2-4 kHz & 45.65 & 42.39 & 47.36 & 45.65 & 47.13 & -3.26 & 1.71 & 0.00 & 1.48 \\
\hline & SPR & -2.46 & -5.84 & 0.12 & -2.46 & -2.50 & -3.38 & 2.58 & 0.00 & -0.04 \\
\hline \multirow[t]{4}{*}{ Mid [a] } & F0 & 40.36 & 34.62 & 38.58 & 40.36 & 42.83 & -5.74 & -1.79 & 0.00 & 2.47 \\
\hline & Peak 0-2 kHz & 45.85 & 41.80 & 41.82 & 45.85 & 46.63 & -4.05 & -4.03 & 0.00 & 0.77 \\
\hline & Peak 2-4 kHz & 41.51 & 37.89 & 37.20 & 41.51 & 40.64 & -3.62 & -4.31 & 0.00 & -0.87 \\
\hline & SPR & -4.34 & -3.91 & -4.62 & -4.34 & -5.98 & 0.43 & -0.28 & 0.00 & -1.64 \\
\hline \multirow[t]{4}{*}{ Mid [E] } & F0 & 42.24 & 37.57 & 38.82 & 42.24 & 41.65 & -4.67 & -3.42 & 0.00 & -0.59 \\
\hline & Peak 0-2 kHz & 43.70 & 45.77 & 43.70 & 43.70 & 44.55 & 2.07 & 0.00 & 0.00 & 0.85 \\
\hline & Peak 2-4 kHz & 41.72 & 41.68 & 39.75 & 41.72 & 40.42 & -0.04 & -1.98 & 0.00 & -1.31 \\
\hline & SPR & -1.98 & -4.09 & -3.95 & -1.98 & -4.14 & -2.11 & -1.97 & 0.00 & -2.16 \\
\hline \multirow[t]{4}{*}{ Mid [i] } & F0 & 39.96 & 40.28 & 37.41 & 39.96 & 38.86 & 0.32 & -2.55 & 0.00 & -1.10 \\
\hline & Peak 0-2 kHz & 48.71 & 40.28 & 44.77 & 48.71 & 47.62 & -8.43 & -3.94 & 0.00 & -1.09 \\
\hline & Peak 2-4 kHz & 42.22 & 36.55 & 37.58 & 42.22 & 41.14 & -5.67 & -4.64 & 0.00 & -1.08 \\
\hline & SPR & -6.49 & -3.73 & -7.19 & -6.49 & -6.48 & 2.76 & -0.70 & 0.00 & 0.01 \\
\hline \multirow[t]{4}{*}{ Low [a] } & F0 & 32.81 & 31.57 & 35.29 & 32.81 & 32.76 & -1.24 & 2.47 & 0.00 & -0.05 \\
\hline & Peak 0-2 kHz & 42.18 & 39.19 & 40.54 & 42.18 & 41.51 & -2.99 & -1.64 & 0.00 & -0.66 \\
\hline & Peak 2-4 kHz & 27.89 & 32.42 & 34.85 & 27.89 & 30.38 & 4.53 & 6.96 & 0.00 & 2.49 \\
\hline & SPR & -14.29 & -6.76 & -5.68 & -14.29 & -11.13 & 7.52 & 8.60 & 0.00 & 3.16 \\
\hline \multirow[t]{4}{*}{ Low $[E]$} & F0 & 33.81 & 27.81 & 31.87 & 33.81 & 34.39 & -6.00 & -1.95 & 0.00 & 0.58 \\
\hline & Peak 0-2 kHz & 38.63 & 32.62 & 37.98 & 38.63 & 40.53 & -6.01 & -0.65 & 0.00 & 1.91 \\
\hline & Peak 2-4 kHz & 30.26 & 26.83 & 32.67 & 30.26 & 33.94 & -3.43 & 2.41 & 0.00 & 3.68 \\
\hline & SPR & -8.36 & -5.78 & -5.30 & -8.36 & -6.59 & 2.58 & 3.06 & 0.00 & 1.77 \\
\hline \multirow[t]{4}{*}{ Low [i] } & F0 & 36.17 & 33.89 & 36.19 & 36.17 & 33.08 & -2.28 & 0.02 & 0.00 & -3.09 \\
\hline & Peak 0-2 kHz & 39.15 & 39.92 & 40.81 & 39.15 & 37.99 & 0.77 & 1.66 & 0.00 & -1.16 \\
\hline & Peak 2-4 kHz & 36.71 & 32.56 & 36.16 & 36.71 & 35.97 & -4.15 & -0.55 & 0.00 & -0.74 \\
\hline & SPR & -2.44 & -7.36 & -4.65 & -2.44 & -2.02 & -4.92 & -2.21 & 0.00 & 0.42 \\
\hline
\end{tabular}


Table E.12

Subject T2 Data

\begin{tabular}{|c|c|c|c|c|c|c|c|c|c|c|}
\hline \multirow[t]{2}{*}{ Pitch } & \multirow[t]{2}{*}{ Harmonic } & \multicolumn{5}{|c|}{ Raw Amplitude Score in dB } & \multicolumn{4}{|c|}{$\begin{array}{l}\text { Normalized Score } \\
\text { (Difference from Habitual) }\end{array}$} \\
\hline & & $\begin{array}{l}\text { Habitual } \\
5^{\circ}\end{array}$ & $-15^{\circ}$ & $\mathbf{0}^{\circ}$ & $15^{-}$ & $30^{\circ}$ & $\mathrm{N}-15^{\circ}$ & $\mathbf{N ~ O}^{\circ}$ & $\mathrm{N}+15^{\circ}$ & $\mathbf{N}+30^{\circ}$ \\
\hline \multirow[t]{4}{*}{ High [a] } & F0 & 42.46 & 44.03 & 40.63 & 40.20 & 44.26 & 1.57 & -1.83 & -2.26 & 1.80 \\
\hline & Peak $0-2 \mathrm{kHz}$ & 56.92 & 52.60 & 56.52 & 53.95 & 60.97 & -4.31 & -0.40 & -2.97 & 4.05 \\
\hline & Peak 2-4 kHz & 40.35 & 38.41 & 43.46 & 39.27 & 43.41 & -1.94 & 3.11 & -1.08 & 3.07 \\
\hline & SPR & -16.57 & -14.19 & -13.06 & -14.68 & -17.55 & 2.38 & 3.51 & 1.88 & -0.98 \\
\hline \multirow[t]{4}{*}{ High [E] } & F0 & 41.59 & 42.87 & 41.71 & 41.65 & 44.57 & 1.28 & 0.12 & 0.06 & 2.98 \\
\hline & Peak $0-2 \mathrm{kHz}$ & 57.22 & 55.19 & 54.39 & 56.81 & 57.46 & -2.03 & -2.83 & -0.41 & 0.24 \\
\hline & Peak 2-4 kHz & 37.18 & 37.43 & 41.22 & 45.72 & 37.05 & 0.25 & 4.04 & 8.55 & -0.13 \\
\hline & SPR & -20.04 & -17.76 & -13.17 & -11.09 & -20.42 & 2.28 & 6.87 & 8.95 & -0.38 \\
\hline \multirow[t]{4}{*}{ High [i] } & F0 & 47.33 & 45.76 & 44.72 & 48.50 & 49.35 & -1.57 & -2.62 & 1.17 & 2.01 \\
\hline & Peak 0-2 kHz & 47.33 & 45.76 & 44.72 & 48.50 & 49.35 & -1.57 & -2.62 & 1.17 & 2.01 \\
\hline & Peak 2-4 kHz & 47.55 & 49.52 & 51.97 & 50.11 & 48.65 & 1.97 & 4.42 & 2.56 & 1.10 \\
\hline & SPR & 0.22 & 3.76 & 7.26 & 1.61 & -0.69 & 3.54 & 7.04 & 1.39 & -0.91 \\
\hline \multirow[t]{4}{*}{ Mid [a] } & F0 & 37.45 & 38.01 & 36.47 & 36.65 & 38.56 & 0.56 & -0.98 & -0.80 & 1.11 \\
\hline & Peak $0-2 \mathrm{kHz}$ & 51.91 & 50.78 & 50.48 & 48.54 & 50.55 & -1.13 & -1.43 & -3.37 & -1.35 \\
\hline & Peak 2-4 kHz & 36.68 & 36.21 & 35.89 & 33.73 & 35.94 & -0.46 & -0.78 & -2.95 & -0.74 \\
\hline & SPR & -15.23 & -14.56 & -14.59 & -14.81 & -14.61 & 0.67 & 0.64 & 0.42 & 0.62 \\
\hline \multirow[t]{4}{*}{ Mid [E] } & F0 & 40.18 & 37.48 & 37.52 & 36.59 & 40.19 & -2.70 & -2.66 & -3.59 & 0.00 \\
\hline & Peak $0-2 \mathrm{kHz}$ & 49.44 & 47.81 & 51.42 & 49.25 & 52.14 & -1.63 & 1.98 & -0.19 & 2.70 \\
\hline & Peak 2-4 kHz & 37.30 & 35.88 & 38.45 & 38.78 & 37.65 & -1.41 & 1.15 & 1.48 & 0.35 \\
\hline & SPR & -12.14 & -11.93 & -12.97 & -10.47 & -14.49 & 0.22 & -0.83 & 1.67 & -2.35 \\
\hline \multirow[t]{4}{*}{ Mid [i] } & F0 & 39.26 & 38.14 & 39.19 & 41.71 & 43.15 & -1.12 & -0.07 & 2.45 & 3.89 \\
\hline & Peak $0-2 \mathrm{kHz}$ & 39.26 & 38.14 & 39.19 & 41.71 & 43.15 & -1.12 & -0.07 & 2.45 & 3.89 \\
\hline & Peak 2-4 kHz & 39.36 & 39.37 & 40.25 & 40.88 & 40.90 & 0.01 & 0.89 & 1.52 & 1.54 \\
\hline & SPR & 0.10 & 1.23 & 1.06 & -0.84 & -2.25 & 1.13 & 0.96 & -0.94 & -2.35 \\
\hline \multirow[t]{4}{*}{ Low [a] } & F0 & 36.31 & 35.19 & 38.84 & 36.36 & 37.52 & -1.11 & 2.54 & 0.06 & 1.21 \\
\hline & Peak 0-2 kHz & 45.06 & 40.83 & 43.54 & 45.85 & 47.36 & -4.23 & -1.51 & 0.79 & 2.30 \\
\hline & Peak 2-4 kHz & 32.43 & 27.61 & 31.31 & 30.84 & 31.79 & -4.82 & -1.12 & -1.58 & -0.64 \\
\hline & SPR & -12.63 & -13.22 & -12.24 & -15.01 & -15.57 & -0.59 & 0.40 & -2.38 & -2.93 \\
\hline \multirow[t]{4}{*}{ Low [E] } & F0 & 38.30 & 37.43 & 37.33 & 36.32 & 40.26 & -0.87 & -0.97 & -1.98 & 1.95 \\
\hline & Peak 0-2 kHz & 42.54 & 42.13 & 46.16 & 42.29 & 44.03 & -0.41 & 3.62 & -0.25 & 1.49 \\
\hline & Peak 2-4 kHz & 34.95 & 32.14 & 29.61 & 28.28 & 29.61 & -2.81 & -5.34 & -6.67 & -5.34 \\
\hline & SPR & -7.59 & -9.99 & -16.55 & -14.00 & -14.41 & -2.40 & -8.96 & -6.42 & -6.83 \\
\hline \multirow[t]{4}{*}{ Low [i] } & F0 & 37.41 & 35.70 & 35.83 & 40.19 & 37.68 & -1.71 & -1.58 & 2.78 & 0.27 \\
\hline & Peak $0-2 \mathrm{kHz}$ & 43.16 & 42.06 & 39.49 & 45.66 & 43.22 & -1.10 & -3.67 & 2.51 & 0.06 \\
\hline & Peak 2-4 kHz & 33.86 & 31.12 & 34.03 & 33.31 & 32.58 & -2.74 & 0.16 & -0.56 & -1.28 \\
\hline & SPR & -9.29 & -10.94 & -5.46 & -12.36 & -10.64 & -1.65 & 3.83 & -3.07 & -1.35 \\
\hline
\end{tabular}


Table E.13

Subject T3 Data

\begin{tabular}{|c|c|c|c|c|c|c|c|c|c|c|}
\hline \multirow[t]{2}{*}{ Pitch } & \multirow[t]{2}{*}{ Harmonic } & \multicolumn{5}{|c|}{ Raw Amplitude Score in dB } & \multicolumn{4}{|c|}{$\begin{array}{l}\text { Normalized Score } \\
\text { (Difference from Habitual) }\end{array}$} \\
\hline & & $\begin{array}{l}\text { Habitual } \\
10^{\circ}\end{array}$ & $-15^{\circ}$ & $\mathbf{0}^{\circ}$ & $15^{-}$ & $30^{\circ}$ & $\mathbf{N}-\mathbf{1 5}^{\circ}$ & $\mathbf{N ~}^{\circ}$ & $\mathrm{N}+15^{\circ}$ & $\mathbf{N}+30^{\circ}$ \\
\hline \multirow[t]{4}{*}{ High [a] } & F0 & 44.98 & 40.83 & 41.44 & 41.66 & 44.01 & -4.15 & -3.54 & -3.32 & -0.97 \\
\hline & Peak $0-2 \mathrm{kHz}$ & 52.39 & 49.32 & 51.45 & 51.98 & 52.02 & -3.07 & -0.94 & -0.41 & -0.37 \\
\hline & Peak 2-4 kHz & 45.48 & 45.83 & 43.59 & 42.16 & 43.79 & 0.35 & -1.89 & -3.32 & -1.69 \\
\hline & SPR & -6.91 & -3.49 & -7.86 & -9.82 & -8.23 & 3.42 & -0.95 & -2.91 & -1.32 \\
\hline \multirow[t]{4}{*}{ High [E] } & F0 & 41.59 & 41.75 & 41.67 & 43.99 & 42.00 & 0.16 & 0.07 & 2.39 & 0.41 \\
\hline & Peak $0-2 \mathrm{kHz}$ & 47.66 & 46.78 & 46.81 & 49.16 & 51.67 & -0.87 & -0.85 & 1.50 & 4.01 \\
\hline & Peak 2-4 kHz & 49.32 & 45.71 & 47.05 & 47.26 & 43.59 & -3.61 & -2.27 & -2.05 & -5.72 \\
\hline & SPR & 1.66 & -1.08 & 0.24 & -1.90 & -8.08 & -2.74 & -1.42 & -3.55 & -9.73 \\
\hline \multirow[t]{4}{*}{ High [i] } & F0 & 53.25 & 49.08 & 50.14 & 53.74 & 52.76 & -4.18 & -3.12 & 0.49 & -0.49 \\
\hline & Peak 0-2 kHz & 53.25 & 49.08 & 50.14 & 53.74 & 52.76 & -4.18 & -3.12 & 0.49 & -0.49 \\
\hline & Peak 2-4 kHz & 47.23 & 43.56 & 40.54 & 50.06 & 46.49 & -3.67 & -6.69 & 2.83 & -0.74 \\
\hline & SPR & -6.03 & -5.52 & -9.59 & -3.69 & -6.27 & 0.50 & -3.57 & 2.34 & -0.25 \\
\hline \multirow[t]{4}{*}{ Mid [a] } & F0 & 40.51 & 39.94 & 40.78 & 40.79 & 43.16 & -0.57 & 0.27 & 0.28 & 2.66 \\
\hline & Peak 0-2 kHz & 43.69 & 40.11 & 42.74 & 44.04 & 43.16 & -3.59 & -0.95 & 0.35 & -0.53 \\
\hline & Peak 2-4 kHz & 39.16 & 35.27 & 34.45 & 34.55 & 36.70 & -3.88 & -4.71 & -4.61 & -2.46 \\
\hline & SPR & -4.54 & -4.83 & -8.29 & -9.49 & -6.47 & -0.29 & -3.75 & -4.96 & -1.93 \\
\hline \multirow[t]{4}{*}{ Mid [E] } & F0 & 42.94 & 42.55 & 45.28 & 42.64 & 42.94 & -0.38 & 2.34 & -0.30 & 0.00 \\
\hline & Peak 0-2 kHz & 44.21 & 42.55 & 46.93 & 42.64 & 44.12 & -1.66 & 2.72 & -1.57 & -0.09 \\
\hline & Peak 2-4 kHz & 39.92 & 30.39 & 41.22 & 38.21 & 38.50 & -9.52 & 1.31 & -1.70 & -1.41 \\
\hline & SPR & -4.29 & -12.16 & -5.70 & -4.43 & -5.62 & -7.87 & -1.41 & -0.13 & -1.33 \\
\hline \multirow[t]{4}{*}{ Mid [i] } & F0 & 49.12 & 45.11 & 46.17 & 46.64 & 48.96 & -4.01 & -2.95 & -2.48 & -0.16 \\
\hline & Peak 0-2 kHz & 49.12 & 45.11 & 46.17 & 46.64 & 48.96 & -4.01 & -2.95 & -2.48 & -0.16 \\
\hline & Peak 2-4 kHz & 42.30 & 39.89 & 39.82 & 38.73 & 40.06 & -2.41 & -2.48 & -3.57 & -2.23 \\
\hline & SPR & -6.82 & -5.22 & -6.36 & -7.91 & -8.89 & 1.60 & 0.47 & -1.09 & -2.07 \\
\hline \multirow[t]{4}{*}{ Low [a] } & F0 & 36.79 & 38.74 & 38.74 & 37.66 & 39.42 & 1.95 & 1.95 & 0.88 & 2.63 \\
\hline & Peak 0-2 kHz & 37.12 & 38.74 & 38.74 & 37.66 & 39.42 & 1.62 & 1.62 & 0.55 & 2.30 \\
\hline & Peak 2-4 kHz & 32.21 & 26.18 & 30.22 & 29.98 & 27.54 & -6.03 & -1.99 & -2.23 & -4.66 \\
\hline & SPR & -4.91 & -12.56 & -8.53 & -7.69 & -11.88 & -7.65 & -3.61 & -2.77 & -6.96 \\
\hline \multirow[t]{4}{*}{ Low $[E]$} & F0 & 36.86 & 35.58 & 37.89 & 38.09 & 35.47 & -1.28 & 1.02 & 1.23 & -1.39 \\
\hline & Peak 0-2 kHz & 36.86 & 35.99 & 39.94 & 38.09 & 42.06 & -0.87 & 3.08 & 1.23 & 5.20 \\
\hline & Peak 2-4 kHz & 29.61 & 31.19 & 29.61 & 30.36 & 28.75 & 1.59 & 0.01 & 0.75 & -0.86 \\
\hline & SPR & -7.25 & -4.80 & -10.33 & -7.73 & -13.31 & 2.45 & -3.07 & -0.48 & -6.05 \\
\hline \multirow[t]{4}{*}{ Low [i] } & F0 & 37.55 & 41.21 & 39.18 & 39.70 & 37.32 & 3.66 & 1.63 & 2.15 & -0.23 \\
\hline & Peak 0-2 kHz & 37.55 & 41.21 & 39.18 & 39.70 & 37.32 & 3.66 & 1.63 & 2.15 & -0.23 \\
\hline & Peak 2-4 kHz & 29.42 & 32.47 & 28.08 & 30.03 & 25.56 & 3.05 & -1.34 & 0.61 & -3.86 \\
\hline & SPR & -8.13 & -8.74 & -11.10 & -9.67 & -11.77 & -0.60 & -2.97 & -1.54 & -3.64 \\
\hline
\end{tabular}


Table E.14

Subject T4 Data

\begin{tabular}{|c|c|c|c|c|c|c|c|c|c|c|}
\hline \multirow[t]{2}{*}{ Pitch } & \multirow[t]{2}{*}{ Harmonic } & \multicolumn{5}{|c|}{ Raw Amplitude Score in dB } & \multicolumn{4}{|c|}{$\begin{array}{l}\text { Normalized Score } \\
\text { (Difference from Habitual) }\end{array}$} \\
\hline & & $\begin{array}{l}\text { Habitual } \\
22^{\circ}\end{array}$ & $-15^{\circ}$ & $\mathbf{0}^{\circ}$ & $15^{-}$ & $30^{\circ}$ & $\mathbf{N}-\mathbf{1 5}^{\circ}$ & $\mathbf{N ~ 0}^{\circ}$ & $\mathrm{N}+15^{\circ}$ & $\mathbf{N}+30^{\circ}$ \\
\hline \multirow[t]{4}{*}{ High [a] } & F0 & 36.03 & 36.24 & 36.84 & 38.58 & 40.23 & 0.21 & 0.81 & 2.55 & 4.21 \\
\hline & Peak $0-2 \mathrm{kHz}$ & 53.03 & 52.89 & 53.97 & 55.04 & 53.92 & -0.15 & 0.94 & 2.00 & 0.88 \\
\hline & Peak 2-4 kHz & 32.87 & 36.84 & 30.40 & 30.57 & 33.95 & 3.97 & -2.48 & -2.30 & 1.08 \\
\hline & SPR & -20.16 & -16.05 & -23.58 & -24.46 & -19.96 & 4.11 & -3.42 & -4.30 & 0.20 \\
\hline \multirow[t]{4}{*}{ High [E] } & F0 & 38.75 & 37.06 & 37.86 & 36.56 & 38.50 & -1.69 & -0.89 & -2.19 & -0.25 \\
\hline & Peak $0-2 \mathrm{kHz}$ & 55.44 & 51.27 & 52.67 & 54.80 & 57.29 & -4.17 & -2.77 & -0.64 & 1.85 \\
\hline & Peak 2-4 kHz & 36.14 & 30.62 & 33.04 & 34.46 & 34.40 & -5.52 & -3.10 & -1.68 & -1.74 \\
\hline & SPR & -19.30 & -20.65 & -19.63 & -20.34 & -22.89 & -1.35 & -0.33 & -1.04 & -3.59 \\
\hline \multirow[t]{4}{*}{ High [i] } & F0 & 46.17 & 43.95 & 41.57 & 42.14 & 42.68 & -2.22 & -4.60 & -4.03 & -3.50 \\
\hline & Peak 0-2 kHz & 46.17 & 43.95 & 41.57 & 43.08 & 42.68 & -2.22 & -4.60 & -3.09 & -3.50 \\
\hline & Peak 2-4 kHz & 40.67 & 36.16 & 38.74 & 35.50 & 39.56 & -4.51 & -1.92 & -5.16 & -1.10 \\
\hline & SPR & -5.51 & -7.79 & -2.83 & -7.58 & -3.11 & -2.28 & 2.68 & -2.07 & 2.39 \\
\hline \multirow[t]{4}{*}{ Mid [a] } & F0 & 31.97 & 37.90 & 37.06 & 35.19 & 36.23 & 5.93 & 5.09 & 3.22 & 4.26 \\
\hline & Peak $0-2 \mathrm{kHz}$ & 47.18 & 46.83 & 46.62 & 48.51 & 47.69 & -0.35 & -0.57 & 1.33 & 0.51 \\
\hline & Peak 2-4 kHz & 28.27 & 30.55 & 28.89 & 26.41 & 31.02 & 2.29 & 0.62 & -1.86 & 2.75 \\
\hline & SPR & -18.92 & -16.28 & -17.73 & -22.10 & -16.67 & 2.64 & 1.19 & -3.19 & 2.25 \\
\hline \multirow[t]{4}{*}{ Mid [E] } & F0 & 37.15 & 37.38 & 36.96 & 31.30 & 39.23 & 0.23 & -0.20 & -5.85 & 2.08 \\
\hline & Peak 0-2 kHz & 51.01 & 44.72 & 46.39 & 48.77 & 50.82 & -6.29 & -4.62 & -2.24 & -0.19 \\
\hline & Peak 2-4 kHz & 29.31 & 30.54 & 30.92 & 27.27 & 30.60 & 1.23 & 1.61 & -2.04 & 1.29 \\
\hline & SPR & -21.70 & -14.18 & -15.48 & -21.50 & -20.21 & 7.52 & 6.22 & 0.20 & 1.48 \\
\hline \multirow[t]{4}{*}{ Mid [i] } & F0 & 39.31 & 39.03 & 39.43 & 40.40 & 38.60 & -0.28 & 0.12 & 1.08 & -0.71 \\
\hline & Peak 0-2 kHz & 47.01 & 44.05 & 44.91 & 48.37 & 44.44 & -2.96 & -2.10 & 1.36 & -2.57 \\
\hline & Peak 2-4 kHz & 28.25 & 28.40 & 31.96 & 27.76 & 28.44 & 0.15 & 3.71 & -0.50 & 0.19 \\
\hline & SPR & -18.76 & -15.65 & -12.94 & -20.61 & -15.99 & 3.11 & 5.82 & -1.85 & 2.76 \\
\hline \multirow[t]{4}{*}{ Low [a] } & F0 & 28.19 & 28.21 & 27.89 & 31.34 & 27.69 & 0.02 & -0.30 & 3.15 & -0.51 \\
\hline & Peak 0-2 kHz & 43.02 & 42.00 & 39.66 & 39.22 & 40.81 & -1.02 & -3.36 & -3.80 & -2.21 \\
\hline & Peak 2-4 kHz & 18.21 & 21.15 & 17.28 & 13.00 & 15.78 & 2.94 & -0.93 & -5.21 & -2.43 \\
\hline & SPR & -24.82 & -20.85 & -22.39 & -26.23 & -25.04 & 3.97 & 2.43 & -1.41 & -0.22 \\
\hline \multirow[t]{4}{*}{ Low $[E]$} & F0 & 29.76 & 28.12 & 27.10 & 27.80 & 32.24 & -1.64 & -2.66 & -1.97 & 2.48 \\
\hline & Peak 0-2 kHz & 41.73 & 39.64 & 39.89 & 37.53 & 44.94 & -2.09 & -1.84 & -4.20 & 3.21 \\
\hline & Peak 2-4 kHz & 20.43 & 23.06 & 17.40 & 17.55 & 19.76 & 2.63 & -3.03 & -2.88 & -0.67 \\
\hline & SPR & -21.30 & -16.58 & -22.49 & -19.98 & -25.18 & 4.72 & -1.19 & 1.33 & -3.88 \\
\hline \multirow[t]{4}{*}{ Low [i] } & F0 & 36.52 & 31.37 & 34.54 & 31.68 & 32.45 & -5.15 & -1.98 & -4.83 & -4.07 \\
\hline & Peak 0-2 kHz & 37.05 & 37.47 & 35.18 & 38.54 & 38.68 & 0.42 & -1.87 & 1.48 & 1.63 \\
\hline & Peak 2-4 kHz & 18.99 & 17.00 & 18.56 & 21.09 & 22.21 & -1.99 & -0.43 & 2.09 & 3.21 \\
\hline & SPR & -18.06 & -20.47 & -16.62 & -17.45 & -16.48 & -2.41 & 1.44 & 0.61 & 1.58 \\
\hline
\end{tabular}


Table E.15

Subject T5 Data

\begin{tabular}{|c|c|c|c|c|c|c|c|c|c|c|}
\hline \multirow[t]{2}{*}{ Pitch } & \multirow[t]{2}{*}{ Harmonic } & \multicolumn{5}{|c|}{ Raw Amplitude Score in dB } & \multicolumn{4}{|c|}{$\begin{array}{l}\text { Normalized Score } \\
\text { (Difference from Habitual) }\end{array}$} \\
\hline & & $\begin{array}{l}\text { Habitual } \\
10^{\circ}\end{array}$ & $-15^{\circ}$ & $\mathbf{0}^{\circ}$ & $15^{-}$ & $30^{\circ}$ & $\mathbf{N}-15^{\circ}$ & $\mathbf{N ~ 0}^{\circ}$ & $\mathbf{N}+15^{\circ}$ & $\mathbf{N}+30^{\circ}$ \\
\hline \multirow[t]{4}{*}{ High [a] } & F0 & 35.58 & 33.40 & 35.60 & 36.10 & 38.04 & -2.46 & -4.64 & -2.44 & -1.94 \\
\hline & Peak $0-2 \mathrm{kHz}$ & 58.25 & 55.91 & 54.13 & 54.60 & 55.63 & 2.61 & 0.28 & -1.51 & -1.03 \\
\hline & Peak 2-4 kHz & 40.99 & 37.74 & 41.41 & 38.75 & 35.43 & 5.56 & 2.31 & 5.98 & 3.32 \\
\hline & SPR & -17.26 & -18.18 & -12.72 & -15.86 & -20.20 & 2.95 & 2.02 & 7.48 & 4.34 \\
\hline \multirow[t]{4}{*}{ High $[\mathbf{E}]$} & F0 & 33.83 & 36.52 & 35.85 & 37.17 & 38.77 & -4.94 & -2.25 & -2.92 & -1.60 \\
\hline & Peak $0-2 \mathrm{kHz}$ & 45.95 & 43.70 & 54.87 & 59.68 & 48.70 & -2.75 & -5.00 & 6.17 & 10.97 \\
\hline & Peak 2-4 kHz & 39.47 & 38.61 & 38.53 & 40.91 & 41.98 & -2.51 & -3.37 & -3.45 & -1.07 \\
\hline & SPR & -6.47 & -5.09 & -16.34 & -18.76 & -6.72 & 0.25 & 1.63 & -9.62 & -12.04 \\
\hline \multirow[t]{4}{*}{ High [i] } & F0 & 36.46 & 37.20 & 42.87 & 41.37 & 40.78 & -4.32 & -3.58 & 2.09 & 0.59 \\
\hline & Peak 0-2 kHz & 36.46 & 44.96 & 42.87 & 41.37 & 46.15 & -9.69 & -1.19 & -3.27 & -4.78 \\
\hline & Peak 2-4 kHz & 46.44 & 38.57 & 49.88 & 46.94 & 38.87 & 7.58 & -0.30 & 11.01 & 8.07 \\
\hline & SPR & 9.99 & -6.39 & 7.00 & 5.57 & -7.28 & 17.27 & 0.89 & 14.28 & 12.85 \\
\hline \multirow[t]{4}{*}{ Mid [a] } & F0 & 38.04 & 35.04 & 33.02 & 37.35 & 34.61 & 3.43 & 0.43 & -1.60 & 2.74 \\
\hline & Peak 0-2 kHz & 49.03 & 48.12 & 47.61 & 49.38 & 48.79 & 0.24 & -0.67 & -1.18 & 0.59 \\
\hline & Peak 2-4 kHz & 30.58 & 27.55 & 27.74 & 34.28 & 24.37 & 6.20 & 3.18 & 3.37 & 9.90 \\
\hline & SPR & -18.45 & -20.57 & -19.86 & -15.10 & -24.42 & 5.97 & 3.85 & 4.55 & 9.32 \\
\hline \multirow[t]{4}{*}{ Mid [E] } & F0 & 39.54 & 37.35 & 42.18 & 38.24 & 37.14 & 2.40 & 0.21 & 5.04 & 1.10 \\
\hline & Peak $0-2 \mathrm{kHz}$ & 45.50 & 46.64 & 45.10 & 44.23 & 43.52 & 1.97 & 3.11 & 1.58 & 0.71 \\
\hline & Peak 2-4 kHz & 35.16 & 39.10 & 42.69 & 38.44 & 35.80 & -0.64 & 3.30 & 6.89 & 2.64 \\
\hline & SPR & -10.34 & -7.54 & -2.41 & -5.79 & -7.72 & -2.62 & 0.18 & 5.32 & 1.93 \\
\hline \multirow[t]{4}{*}{ Mid [i] } & F0 & 37.74 & 40.31 & 38.97 & 38.63 & 41.15 & -3.41 & -0.84 & -2.18 & -2.53 \\
\hline & Peak 0-2 kHz & 37.74 & 40.31 & 39.17 & 38.63 & 41.15 & -3.41 & -0.84 & -1.98 & -2.53 \\
\hline & Peak 2-4 kHz & 29.32 & 38.40 & 39.42 & 36.96 & 34.95 & -5.63 & 3.45 & 4.47 & 2.01 \\
\hline & SPR & -8.42 & -1.91 & 0.25 & -1.66 & -6.20 & -2.22 & 4.29 & 6.45 & 4.54 \\
\hline \multirow[t]{4}{*}{ Low [a] } & F0 & 38.59 & 38.82 & 33.86 & 34.85 & 32.79 & 5.80 & 6.03 & 1.07 & 2.06 \\
\hline & Peak 0-2 kHz & 42.98 & 45.24 & 44.65 & 48.48 & 45.57 & -2.59 & -0.32 & -0.92 & 2.91 \\
\hline & Peak 2-4 kHz & 22.95 & 25.78 & 32.82 & 35.85 & 30.52 & -7.57 & -4.74 & 2.31 & 5.33 \\
\hline & SPR & -20.03 & -19.47 & -11.83 & -12.63 & -15.05 & -4.98 & -4.42 & 3.22 & 2.42 \\
\hline \multirow[t]{4}{*}{ Low $[E]$} & F0 & 39.36 & 36.66 & 35.16 & 35.31 & 37.27 & 2.09 & -0.61 & -2.10 & -1.96 \\
\hline & Peak 0-2 kHz & 40.57 & 39.20 & 40.75 & 45.28 & 45.61 & -5.04 & -6.41 & -4.86 & -0.32 \\
\hline & Peak 2-4 kHz & 25.77 & 29.41 & 28.91 & 29.68 & 32.61 & -6.84 & -3.20 & -3.70 & -2.93 \\
\hline & SPR & -14.80 & -9.79 & -11.84 & -15.60 & -13.00 & -1.80 & 3.21 & 1.16 & -2.60 \\
\hline \multirow[t]{4}{*}{ Low [i] } & F0 & 38.31 & 35.31 & 35.02 & 40.05 & 37.18 & 1.13 & -1.88 & -2.16 & 2.87 \\
\hline & Peak $0-2 \mathrm{kHz}$ & 40.46 & 40.44 & 35.02 & 41.20 & 38.10 & 2.35 & 2.34 & -3.08 & 3.10 \\
\hline & Peak 2-4 kHz & 34.94 & 35.69 & 32.91 & 39.37 & 33.26 & 1.68 & 2.42 & -0.35 & 6.11 \\
\hline & SPR & -5.52 & -4.76 & -2.11 & -1.83 & -4.84 & -0.68 & 0.08 & 2.73 & 3.01 \\
\hline
\end{tabular}


Table E.16

Subject B1 Data

\begin{tabular}{|c|c|c|c|c|c|c|c|c|c|c|}
\hline \multirow[t]{2}{*}{ Pitch } & \multirow[t]{2}{*}{ Harmonic } & \multicolumn{5}{|c|}{ Raw Amplitude Score in dB } & \multicolumn{4}{|c|}{$\begin{array}{l}\text { Normalized Score } \\
\text { (Difference from Habitual) }\end{array}$} \\
\hline & & $\begin{array}{l}\text { Habitual } \\
10^{\circ}\end{array}$ & $-15^{\circ}$ & $\mathbf{0}^{\circ}$ & $15^{-}$ & $30^{\circ}$ & $\mathbf{N}-\mathbf{1 5}^{\circ}$ & $\mathbf{N ~ 0}^{\circ}$ & $\mathrm{N}+15^{\circ}$ & $\mathbf{N}+30^{\circ}$ \\
\hline \multirow[t]{4}{*}{ High [a] } & F0 & 46.61 & 45.19 & 46.98 & 46.43 & 48.83 & -1.42 & 0.37 & -0.18 & 2.22 \\
\hline & Peak $0-2 \mathrm{kHz}$ & 57.07 & 51.58 & 52.93 & 54.79 & 50.97 & -5.49 & -4.14 & -2.28 & -6.10 \\
\hline & Peak 2-4 kHz & 40.73 & 42.88 & 42.25 & 36.54 & 39.32 & 2.15 & 1.51 & -4.19 & -1.42 \\
\hline & SPR & -16.33 & -8.70 & -10.68 & -18.25 & -11.65 & 7.64 & 5.65 & -1.92 & 4.68 \\
\hline \multirow[t]{4}{*}{ High [E] } & F0 & 48.82 & 49.00 & 46.00 & 44.44 & 46.91 & 0.18 & -2.82 & -4.38 & -1.92 \\
\hline & Peak $0-2 \mathrm{kHz}$ & 51.77 & 52.23 & 52.19 & 48.26 & 49.62 & 0.45 & 0.41 & -3.51 & -2.15 \\
\hline & Peak 2-4 kHz & 41.77 & 44.74 & 43.27 & 40.65 & 39.04 & 2.97 & 1.51 & -1.11 & -2.72 \\
\hline & SPR & -10.01 & -7.49 & -8.91 & -7.61 & -10.57 & 2.52 & 1.10 & 2.40 & -0.57 \\
\hline \multirow[t]{4}{*}{ High [i] } & F0 & 51.12 & 49.52 & 53.24 & 50.40 & 52.08 & -1.60 & 2.12 & -0.72 & 0.96 \\
\hline & Peak 0-2 kHz & 51.12 & 49.52 & 53.24 & 50.40 & 52.08 & -1.60 & 2.12 & -0.72 & 0.96 \\
\hline & Peak 2-4 kHz & 42.13 & 43.55 & 41.42 & 38.91 & 41.32 & 1.41 & -0.71 & -3.22 & -0.82 \\
\hline & SPR & -8.99 & -5.98 & -11.82 & -11.49 & -10.76 & 3.01 & -2.83 & -2.50 & -1.78 \\
\hline \multirow[t]{4}{*}{ Mid [a] } & F0 & 41.61 & 43.87 & 39.44 & 43.94 & 45.85 & 2.26 & -2.16 & 2.34 & 4.24 \\
\hline & Peak $0-2 \mathrm{kHz}$ & 49.61 & 50.67 & 47.67 & 50.04 & 54.53 & 1.07 & -1.93 & 0.44 & 4.92 \\
\hline & Peak 2-4 kHz & 35.61 & 39.18 & 32.07 & 35.65 & 37.40 & 3.57 & -3.53 & 0.04 & 1.79 \\
\hline & SPR & -14.00 & -11.50 & -15.60 & -14.40 & -17.13 & 2.50 & -1.60 & -0.40 & -3.13 \\
\hline \multirow[t]{4}{*}{ Mid [E] } & F0 & 45.92 & 44.62 & 46.47 & 44.88 & 44.94 & -1.31 & 0.55 & -1.04 & -0.98 \\
\hline & Peak 0-2 kHz & 50.27 & 46.45 & 49.22 & 50.81 & 48.45 & -3.82 & -1.04 & 0.54 & -1.82 \\
\hline & Peak 2-4 kHz & 35.73 & 37.86 & 39.46 & 37.36 & 32.26 & 2.13 & 3.73 & 1.63 & -3.47 \\
\hline & SPR & -14.54 & -8.59 & -9.77 & -13.45 & -16.19 & 5.95 & 4.78 & 1.09 & -1.65 \\
\hline \multirow[t]{4}{*}{ Mid [i] } & F0 & 44.42 & 41.36 & 43.30 & 44.90 & 48.50 & -3.06 & -1.12 & 0.49 & 4.08 \\
\hline & Peak 0-2 kHz & 47.30 & 45.22 & 44.20 & 45.99 & 48.50 & -2.08 & -3.09 & -1.31 & 1.20 \\
\hline & Peak 2-4 kHz & 35.82 & 34.06 & 37.16 & 32.30 & 34.97 & -1.76 & 1.34 & -3.52 & -0.85 \\
\hline & SPR & -11.48 & -11.16 & -7.04 & -13.68 & -13.53 & 0.32 & 4.43 & -2.21 & -2.05 \\
\hline \multirow[t]{4}{*}{ Low [a] } & F0 & 41.08 & 38.91 & 39.97 & 40.50 & 41.11 & -2.17 & -1.11 & -0.58 & 0.04 \\
\hline & Peak 0-2 kHz & 45.90 & 46.88 & 43.81 & 44.70 & 45.09 & 0.98 & -2.09 & -1.20 & -0.81 \\
\hline & Peak 2-4 kHz & 29.96 & 33.22 & 33.71 & 27.11 & 30.82 & 3.26 & 3.75 & -2.85 & 0.86 \\
\hline & SPR & -15.94 & -13.66 & -10.11 & -17.59 & -14.27 & 2.28 & 5.83 & -1.65 & 1.67 \\
\hline \multirow[t]{4}{*}{ Low $[E]$} & F0 & 38.58 & 37.47 & 40.54 & 40.92 & 39.58 & -1.11 & 1.97 & 2.34 & 1.00 \\
\hline & Peak 0-2 kHz & 42.52 & 38.78 & 44.40 & 50.75 & 40.61 & -3.75 & 1.88 & 8.22 & -1.92 \\
\hline & Peak 2-4 kHz & 31.49 & 33.44 & 32.99 & 33.01 & 24.39 & 1.94 & 1.49 & 1.51 & -7.11 \\
\hline & SPR & -11.03 & -5.34 & -11.41 & -17.74 & -16.22 & 5.69 & -0.38 & -6.71 & -5.19 \\
\hline \multirow[t]{4}{*}{ Low [i] } & F0 & 41.53 & 40.78 & 37.88 & 40.68 & 40.23 & -0.75 & -3.65 & -0.84 & -1.29 \\
\hline & Peak 0-2 kHz & 47.03 & 45.43 & 44.69 & 46.79 & 48.05 & -1.60 & -2.34 & -0.24 & 1.02 \\
\hline & Peak 2-4 kHz & 28.79 & 32.61 & 33.05 & 28.08 & 30.15 & 3.81 & 4.26 & -0.72 & 1.36 \\
\hline & SPR & -18.24 & -12.82 & -11.64 & -18.72 & -17.90 & 5.41 & 6.60 & -0.48 & 0.34 \\
\hline
\end{tabular}


Table E.17

Subject B2 Data

\begin{tabular}{|c|c|c|c|c|c|c|c|c|c|c|}
\hline \multirow[t]{2}{*}{ Pitch } & \multirow[t]{2}{*}{ Harmonic } & \multicolumn{5}{|c|}{ Raw Amplitude Score in dB } & \multicolumn{4}{|c|}{$\begin{array}{l}\text { Normalized Score } \\
\text { (Difference from Habitual) }\end{array}$} \\
\hline & & $\begin{array}{l}\text { Habitual } \\
10^{\circ}\end{array}$ & $-15^{\circ}$ & $\mathbf{0}^{\circ}$ & $15^{-}$ & $30^{\circ}$ & $\mathbf{N}-15^{\circ}$ & $\mathbf{N ~ O}^{\circ}$ & $\mathbf{N}+15^{\circ}$ & $\mathbf{N}+30^{\circ}$ \\
\hline \multirow[t]{4}{*}{ High [a] } & F0 & 47.57 & 45.52 & 47.83 & 46.99 & 49.52 & -2.04 & 0.26 & -0.57 & 1.95 \\
\hline & Peak $0-2 \mathrm{kHz}$ & 57.96 & 54.84 & 55.36 & 53.98 & 59.20 & -3.12 & -2.60 & -3.98 & 1.24 \\
\hline & Peak 2-4 kHz & 36.72 & 35.43 & 35.43 & 36.89 & 42.11 & -1.29 & -1.29 & 0.17 & 5.39 \\
\hline & SPR & -21.24 & -19.40 & -19.93 & -17.09 & -17.09 & 1.84 & 1.31 & 4.15 & 4.15 \\
\hline \multirow[t]{4}{*}{ High [E] } & F0 & 45.21 & 46.35 & 45.91 & 48.15 & 52.18 & 1.15 & 0.71 & 2.94 & 6.98 \\
\hline & Peak $0-2 \mathrm{kHz}$ & 52.93 & 51.50 & 56.38 & 55.43 & 58.93 & -1.43 & 3.45 & 2.50 & 6.00 \\
\hline & Peak 2-4 kHz & 36.60 & 39.71 & 39.34 & 36.24 & 40.59 & 3.11 & 2.74 & -0.36 & 3.99 \\
\hline & SPR & -16.33 & -11.79 & -17.04 & -19.20 & -18.35 & 4.54 & -0.71 & -2.87 & -2.02 \\
\hline \multirow[t]{4}{*}{ High [i] } & F0 & 48.82 & 47.71 & 48.38 & 50.89 & 51.63 & -1.12 & -0.44 & 2.06 & 2.81 \\
\hline & Peak $0-2 \mathrm{kHz}$ & 48.82 & 47.71 & 48.38 & 50.89 & 51.63 & -1.12 & -0.44 & 2.06 & 2.81 \\
\hline & Peak 2-4 kHz & 35.01 & 33.21 & 32.37 & 34.36 & 38.81 & -1.79 & -2.63 & -0.64 & 3.80 \\
\hline & SPR & -13.82 & -14.49 & -16.01 & -16.52 & -12.82 & -0.67 & -2.19 & -2.71 & 0.99 \\
\hline \multirow[t]{4}{*}{ Mid [a] } & F0 & 40.67 & 40.38 & 43.62 & 47.27 & 45.91 & -0.30 & 2.94 & 6.60 & 5.23 \\
\hline & Peak $0-2 \mathrm{kHz}$ & 47.98 & 48.89 & 50.56 & 51.43 & 52.94 & 0.91 & 2.58 & 3.46 & 4.97 \\
\hline & Peak 2-4 kHz & 26.93 & 30.77 & 27.51 & 29.44 & 27.44 & 3.85 & 0.58 & 2.51 & 0.52 \\
\hline & SPR & -21.05 & -18.11 & -23.05 & -22.00 & -25.50 & 2.93 & -2.00 & -0.95 & -4.45 \\
\hline \multirow[t]{4}{*}{ Mid [E] } & F0 & 44.20 & 40.91 & 42.87 & 47.52 & 47.14 & -3.29 & -1.33 & 3.32 & 2.94 \\
\hline & Peak 0-2 kHz & 45.33 & 44.30 & 47.28 & 51.14 & 51.89 & -1.03 & 1.96 & 5.81 & 6.56 \\
\hline & Peak 2-4 kHz & 34.28 & 33.87 & 27.17 & 31.99 & 35.03 & -0.41 & -7.10 & -2.29 & 0.75 \\
\hline & SPR & -11.05 & -10.43 & -20.11 & -19.15 & -16.86 & 0.62 & -9.06 & -8.10 & -5.81 \\
\hline \multirow[t]{4}{*}{ Mid [i] } & F0 & 47.80 & 44.28 & 43.45 & 47.16 & 46.91 & -3.52 & -4.35 & -0.64 & -0.89 \\
\hline & Peak 0-2 kHz & 51.32 & 45.47 & 50.42 & 49.86 & 52.45 & -5.86 & -0.91 & -1.46 & 1.13 \\
\hline & Peak 2-4 kHz & 29.08 & 26.30 & 35.36 & 30.05 & 30.85 & -2.78 & 6.28 & 0.98 & 1.77 \\
\hline & SPR & -22.25 & -19.17 & -15.06 & -19.81 & -21.60 & 3.08 & 7.19 & 2.44 & 0.64 \\
\hline \multirow[t]{4}{*}{ Low [a] } & F0 & 34.68 & 33.94 & 39.62 & 40.56 & 39.14 & -0.74 & 4.94 & 5.88 & 4.46 \\
\hline & Peak 0-2 kHz & 43.01 & 45.17 & 46.39 & 42.30 & 42.45 & 2.16 & 3.38 & -0.71 & -0.56 \\
\hline & Peak 2-4 kHz & 24.37 & 29.88 & 29.56 & 24.95 & 13.87 & 5.51 & 5.19 & 0.58 & -10.50 \\
\hline & SPR & -18.64 & -15.29 & -16.83 & -17.35 & -28.58 & 3.35 & 1.81 & 1.29 & -9.95 \\
\hline \multirow[t]{4}{*}{ Low $[E]$} & F0 & 44.07 & 37.99 & 39.42 & 41.26 & 42.99 & -6.09 & -4.66 & -2.81 & -1.09 \\
\hline & Peak $0-2 \mathrm{kHz}$ & 44.07 & 40.67 & 42.13 & 45.50 & 43.94 & -3.41 & -1.95 & 1.43 & -0.13 \\
\hline & Peak 2-4 kHz & 28.12 & 28.25 & 31.67 & 27.66 & 22.86 & 0.12 & 3.54 & -0.46 & -5.26 \\
\hline & SPR & -15.95 & -12.42 & -10.46 & -17.84 & -21.08 & 3.53 & 5.49 & -1.89 & -5.13 \\
\hline \multirow[t]{4}{*}{ Low [i] } & F0 & 37.38 & 37.83 & 40.49 & 39.98 & 41.98 & 0.44 & 3.11 & 2.59 & 4.60 \\
\hline & Peak $0-2 \mathrm{kHz}$ & 41.47 & 40.66 & 42.93 & 42.71 & 45.31 & -0.81 & 1.46 & 1.24 & 3.84 \\
\hline & Peak 2-4 kHz & 29.64 & 28.48 & 26.31 & 24.83 & 30.75 & -1.16 & -3.33 & -4.81 & 1.11 \\
\hline & SPR & -11.83 & -12.17 & -16.61 & -17.87 & -14.56 & -0.35 & -4.79 & -6.05 & -2.73 \\
\hline
\end{tabular}


Table E.18

Subject B3 Data

\begin{tabular}{|c|c|c|c|c|c|c|c|c|c|c|}
\hline \multirow[t]{2}{*}{ Pitch } & \multirow[t]{2}{*}{ Harmonic } & \multicolumn{5}{|c|}{ Raw Amplitude Score in dB } & \multicolumn{4}{|c|}{$\begin{array}{l}\text { Normalized Score } \\
\text { (Difference from Habitual) }\end{array}$} \\
\hline & & $\begin{array}{l}\text { Habitual } \\
7.5^{\circ}\end{array}$ & $-15^{\circ}$ & $\mathbf{0}^{\circ}$ & $15^{-}$ & $30^{\circ}$ & $\mathbf{N}-\mathbf{1 5}^{\circ}$ & $\mathbf{N ~ 0}^{\circ}$ & $\mathrm{N}+15^{\circ}$ & $\mathbf{N}+30^{\circ}$ \\
\hline \multirow[t]{4}{*}{ High [a] } & F0 & 43.13 & 42.57 & 45.54 & 45.71 & 46.29 & -0.55 & 2.42 & 2.59 & 3.17 \\
\hline & Peak $0-2 \mathrm{kHz}$ & 53.91 & 53.66 & 52.84 & 54.03 & 56.76 & -0.25 & -1.07 & 0.12 & 2.86 \\
\hline & Peak 2-4 kHz & 37.53 & 33.41 & 35.75 & 35.95 & 39.63 & -4.12 & -1.78 & -1.58 & 2.10 \\
\hline & SPR & -16.38 & -20.24 & -17.09 & -18.08 & -17.13 & -3.87 & -0.72 & -1.70 & -0.76 \\
\hline \multirow[t]{4}{*}{ High [E] } & F0 & 41.16 & 42.36 & 47.47 & 43.05 & 46.48 & 1.20 & 6.31 & 1.89 & 5.32 \\
\hline & Peak $0-2 \mathrm{kHz}$ & 53.85 & 56.35 & 54.86 & 55.51 & 57.51 & 2.50 & 1.01 & 1.66 & 3.66 \\
\hline & Peak 2-4 kHz & 40.41 & 36.23 & 39.91 & 38.38 & 40.70 & -4.17 & -0.49 & -2.03 & 0.29 \\
\hline & SPR & -13.44 & -20.12 & -14.94 & -17.14 & -16.81 & -6.68 & -1.50 & -3.69 & -3.37 \\
\hline \multirow[t]{4}{*}{ High [i] } & F0 & 50.46 & 50.40 & 50.98 & 50.44 & 49.90 & -0.05 & 0.52 & -0.02 & -0.56 \\
\hline & Peak 0-2 kHz & 50.46 & 50.40 & 50.98 & 50.44 & 49.90 & -0.05 & 0.52 & -0.02 & -0.56 \\
\hline & Peak 2-4 kHz & 39.13 & 38.32 & 40.04 & 40.44 & 39.92 & -0.82 & 0.90 & 1.31 & 0.78 \\
\hline & SPR & -11.32 & -12.09 & -10.94 & -10.00 & -9.98 & -0.76 & 0.38 & 1.33 & 1.34 \\
\hline \multirow[t]{4}{*}{ Mid [a] } & F0 & 43.02 & 41.46 & 43.81 & 40.65 & 42.75 & -1.56 & 0.79 & -2.37 & -0.27 \\
\hline & Peak 0-2 kHz & 56.37 & 51.83 & 51.34 & 51.23 & 52.85 & -4.54 & -5.03 & -5.15 & -3.52 \\
\hline & Peak 2-4 kHz & 36.33 & 36.00 & 31.51 & 36.14 & 33.25 & -0.33 & -4.81 & -0.19 & -3.07 \\
\hline & SPR & -20.04 & -15.83 & -19.83 & -15.09 & -19.59 & 4.21 & 0.21 & 4.96 & 0.45 \\
\hline \multirow[t]{4}{*}{ Mid [E] } & F0 & 41.56 & 40.72 & 39.92 & 44.67 & 45.03 & -0.84 & -1.65 & 3.11 & 3.47 \\
\hline & Peak 0-2 kHz & 56.37 & 53.33 & 55.52 & 56.10 & 57.60 & -3.04 & -0.85 & -0.26 & 1.24 \\
\hline & Peak 2-4 kHz & 36.22 & 33.61 & 34.40 & 34.89 & 36.20 & -2.62 & -1.83 & -1.33 & -0.03 \\
\hline & SPR & -20.14 & -19.72 & -21.12 & -21.21 & -21.41 & 0.43 & -0.98 & -1.07 & -1.27 \\
\hline \multirow[t]{4}{*}{ Mid [i] } & F0 & 41.80 & 40.31 & 44.37 & 45.14 & 46.30 & -1.49 & 2.57 & 3.34 & 4.50 \\
\hline & Peak 0-2 kHz & 44.97 & 48.06 & 49.12 & 48.36 & 49.29 & 3.09 & 4.15 & 3.39 & 4.32 \\
\hline & Peak 2-4 kHz & 36.56 & 33.05 & 33.83 & 33.49 & 34.73 & -3.51 & -2.74 & -3.08 & -1.83 \\
\hline & SPR & -8.41 & -15.01 & -15.29 & -14.87 & -14.56 & -6.60 & -6.89 & -6.47 & -6.15 \\
\hline \multirow[t]{4}{*}{ Low [a] } & F0 & 40.08 & 39.48 & 38.14 & 38.11 & 40.93 & -0.61 & -1.94 & -1.97 & 0.84 \\
\hline & Peak 0-2 kHz & 44.97 & 43.62 & 44.94 & 49.15 & 45.65 & -1.35 & -0.03 & 4.17 & 0.67 \\
\hline & Peak 2-4 kHz & 30.06 & 27.33 & 28.34 & 25.41 & 25.60 & -2.73 & -1.72 & -4.65 & -4.46 \\
\hline & SPR & -14.92 & -16.30 & -16.61 & -23.74 & -20.05 & -1.38 & -1.69 & -8.82 & -5.13 \\
\hline \multirow[t]{4}{*}{ Low $[E]$} & F0 & 39.65 & 40.25 & 39.05 & 38.11 & 41.02 & 0.60 & -0.60 & -1.54 & 1.37 \\
\hline & Peak 0-2 kHz & 47.49 & 47.63 & 48.86 & 45.54 & 43.36 & 0.14 & 1.37 & -1.96 & -4.13 \\
\hline & Peak 2-4 kHz & 28.57 & 27.75 & 27.99 & 29.22 & 29.29 & -0.83 & -0.58 & 0.65 & 0.71 \\
\hline & SPR & -18.92 & -19.88 & -20.87 & -16.31 & -14.08 & -0.96 & -1.95 & 2.61 & 4.84 \\
\hline \multirow[t]{4}{*}{ Low [i] } & F0 & 38.23 & 37.66 & 39.75 & 39.73 & 39.56 & -0.57 & 1.52 & 1.50 & 1.33 \\
\hline & Peak 0-2 kHz & 45.15 & 43.85 & 46.96 & 46.49 & 47.16 & -1.30 & 1.81 & 1.34 & 2.01 \\
\hline & Peak 2-4 kHz & 30.38 & 31.23 & 29.44 & 26.25 & 25.28 & 0.85 & -0.94 & -4.13 & -5.10 \\
\hline & SPR & -14.77 & -12.62 & -17.52 & -20.25 & -21.88 & 2.15 & -2.75 & -5.48 & -7.11 \\
\hline
\end{tabular}


Table E.19

Subject B4 Data

\begin{tabular}{|c|c|c|c|c|c|c|c|c|c|c|}
\hline \multirow[t]{2}{*}{ Pitch } & \multirow[t]{2}{*}{ Harmonic } & \multicolumn{5}{|c|}{ Raw Amplitude Score in dB } & \multicolumn{4}{|c|}{$\begin{array}{l}\begin{array}{l}\text { Normalized Score } \\
\text { (Difference from Habitual) }\end{array} \\
\end{array}$} \\
\hline & & $\begin{array}{l}\text { Habitual } \\
12^{\circ}\end{array}$ & $-15^{\circ}$ & $\mathbf{0}^{\circ}$ & $15^{-}$ & $30^{\circ}$ & $\mathrm{N}-15^{\circ}$ & $\mathbf{N ~ O}^{\circ}$ & $\mathbf{N}+15^{\circ}$ & $\mathbf{N}+\mathbf{3 0}^{\circ}$ \\
\hline \multirow[t]{4}{*}{ High [a] } & F0 & 43.21 & 40.77 & 40.17 & 38.49 & 43.24 & -2.43 & -3.04 & -4.72 & 0.04 \\
\hline & Peak 0-2 kHz & 47.81 & 47.03 & 47.21 & 46.30 & 49.40 & -0.77 & -0.60 & -1.50 & 1.60 \\
\hline & Peak 2-4 kHz & 32.84 & 30.47 & 31.11 & 31.50 & 37.54 & -2.37 & -1.74 & -1.35 & 4.70 \\
\hline & SPR & -14.96 & -16.56 & -16.10 & -14.81 & -11.86 & -1.60 & -1.14 & 0.15 & 3.10 \\
\hline \multirow[t]{4}{*}{ High [E] } & F0 & 42.85 & 39.66 & 41.02 & 40.42 & 42.06 & -3.19 & -1.83 & -2.43 & -0.80 \\
\hline & Peak 0-2 kHz & 45.69 & 48.62 & 47.47 & 45.92 & 48.29 & 2.94 & 1.79 & 0.23 & 2.61 \\
\hline & Peak 2-4 kHz & 35.98 & 27.94 & 35.01 & 31.64 & 32.62 & -8.05 & -0.98 & -4.34 & -3.36 \\
\hline & SPR & -9.70 & -20.69 & -12.46 & -14.27 & -15.67 & -10.99 & -2.76 & -4.57 & -5.97 \\
\hline \multirow[t]{4}{*}{ High [i] } & F0 & 46.31 & 44.08 & 42.55 & 44.37 & 44.07 & -2.23 & -3.75 & -1.94 & -2.24 \\
\hline & Peak 0-2 kHz & 46.31 & 44.08 & 42.55 & 44.37 & 44.07 & -2.23 & -3.75 & -1.94 & -2.24 \\
\hline & Peak 2-4 kHz & 32.86 & 31.51 & 30.72 & 27.70 & 37.17 & -1.35 & -2.14 & -5.16 & 4.31 \\
\hline & SPR & -13.45 & -12.57 & -11.83 & -16.67 & -6.90 & 0.87 & 1.61 & -3.23 & 6.54 \\
\hline \multirow[t]{4}{*}{ Mid [a] } & F0 & 37.63 & 40.19 & 36.70 & 39.77 & 40.21 & 2.56 & -0.93 & 2.14 & 2.58 \\
\hline & Peak 0-2 kHz & 41.35 & 43.83 & 40.91 & 45.26 & 45.25 & 2.48 & -0.44 & 3.91 & 3.90 \\
\hline & Peak 2-4 kHz & 29.17 & 25.63 & 26.19 & 29.57 & 28.83 & -3.53 & -2.98 & 0.40 & -0.34 \\
\hline & SPR & -12.18 & -18.19 & -14.72 & -15.69 & -16.42 & -6.01 & -2.54 & -3.51 & -4.24 \\
\hline \multirow[t]{4}{*}{ Mid [E] } & F0 & 40.78 & 41.38 & 40.04 & 38.61 & 41.90 & 0.61 & -0.74 & -2.17 & 1.12 \\
\hline & Peak 0-2 kHz & 44.47 & 45.84 & 43.42 & 41.30 & 43.64 & 1.37 & -1.05 & -3.16 & -0.83 \\
\hline & Peak 2-4 kHz & 30.54 & 28.48 & 26.52 & 25.80 & 33.42 & -2.06 & -4.02 & -4.74 & 2.89 \\
\hline & SPR & -13.93 & -17.36 & -16.90 & -15.51 & -10.22 & -3.43 & -2.97 & -1.58 & 3.71 \\
\hline \multirow[t]{4}{*}{ Mid [i] } & F0 & 40.32 & 38.50 & 39.96 & 41.62 & 43.65 & -1.82 & -0.36 & 1.30 & 3.33 \\
\hline & Peak 0-2 kHz & 40.32 & 38.50 & 39.96 & 41.62 & 43.65 & -1.82 & -0.36 & 1.30 & 3.33 \\
\hline & Peak 2-4 kHz & 24.65 & 22.27 & 21.75 & 23.97 & 22.70 & -2.39 & -2.91 & -0.68 & -1.96 \\
\hline & SPR & -15.67 & -16.23 & -18.21 & -17.65 & -20.95 & -0.56 & -2.55 & -1.99 & -5.28 \\
\hline \multirow[t]{4}{*}{ Low [a] } & F0 & 38.16 & 35.05 & 36.30 & 36.92 & 36.14 & -3.12 & -1.86 & -1.24 & -2.02 \\
\hline & Peak 0-2 kHz & 38.16 & 38.16 & 37.79 & 39.47 & 39.31 & 0.00 & -0.37 & 1.31 & 1.15 \\
\hline & Peak 2-4 kHz & 20.16 & 24.18 & 26.01 & 27.45 & 25.07 & 4.02 & 5.85 & 7.29 & 4.92 \\
\hline & SPR & -18.00 & -13.98 & -11.78 & -12.02 & -14.24 & 4.02 & 6.22 & 5.98 & 3.77 \\
\hline \multirow[t]{4}{*}{ Low $[E]$} & F0 & 36.75 & 33.74 & 33.58 & 37.60 & 37.39 & -3.01 & -3.17 & 0.85 & 0.64 \\
\hline & Peak 0-2 kHz & 41.11 & 37.44 & 38.90 & 37.86 & 39.06 & -3.67 & -2.21 & -3.25 & -2.05 \\
\hline & Peak 2-4 kHz & 31.76 & 12.53 & 23.96 & 22.28 & 27.74 & -19.22 & -7.80 & -9.48 & -4.02 \\
\hline & SPR & -9.35 & -24.91 & -14.94 & -15.59 & -11.32 & -15.55 & -5.59 & -6.23 & -1.97 \\
\hline \multirow[t]{4}{*}{ Low [i] } & F0 & 35.37 & 34.08 & 38.37 & 36.56 & 38.49 & -1.29 & 3.01 & 1.20 & 3.12 \\
\hline & Peak 0-2 kHz & 39.11 & 36.67 & 39.47 & 36.94 & 38.49 & -2.44 & 0.36 & -2.17 & -0.62 \\
\hline & Peak 2-4 kHz & 21.23 & 19.50 & 23.66 & 23.97 & 22.82 & -1.73 & 2.43 & 2.74 & 1.59 \\
\hline & SPR & -17.88 & -17.17 & -15.81 & -12.97 & -15.66 & 0.71 & 2.07 & 4.91 & 2.22 \\
\hline
\end{tabular}


Table E.20

Subject B5 Data

\begin{tabular}{|c|c|c|c|c|c|c|c|c|c|c|}
\hline \multirow[t]{2}{*}{ Pitch } & \multirow[t]{2}{*}{ Harmonic } & \multicolumn{5}{|c|}{ Raw Amplitude Score in dB } & \multicolumn{4}{|c|}{$\begin{array}{l}\text { Normalized Score } \\
\text { (Difference from Habitual) }\end{array}$} \\
\hline & & $\begin{array}{l}\text { Habitual } \\
0^{\circ}\end{array}$ & $-15^{\circ}$ & $\mathbf{0}^{\circ}$ & $15^{-}$ & $30^{\circ}$ & $\mathbf{N}-\mathbf{1 5}^{\circ}$ & $\mathbf{N ~ 0}^{\circ}$ & $\mathrm{N}+15^{\circ}$ & $\mathbf{N}+30^{\circ}$ \\
\hline \multirow[t]{4}{*}{ High [a] } & F0 & 47.11 & 41.83 & 47.11 & 47.46 & 49.03 & -5.28 & 0.00 & 0.35 & 1.92 \\
\hline & Peak $0-2 \mathrm{kHz}$ & 56.55 & 55.35 & 56.55 & 56.23 & 58.44 & -1.20 & 0.00 & -0.32 & 1.89 \\
\hline & Peak 2-4 kHz & 44.29 & 45.80 & 44.29 & 42.33 & 39.12 & 1.51 & 0.00 & -1.95 & -5.16 \\
\hline & SPR & -12.26 & -9.55 & -12.26 & -13.89 & -19.32 & 2.71 & 0.00 & -1.63 & -7.06 \\
\hline \multirow[t]{4}{*}{ High [E] } & F0 & 47.70 & 47.96 & 47.70 & 50.66 & 48.90 & 0.26 & 0.00 & 2.96 & 1.20 \\
\hline & Peak $0-2 \mathrm{kHz}$ & 57.01 & 60.57 & 57.01 & 56.70 & 59.18 & 3.56 & 0.00 & -0.32 & 2.17 \\
\hline & Peak 2-4 kHz & 47.29 & 45.19 & 47.29 & 44.33 & 46.57 & -2.10 & 0.00 & -2.96 & -0.72 \\
\hline & SPR & -9.72 & -15.38 & -9.72 & -12.36 & -12.61 & -5.66 & 0.00 & -2.64 & -2.89 \\
\hline \multirow[t]{4}{*}{ High [i] } & F0 & 50.74 & 52.23 & 50.74 & 54.28 & 54.24 & 1.49 & 0.00 & 3.54 & 3.51 \\
\hline & Peak 0-2 kHz & 50.74 & 52.23 & 50.74 & 54.28 & 54.24 & 1.49 & 0.00 & 3.54 & 3.51 \\
\hline & Peak 2-4 kHz & 41.57 & 45.27 & 41.57 & 43.36 & 42.07 & 3.70 & 0.00 & 1.79 & 0.50 \\
\hline & SPR & -9.16 & -6.95 & -9.16 & -10.91 & -12.17 & 2.21 & 0.00 & -1.75 & -3.01 \\
\hline \multirow[t]{4}{*}{ Mid [a] } & F0 & 39.57 & 38.63 & 39.57 & 43.74 & 43.75 & -0.94 & 0.00 & 4.17 & 4.19 \\
\hline & Peak $0-2 \mathrm{kHz}$ & 53.96 & 50.16 & 53.96 & 49.21 & 55.68 & -3.80 & 0.00 & -4.74 & 1.72 \\
\hline & Peak 2-4 kHz & 34.20 & 34.54 & 34.20 & 32.86 & 26.86 & 0.35 & 0.00 & -1.33 & -7.34 \\
\hline & SPR & -19.76 & -15.62 & -19.76 & -16.35 & -28.82 & 4.15 & 0.00 & 3.41 & -9.06 \\
\hline \multirow[t]{4}{*}{ Mid [E] } & F0 & 39.89 & 40.44 & 39.89 & 41.38 & 46.16 & 0.55 & 0.00 & 1.49 & 6.27 \\
\hline & Peak 0-2 kHz & 51.17 & 51.01 & 51.17 & 50.24 & 51.56 & -0.17 & 0.00 & -0.93 & 0.38 \\
\hline & Peak 2-4 kHz & 37.34 & 38.77 & 37.34 & 35.69 & 36.81 & 1.44 & 0.00 & -1.64 & -0.53 \\
\hline & SPR & -13.84 & -12.23 & -13.84 & -14.55 & -14.75 & 1.60 & 0.00 & -0.71 & -0.91 \\
\hline \multirow[t]{4}{*}{ Mid [i] } & F0 & 44.43 & 42.13 & 44.43 & 49.10 & 48.11 & -2.29 & 0.00 & 4.67 & 3.68 \\
\hline & Peak 0-2 kHz & 44.82 & 45.33 & 44.82 & 49.10 & 52.85 & 0.51 & 0.00 & 4.29 & 8.03 \\
\hline & Peak 2-4 kHz & 32.31 & 32.14 & 32.31 & 30.70 & 32.81 & -0.18 & 0.00 & -1.61 & 0.50 \\
\hline & SPR & -12.50 & -13.19 & -12.50 & -18.40 & -20.03 & -0.69 & 0.00 & -5.90 & -7.53 \\
\hline \multirow[t]{4}{*}{ Low [a] } & F0 & 34.52 & 31.57 & 34.52 & 33.98 & 33.82 & -2.95 & 0.00 & -0.54 & -0.70 \\
\hline & Peak 0-2 kHz & 43.79 & 42.79 & 43.79 & 40.15 & 41.61 & -1.00 & 0.00 & -3.64 & -2.17 \\
\hline & Peak 2-4 kHz & 25.32 & 27.79 & 25.32 & 16.15 & 18.45 & 2.47 & 0.00 & -9.17 & -6.87 \\
\hline & SPR & -18.47 & -15.00 & -18.47 & -24.00 & -23.16 & 3.47 & 0.00 & -5.53 & -4.69 \\
\hline \multirow[t]{4}{*}{ Low $[E]$} & F0 & 36.23 & 35.38 & 36.23 & 32.54 & 37.09 & -0.85 & 0.00 & -3.69 & 0.87 \\
\hline & Peak 0-2 kHz & 43.82 & 41.27 & 43.82 & 42.88 & 45.40 & -2.55 & 0.00 & -0.94 & 1.58 \\
\hline & Peak 2-4 kHz & 31.61 & 31.21 & 31.61 & 28.54 & 29.64 & -0.40 & 0.00 & -3.08 & -1.97 \\
\hline & SPR & -12.21 & -10.06 & -12.21 & -14.34 & -15.76 & 2.15 & 0.00 & -2.14 & -3.55 \\
\hline \multirow[t]{4}{*}{ Low [i] } & F0 & 33.69 & 32.92 & 33.69 & 36.00 & 32.31 & -0.77 & 0.00 & 2.31 & -1.38 \\
\hline & Peak 0-2 kHz & 42.01 & 38.38 & 42.01 & 41.49 & 39.37 & -3.64 & 0.00 & -0.53 & -2.64 \\
\hline & Peak 2-4 kHz & 27.46 & 27.76 & 27.46 & 26.77 & 27.07 & 0.30 & 0.00 & -0.69 & -0.39 \\
\hline & SPR & -14.56 & -10.62 & -14.56 & -14.72 & -12.30 & 3.94 & 0.00 & -0.16 & 2.25 \\
\hline
\end{tabular}




\section{BIBLIOGRAPHY}

Articles

Acker, B. F. "Vocal Tract Adjustments for the Projected Voice.” Journal of Voice 1, no. 1 (1987): 77-82.

Amir, Ofer, Noam Amir, and Orit Michaeli. "Evaluating the Influence of Warmup on Singing Voice Quality Using Acoustic Measures.” Journal of Voice 19, no. 2 (2005): 252-260.

Austin, Stephen F. “Bobble-heads.” Journal of Singing 68, no. 4 (March/April 2012): 457-459.

Austin, Stephen F. "Jaw Opening in Novice and Experienced Classically Trained Singers." Journal of Voice 21, no. 1 (2007): 72-79.

Arboleda, Barbara M. Wilson and Arlette L. Frederick. "Considerations for Maintenance of Postural Alignment for Voice Production.” Journal of Voice 22, no. 1 (2008): 90-99.

Armijo-Olivo, S., X. Jara, N. Castillo, L. Alfonso, A. Schilling, E. Valenzuela, R. Frugone, and D. Magee. "A Comparison of the Head and Cervical Posture Between the Self-Balanced Position and the Frankfurt Method." Journal of Oral Rehabilitation 33, no. 3 (2006): 194-201.

Baken, R. J. and Robert F. Orlikoff. "The Effect of Articulation on Fundamental Frequency in Singers and Speakers.” Journal of Voice 1, no. 1 (1987): 68-76.

Barnes-Burroughs, Kathryn, Edward E. Anderson, Thomas Hughes, William Y. Lan, Karl Dent, Sue Arnold, Gerald Dolter, and Kathy McNeil. "Pedagogical Efficiency of Melodic Contour Mapping Technology as it Relates to Vocal Timbre in Singers of Classical Music Repertoire.” Journal of Voice 21, no. 6 (2007): 689-698.

Barnes-Burroughs, Kathryn, Christopher Watts, Oren L. Brown, and Jeannette LoVetri. "The Visual/Kinesthetic Effects of Melodic Contour in Musical Notation as it Affects Vocal Timbre in Singers of Classical and Music Theater Repertoire.” Journal of Voice 19, no. 3 (2005): 411-419.

Bunch, Meribeth A. "A Cephalometric Study of Structures of the Head and Neck During Sustained Phonation Of Covered And Open Qualities.” Folia Phoniatrica 28 (1976): 321-328.

Brown, Jr., W.S., Howard B. Rothman, and Christine M. Sapienza. "Perceptual and Acoustic Study of Professionally Trained Versus Untrained Voices." Journal of Voice 14, no. 3 (2000): 301-309.

Dejonckere, P. H. and J. Lebacq. "Plasticity of Voice Quality: A Prognostic Factor for Outcome of Voice Therapy?” Journal of Voice 15, no. 2 (2001): 251-256. 
Dmitriev, L. and A. Kiselev. "Relationship Between the Formant Structure of Different Types of Singing Voices and the Dimensions of the Supraglottic Cavities." Folia Phoniatrica 31 (1979): 238-241.

Ekholm, Elizabeth, Georgios C. Papagiannis, and Françoise P. Chagnon. "Relating Objective Measurements to Expert Evaluation of Voice Quality in Western Classical Singing: Critical Perceptual Parameters.” Journal of Voice 12, no. 2 (1998): 182-196.

Ferrario, Virgilio F., Chiarella Sforza, Domenica Germanò, Luca L. Dalloca, and Alessandro Miani, Jr. "Head Posture and Cephalometric Analyses: An Integrated Photographic/Radiographic Technique." American Journal of Orthodontics and Dentofacial Orthopedics 106, no. 3 (1994): 257-266.

Ferrario, Virgilio F., Chiarella Sforza, Alessandro Miani, and Gianluca Tartaglia. "Craniofacial Morphometry by Photographic Evaluations." American Journal of Orthodontics and Dentofacial Orthopedics 103, no. 4 (1993): 327-337.

Gould, W. J. "Effect of Respiratory and Postural Mechanisms upon Action of the Vocal Cords." Folia Phoniatrica 23 (1971): 211-224.

Heman-Ackah, Yolanda D. "Physiology of Voice Production: Considerations for the Vocal Performer." Journal of Singing 62, no. 2 (November/December 2005): 173-176.

Honda, Kiyoshi, Hiroyuki Hirai, Jo Estill, and Yoh'ichi Tohkura. "Contributions of Vocal Tract Shape to Voice Quality: MRI Data And Articulatory Modeling." In Vocal Fold Physiology: Voice Quality Control, ed. Osamu Fujimura and Minoru Hirano, 23-38. San Diego: Singular Publishing, 1995.

Honda, Kiyoshi, Hiroyuki Hirai, Shinobu Masaki, and Yasohiro Shimada. "Role of Vertical Larynx Movement and Cervical Lordosis In F0 Control.” In Language and Speech 42, no. 4 (1999): 401-411.

Iwarsson, Jenny. "Effects of Inhalatory Abdominal Wall Movement on Vertical Laryngeal Position During Phonation." Journal of Voice 15, no. 3 (2001): 384-394.

Johnson, Gillian and Margot Skinner. "The Demands of Professional Opera Singing on CranioCervical Posture.” European Spine Journal 18 (2009): 562-569.

Jones, Frank Pierce. "Voice Production as a Function of Head Balance in Singers." The Journal of Psychology 82 (1972): 209-215.

Kenny, Dianna T. and Helen F. Mitchell. "Visual and Auditory Perception of Vocal Beauty: Conflict or Concurrence?" In Proceedings of the $8^{\text {th }}$ International Conference on Music Perception and Cognition, Evanston, IL, August 3-7, 2004, edited by S.D. Lipscomb, R. Ashley, R.O. Gjerdingen, and P. Webster, 171-174. Adelaide, Australia: Causal Productions, 2004. 
Kooijman, P.G.C., F.I.C.R.S. de Jong, M.J. Oudes, W. Huinck, H. van Acht, and K. Graamans. "Muscular Tension and Body Posture in Relation to Voice Handicap and Voice Quality in Teachers with Persistent Voice Complaints." Folia Phoniatrica et Logopaedica 57 (2005): 134-147.

Lagier, Aude, Marianne Vaugoyeau, Alain Ghio, Thierry Legou, Antoine Giovanni, and Christine Assaiante. "Coordination Between Posture and Phonation in Vocal Effort Behavior.” Folia Phoniatrica et Logopaedica 62 (2010): 195-202.

Laukkanen, Anne-Maria, Eva Björkner, and Johan Sundberg. “Throaty Voice Quality: Subglottal Pressure, Voice Source, and Formant Characteristics." Journal of Voice 20, no. 1 (2006): 25-37.

Leitao, Pedro and Ram S. Nanda. "Relationship of Natural Head Position to Craniofacial Morphology." American Journal of Orthodontics and Dentofacial Orthopedics 117, no. 4 (2000): 406-417.

Lin, Emily, Jack Jiang, Stephen D. Noon, and David G. Hanson. "Effects of Head Extension and Head Protrusion on Voice Perturbation Measures." Journal of Voice 14, no. 1 (2000): 816.

Lindblom, Björn E. F. and Johan E. F. Sundberg. "Acoustical Consequences of Lip, Tongue, Jaw, and Larynx Movement." Journal of the Acoustical Society of America 50, no. 4 (1971): 1166-1179.

Mendes, Ana P., Howard B. Rothman, Christine Sapienza, and W.S. Brown, Jr. "Effects of Vocal Training on the Acoustic Parameters of the Singing Voice." Journal of Voice 17, no. 4 (2003): 529-543.

Miller, Donald G. and Harm K. Schutte. "Feedback from Spectrum Analysis Applied to the Singing Voice." Journal of Voice 4, no. 4 (1990): 329-334.

Miller, Nicola A., Jennifer S. Gregory, Scottle I. K. Semple, Richard M. Aspden, Peter J. Stollery, and Fiona J. Gilbert. "The Effects of Humming and Pitch on Craniofacial and Craniocervical Morphology Measured Using MRI.” Journal of Voice 26, no. 1 (2012): 90-101.

Moorrees, Coenraad F. A. "Natural Head Position, a Basic Consideration in the Interpretation of Cephalometric Radiographs.” American Journal of Physical Anthropology, 16, no. 2(1958): 213-234.

Muto, Toshitaka and Masaaki Kanazawa. "Positional Change of the Hyoid Bone at Maximal Mouth Opening.” Oral Surgery Oral Medicine Oral Pathology 77, no. 5 (May 1994): 451-455. 
Muto, Toshitaka, S. Takeda, M. Kanazawa, A. Yamazaki, Y. Fujiwara, and I. Mizoguchi. "The Effect of Head Posture on the Pharyngeal Airway Space (PAS)." International Journal of Oral and Maxillofacial Surgery 31 (2002): 579-583.

Omori, Koichi, Ashutosh Kacker, Linda M. Carroll, William D. Riley, and Stanley M. Blaugrund. "Singing Power Ratio: Quantitative Evaluation of Singing Voice Quality." Journal of Voice 10, no. 3 (1996): 228-235.

Pershall, Kim E. and Daniel R. Boone. "Supraglottic Contribution to Voice Quality." Journal of Voice 1, no. 2 (1987): 186-190.

Pettersen, Viggo and Rolf H. Westgaard. "The Activity Patterns of Neck Muscles in Professional Classical Singing." Journal of Voice 19, no. 2 (2005): 238-251.

Reid, Katherine L.P., Pamela Davis, Jennifer Oates, Densil Cabrera, Sten Ternström, Michael Black, and Janice Chapman. "The Acoustic Characteristics of Professional Opera Singers Performing in Chorus versus Solo Mode.” Journal of Voice 21, no. 1 (2007): 35-45.

Rubin, John S., Ed Blake, and Lesley Mathieson. "Musculoskeletal Patterns in Patients with Voice Disorders." Journal of Voice 21, no. 4 (2007): 477-484.

Rubin, John S., Lesley Mathieson, and Ed Blake. "Posture and Voice.” Journal of Singing 60, no. 3 (January/February 2004): 271-275.

Schneider, Carole M., Carolyn a. Dennehy, and Keith G. Saxon. "Exercise Physiology Principles Applied to Vocal Performance: The Improvement of Postural Alignment." Journal of Voice 11, no. 3 (1997): 332-337.

Scotto Di Carlo, Nicole. "Cervical Spine Abnormalities in Professional Singers." Folia Phoniatrica et Logopaedica 50, no. 4 (1998): 212-218.

Scotto Di Carlo, Nicole. "X-Ray Study of a Professional Soprano's Postural Strategy for Increasing Laryngeal Mobility." Folia Phoniatrica et Logopaedica 54 (2002): 165-170.

Sonninen, Aatto, Pertti Hurme, and Anne-Maria Laukkanen. "The External Frame Function in the Control of Pitch, Register, and Singing Mode: Radiographic Observations of a Female Singer." Journal of Voice 13, no. 3 (1999): 319-340.

Staes, Filip F., Lieve Jansen, Ann Vilette, Yannick Coveliers, Kim Daniels, and Wivine Decoster. "Physical Therapy as a Means to Optimize Posture and Voice Parameters in Student Classical Singers: A Case Report.” Journal of Voice 25, no. 3 (2011): 91-101.

Sulter, Arend M., Donald G. Miller, Rienhart F. Wolf, Harm K. Schutte, Hero P. Wit, and Eduard L. Mooyaart. "On the Relation Between the Dimensions and Resonance of the Vocal Tract: A Study with MRI.” Magnetic Resonance Imaging 10 (1992): 365-373. 
Sundberg, Johan. "Articulatory Configuration and Pitch in a Classically Trained Soprano Singer." Journal of Voice 23, no. 5 (2009): 546-551.

Sundberg, Johan. "Formant Technique in a Professional Female Singer." Acoustica 32 (1975): 89-96.

Sundberg, Johan. "The Source Spectrum in Professional Singing." Folia Phoniatrica et Logopaedica 25 (1973): 71-90.

Vilkman, E., A. Sonninen, P. Hurme, and P. Körkkö. "External Laryngeal Frame Function in Voice Production Revisited: A Review." Journal of Voice 10, no. 1 (1996): 78-92.

Watts, Christopher, Kathryn Barnes-Burroughs, Julie Estis, and Debra Blanton. "The Singing Power Ratio as an Objective Measure of Singing Voice Quality in Untrained Talented and Nontalented Singers." Journal of Voice 20, no. 1 (2006): 82-88.

\section{Books}

Coffin, Berton. Overtones of Bel Canto. Lanham, MD: Scarecrow Press, 1980.

Coffin, Berton. Sounds of Singing, 2d ed. Metuchen, NJ: Scarecrow Press, 1987.

Colton, Raymond H. and Jo A. Estill. "Elements of Voice Quality: Perceptual, Acoustic, and Physiologic Aspects." In Speech and Language: Advances in Basic Research and Practice, Vol. 5, ed. Norman J. Lass, 311-403. New York: Academic Press, 1981.

Doscher, Barbara M. The Functional Unity of the Singing Voice, 2d ed. Lanham, MD: Scarecrow Press, 1994.

Fant, Gunnar. Acoustic Theory of Speech Production. The Hague: Mouton \& Co, 1960.

Fields, Victor A. Training the Singing Voice: An Analysis of the Working Concepts Contained in Recent Contributions to Vocal Pedagogy. Morningside Heights, NY: King's Crown Press, 1947.

Garcia, Manuel. A Complete Treatise on the Art Of Singing, Part One. The editions of 1841 and 1872 collated, edited, and translated by Donald V. Paschke. New York: Da Capo Press, 1984.

Hoffman, Jay. Norms for Fitness, Performance, and Health. Champaign, IL: Human Kinetics, Inc., 2006.

Kirkwood, Betty R. and Jonathan A. C. Sterne. Essential Medical Statistics, 2d ed. Malden, MA: Blackwell Science, 2003. 
McKinney, James C. The Diagnosis and Correction of Vocal Faults, revised ed. Nashville: Genevox Music Group, 1994.

Miller, Richard. National Schools of Singing, rev. ed. Lanham, MD: Scarecrow Press, 1997.

Miller, Richard. The Structure of Singing. New York: Schirmer Books, 1986.

Miller, Richard. Training Soprano Voices. Oxford: Oxford University Press, 2000.

Miller, Richard. Training Tenor Voices. New York: Schirmer Books, 1993.

Monahan, Brent J. The Art of Singing: A Compendium of Thoughts on Singing Published Between 1777 and 1927. Metuchen, NJ: Scarecrow Press, Inc., 1978.

Nair, Garyth. Voice Tradition and Technology: A State-Of-The-Art Studio. San Diego: Singular Publishing, 1999.

Shakespeare, William. The Art of Singing. Philadelphia: Oliver Ditson, 1899.

Smith, Brenda and Robert Thayer Sataloff. Choral Pedagogy. San Diego: Singular Publishing, 1999.

Stark, James. Bel Canto: A History of Vocal Pedagogy. Toronto: University of Toronto Press, 1999.

Sundberg, Johan. The Science of Musical Sounds. Translated by Johan Sundberg. San Diego: Academic Press, 1991.

Sundberg, Johan. The Science of the Singing Voice. DeKalb: Northern Illinois University Press, 1987.

Vennard, William. Singing: The Mechanism and the Technic, 2d ed. Ann Arbor: Edwards Brothers, 1950.

Ware, Clifton. Basics of Vocal Pedagogy: The Foundations and Process of Singing. Boston: McGraw Hill, 1998.

Zemlin, Willard R. Speech and Hearing Science: Anatomy and Physiology, $4^{\text {th }}$ ed. Boston: Allyn and Bacon, 1998. 